Pontifícia Universidade Católica $_{\text {a }}$

DO RIO DE JANEIRO

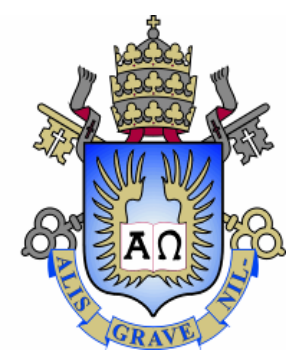

Ana Lara Soares Blum Malak

\title{
SINTOMAS DE DEPRESSÃO EM PACIENTES COM DECLÍNIO COGNITIVO LEVE NA DOENÇA DE PARKINSON
}

Dissertação de Mestrado

Dissertação apresentada ao Programa de Pós-Graduação em Psicologia (Psicologia Clínica) da PUC-Rio como requisito parcial para a obtenção do título de Mestre em Psicologia Clínica.

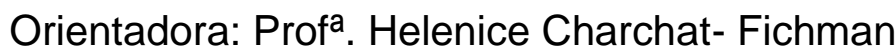




\title{
Pontifícia Universidade Católica $_{\text {mat }}$
}

DO RIO DE JANEIRO

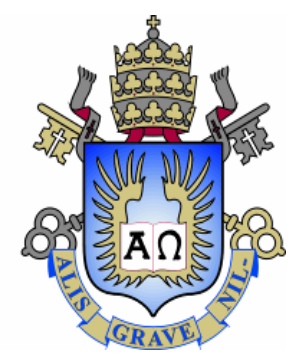

Ana Lara Soares Blum Malak

\section{Sintomas de Depressão em pacientes com Declínio Cognitivo Leve na Doença de Parkinson}

Dissertação apresentada como requisito parcial para obtenção do grau de Mestre pelo Programa de Pós-Graduação em Psicologia (Psicologia Clínica) do Departamento de Psicologia do Centro de Teologia e Ciências Humanas da PUC-Rio. Aprovada pela Comissão Examinadora abaixo assinada.

\author{
Prof ${ }^{\mathrm{a}}$. Helenice Charchat- Fichman \\ Orientadora \\ Departamento de Psicologia - PUC-Rio \\ Profa. Mariana Spitz \\ Departamento de Neurologia - UERJ
}

Prof ${ }^{2}$. Heloisa Veiga

Departamento de Psicologia - PUC- Rio

Profá. Denise Berruezo Portinari

Coordenadora Setorial de Pós-Graduação

e Pesquisa do Centro de Teologia e Ciências Humanas - PUC-Rio 
Todos os direitos reservados. É proibida a reprodução total ou parcial do trabalho sem autorização da universidade, da autora e do orientador.

\section{Ana Lara Soares Blum Malak}

Aluna de Mestrado em Psicologia Clínica pela linha Clínica e Neurociências, Departamento de Psicologia PUC-Rio, início em 03/2014 - Bolsa CAPES. Especialista em Psicogeriatria- Universidade Federal do Rio de Janeiro (UFRJ) 2009. Graduada em Psicologia - Pontifícia Universidade Católica do Rio de Janeiro (PUC-Rio) 03/1995 - 12/2000.

Ficha Catalográfica

Malak, Ana Lara Soares Blum

Sintomas de depressão em pacientes com declínio cognitivo leve na doença de Parkinson / Ana Lara Soares Blum Malak ; orientadora: Helenice Charchat Fichman. - 2016.

109 f. : il. color. ; $30 \mathrm{~cm}$

Dissertação (mestrado) - Pontifícia Universidade Católica do Rio de Janeiro, Departamento de Psicologia, 2016.

Inclui bibliografia

1. Psicologia - Teses. 2. Doença de Parkinson. 3. Depressão. 4. Cognição. 5. Declínio cognitivo leve. I. Fichman, Helenice Charchat. II. Pontifícia Universidade Católica do Rio de Janeiro. Departamento de Psicologia. III. Título.

CDD: 150 


\section{Agradecimentos}

A Deus, por permitir que eu alcance mais um degrau na minha formação profissional. Em um país onde poucos têm acesso à educação, sinto-me extremamente privilegiada!

Aos meus pais, por tudo que me proporcionam, pela minha formação e pelo cuidado e preocupação com meus filhos.

Ao meu marido Charles Malak, por compreender a importância desta etapa na minha vida.

Aos meus filhos Eduardo e Sofia, que deixam minha vida mais colorida e divertida, me fazendo acreditar e continuar.

Ao meu avô Heitor, sempre preocupado e interessado na minha formação e na educação dos meus filhos.

À minha avó Dulce, sempre presente na minha vida, até mesmo no meu encontro com a neuropsicologia. Obrigada por estar sempre perto de mim!

Aos meus colegas do mestrado, que por várias vezes mostraram-se disponíveis em me ajudar.

Às minhas companheiras de pesquisa - e agora amigas - Denise Greca e Manuela Cruz. Sem vocês este trabalho não seria possível!

À professora e orientadora Helenice Charchat-Fichman, por ter me acolhido em seu grupo de pesquisa e, sobretudo, por não me deixar desistir. 
Aos médicos Luiz Felipe Vasconcellos e João dos Santos Pereira pela colaboração e possibilidade de inserção nas instituições onde este estudo foi realizado.

Aos pacientes e familiares, que muitas vezes, mesmo em condições difíceis, se disponibilizaram para colaborar com a realização deste trabalho.

Por fim, ao CAPES e à PUC-Rio, pelos auxílios concedidos, sem os quais este trabalho não poderia ter sido realizado. 


\section{Resumo}

Malak, Ana Lara Soares Blum; Charchat-Fichman, Helenice. Sintomas de Depressão em pacientes com Declínio Cognitivo Leve na Doença de Parkinson. Rio de Janeiro, 2016. 109 p. Dissertação de Mestrado Departamento de Psicologia, Pontifícia Universidade Católica do Rio de Janeiro.

A Doença de Parkinson (DP) é caracterizada pela ocorrência de sintomas motores. No entanto, sintomas não motores, como depressão e comprometimento cognitivo, são comuns e não devem ser ignorados. A presente dissertação investigou a frequência dos sintomas depressivos e seus efeitos na cognição de indivíduos com DP com declínio cognitivo leve (DCL). Foram avaliados 48 sujeitos com DP e 44 controles (GC), com idade entre 50 e 80 anos e escolaridade superior a 4 anos, todos com DCL e sem diagnóstico de depressão. Os participantes foram submetidos à avaliação clínica com neurologista, seguida de avaliação neuropsicológica. Os sintomas depressivos foram mensurados com o uso do Inventário de Depressão de Beck. Dificuldade no trabalho, fadiga e distúrbio do sono foram sintomas mais frequentes no grupo DP, enquanto o grupo sem DP apresentou além de distúrbios do sono, sintomas de irritabilidade e diminuição da libido. A presença destes sintomas mostrou-se associada a prejuízo da atenção combinado a déficit de memória episódica, especialmente em tarefas de reconhecimento de novas informações verbais. Os sintomas depressivos prevalentes nos Parkinsonianos com DCL podem ser atribuídos à DP, dificultando o diagnóstico diferencial entre essas condições.

\section{Palavras-chave}

Doença de Parkinson; Depressão; Cognição; Declínio Cognitivo Leve. 


\section{Abstract}

Malak, Ana Lara Soares Blum; Charchat-Fichman, Helenice (Advisor). Depression symptoms in patients with Mild Cognitive Impairment in Parkinson's disease. Rio de Janeiro, 2016. 109 p. MSc. Dissertation Departamento de Psicologia, Pontifícia Universidade Católica do Rio de Janeiro.

Parkinson's Disease (PD) is characterized by the occurrence of motor symptoms. However, non motor symptoms such as depression and cognitive impairment are common and should not be ignored. This thesis investigated the frequency of depressive symptoms and their effect on cognition in individuals with PD with mild cognitive impairment (MCI). Forty eight subjects with PD and 44 controls (CG), aged between 50 and 80 years and higher education to four years, all with MCI and undiagnosed depression were studied. The participants underwent clinical evaluation with a neurologist, followed by neuropsychological assessment. Depressive symptoms were measured using the Beck Depression Inventory. Difficulty in work, fatigue and sleep disorders were more frequent symptoms in PD group, whereas the group without PD presented beyond sleep disorders, symptoms of irritability, and decreased libido. The presence of these symptoms was found to be associated with loss of attention combined to episodic memory deficits, especially in recognition tasks of new verbal information. The prevalent depressive symptoms in parkinsonians with MCI can be attributed to PD, complicating the differential diagnosis between these conditions.

\section{Keywords}

Parkinson's disease; Depression; Cognition; Mild Cognitive Impairment. 


\section{Sumário}

1. Introdução 14

$\begin{array}{ll}1.1 \text { Objetivo } & 15\end{array}$

2. Fundamentação Teórica 16

$\begin{array}{ll}\text { 2.1 Doença de Parkinson (DP) } & 16\end{array}$

$\begin{array}{ll}2.2 \text { Depressão } & 19\end{array}$

2.2.1 Depressão e envelhecimento 20

$\begin{array}{ll}\text { 2.2.2 Aspectos cognitivos da depressão } & 21\end{array}$

§ $\quad$ 2.2.3 Depressão e DP 24

2.2.4 Escalas de avaliação de depressão na DP 27

2.3 Declínio Cognitivo Leve (DCL) 28

2.3.1 Breve Histórico e evolução do conceito de DCL 31

2.3.2 Taxas de prevalência e incidência de DCL 33

$\begin{array}{ll}\text { 2.3.3 DCL e DP } & 34\end{array}$

2.3.4 Diagnóstico de DCL na DP segundo critérios da Movement

$\begin{array}{ll}\text { Disorder Society Task Force Guidelines } & 37\end{array}$

2.3.5 Conceito de reserva cognitiva na DP 39

2.3.6 Sintomas de depressão, DCL e DP 40

3. Metodologia 42

3.1 Sujeitos 42

3.1.1 Grupo DP 42

3.1.2 Grupo dos controles $\quad 43$ 
3.1.3 Frequência dos sintomas depressivos nos grupos DP e Controle

3.2 Instrumentos

3.2.1 Descrição dos testes neuropsicológicos

3.3 Procedimento

3.4 Questões Éticas

5. Resultados

5.1 Análise descritiva dos dados $\quad 55$

5.2 Frequência dos sintomas depressivos

5.3 Correlação entre Inventário de Depressão de Beck e os testes neuropsicológicos

5.4 Desempenho dos grupos DP e controle nos testes

neuropsicológicos a partir da divisão em subgrupos com e sem sintomas de depressão

6. Discussão

6.1 Frequência dos sintomas depressivos

6.2 Correlação entre BDI e os testes neuropsicológicos 
8. Referências bibliográficas

$\begin{array}{ll}\text { Anexo I-TCLE } & 79\end{array}$

Anexo II - Protocolo de testes neuropsicológicos 81

Anexo III - Artigo empírico $\quad 91$ 


\section{Lista de Tabelas e Figuras}

Tabela 1 - Conceitos e critérios de DCL 33

Tabela 2 - Critérios diagnósticos para DCL na DP 38

Tabela 3 - Testes utilizados na avaliação das funções cognitivas $\quad 50$

Tabela 4 - Caracterização da amostra 55

Tabela 5 - Frequência dos sintomas depressivos nos grupos DP e Controle 56

Tabela 6 - Desempenho dos grupos nos testes neuropsicológicos $\quad 58$

Figura 1 - Critérios para diagnóstico de DCL 31

Figura 2 - Frequência dos sintomas depressivos no grupo DP 45

Figura 3 - Frequência dos sintomas depressivos no grupo controle $\quad 45$

Figura 4 - Ordem de aplicação dos testes neuropsicológicos 52

Figura 5 - Frequência dos sintomas de depressão 57

Figura 6 - Resultado da análise post-hoc Bonferroni no TMF 59

Figura 7 - Resultado da análise post-hoc Bonferroni no RAVLT 60 


\section{Lista de Abreviaturas e Siglas}

\begin{tabular}{|c|c|}
\hline APA & Associação Americana de Psicologia \\
\hline BDI & Inventário de Depressão de Beck \\
\hline CID & Classificação Internacional de Doenças \\
\hline DA & Doença de Alzheimer \\
\hline $\mathrm{DCL}$ & Declínio Cognitivo Leve \\
\hline DP & Doença de Parkinson \\
\hline DSM & Manual Estatístico e Diagnóstico de Desordens Mentais \\
\hline FAS & Teste de Fluência Verbal Fonêmica \\
\hline FE & Funções Executivas \\
\hline MDS & Movement Disorders Society \\
\hline MEEM & Mini Exame do Estado Mental \\
\hline OMS & Organização Mundial da Saúde \\
\hline PDQ-39 & Questionário de qualidade de vida na Doença de Parkinson \\
\hline RAVLT & Teste de Aprendizagem Auditivo Verbal de Rey \\
\hline TCLE & Termo de Consentimento Livre e Esclarecido \\
\hline TDR & Teste do Desenho do Relógio \\
\hline TFV animais & Teste de Fluência Verbal categoria animais \\
\hline TMF & Teste de Memória de Figuras \\
\hline TMT & Teste de Trilhas \\
\hline UPDRS & Escala Unificada de Avaliação para Doença de Parkinson \\
\hline WAIS-III & Escala Weshler de Inteligência \\
\hline
\end{tabular}


"Somos assim: sonhamos o voo mas tememos a altura. Para voar é preciso ter coragem para enfrentar o terror do vazio. Porque é só no vazio que o voo acontece. O vazio é o espaço da liberdade, a ausência de certezas. Mas é isso o que tememos: o não ter certezas. Por isso trocamos o voo por gaiolas. As gaiolas são o lugar onde as certezas moram."

Fiódor Dostoiévski, em Os Irmãos Karamazov 


\section{Introdução}

Há algumas décadas, é possível observar um rápido crescimento da população idosa, principalmente nos países em desenvolvimento. Trata-se de um fenômeno mundial decorrente da queda nas taxas de mortalidade e, sobretudo, de fecundidade. Como consequência, ocorrem repercussões importantes a nível econômico e social (Rabelo, 2009). O aumento de doenças crônico-degenerativas e, portanto, a necessidade de cuidados especiais a esta crescente camada da população, ressalta a necessidade de severas mudanças no sistema de saúde (Nasri, 2008).

A Doença de Parkinson (DP), cujo principal fator de risco é a idade, é a segunda doença neurodegenerativa mais comum na população idosa. No Brasil, estima-se uma prevalência de 3,3\% (Barbosa et al 2006). Embora inicialmente considerada como uma patologia de sintomatologia estritamente motora, ela apresenta também sintomas não motores, os quais são responsáveis por consequências diversas, como perda da autonomia e independência, aumento nas taxas de hospitalização/institucionalização e piora na qualidade de vida (Stacy, 2011).

Dentre os sintomas não motores, a depressão é o que mais se associa à DP. Entretanto, as estimativas de sua prevalência variam de acordo com o objetivo e metodologia do estudo (Chen et al., 2007; Cummings, 1992). Veazey et al. (2005) relatam que as taxas de depressão em estudos publicados apresentam variação de 7 a 76\%. Identificá-la na DP não é tarefa fácil, já que alguns sintomas de depressão, como cansaço e distúrbios do sono, também podem ser atribuídos exclusivamente à DP, o que acaba contribuindo com alto índice de subdiagnósticos (Ravina et al., 2007). Reconhecer de que maneira os sintomas depressivos se apresentam na DP é de extrema importância, pois possibilitará melhor planejamento terapêutico e, por consequência, amenizará o impacto desses sintomas no cotidiano do indivíduo, bem como no curso da doença. 
Diante disto, este trabalho se propõe a investigar o impacto dos sintomas de depressão na cognição de parkinsonianos, comparando o perfil desses sintomas entre pacientes com DP e controles. Além disso, tem o objetivo de determinar quais medidas cognitivas apresentam-se alteradas em razão da presença de sintomas de depressão. O estudo justifica-se pela necessidade de aumentar a compreensão atual acerca da influência dos sintomas depressivos na DP com DCL, discriminando o que é característico de cada patologia, a fim de possibilitar melhor planejamento clínico, considerando que a comorbidade entre depressão e DCL na DP constitui fator de risco para quadros demenciais.

\subsection{Objetivo}

a. Objetivo Geral:

Investigar os sintomas depressivos mais frequentes e seu impacto na cognição de indivíduos com DP com DCL.

b. Objetivos Específicos:

- Comparar o desempenho nos testes neuropsicológicos do grupo de pacientes com DP e o grupo controle.

- Destacar as funções cognitivas comprometidas pela presença de sintomas de depressão na DP com DCL;

- Identificar os sintomas de depressão mais frequentes na DP com DCL baseado no Inventário de Depressão de Beck (BDI) e comparar com o grupo controle;

- Relacionar a intensidade de depressão com o desempenho cognitivo na DP com DCL. 


\section{Fundamentação teórica}

\subsection{Doença de Parkinson}

Com o avanço da ciência e da tecnologia, é possível observar o aumento da expectativa de vida, acompanhado de queda na taxa de natalidade, no Brasil e no mundo. Isso contribui para um crescimento significativo da população idosa. Estudos indicam como responsáveis pelo envelhecimento populacional global não só o declínio da mortalidade, mas, sobretudo, da fecundidade. De acordo com as projeções demográficas da Organização Mundial de Saúde (OMS), em 2050 o número de idosos (pessoas acima de 60 anos de idade) alcançará o número de jovens. Além disso, há o registro de envelhecimento da população idosa, ou seja, percebe-se um rápido crescimento de pessoas idosas com idade superior a 80 anos (OMS, 2002).

Tal fato vem ocorrendo com mais intensidade nos países em desenvolvimento, embora tenha iniciado nos países da Europa Ocidental no final do século XIX (Carvalho \& Garcia, 2003). Em 2008, o Brasil tinha aproximadamente 21 milhões de pessoas com 60 anos ou mais, ultrapassando o número de idosos de vários países europeus, como a França, Inglaterra e a Itália (Ikuta, 2012). Trata-se, deste modo, de uma inversão demográfica, que traz consequências para os diversos âmbitos da sociedade, dentre eles uma maior incidência de doenças crônico-degenerativas nesta camada da população.

A DP é a segunda doença neurodegenerativa mais comum na população idosa, perdendo apenas para a Doença de Alzheimer (DA). Ela está presente em até dois terços dos pacientes que visitam os grandes centros de distúrbios do movimento em todo o mundo. A cada 100.000 indivíduos, 350 desenvolvem esta patologia e estima-se o aparecimento de nove milhões de novos casos até o ano de 2030 (McPherson \& Cummings, 2009). A DP apresenta incidência mais elevada em homens do que em mulheres, e não há diferenças entre raças e grupos étnicos (Wooten et al., 2004). O maior fator de risco para a DP é a idade, com o aparecimento dos primeiros sintomas entre a $4^{\mathrm{a}}$ e a $7^{\mathrm{a}}$ década de vida. Há registros desta patologia desde a antiguidade, tendo sido reconhecida por Galeno em 175 D.C. No entanto, somente em 1817, com a publicação do trabalho An essay on the 
Shaking Palsy, de James Parkinson, a DP foi de fato documentada e definida como paralisia agitante. Nesta época, a DP foi caracterizada pela presença de movimentos involuntários tremulantes, com diminuição da força muscular, inclinação do tronco para frente e com alteração da marcha, tendo os sentidos e o intelecto não afetados (Teive, 1998).

Por não ter uma etiologia definida, é tida como idiopática, já que a razão pela qual um indivíduo a desenvolve permanece obscura. Apesar do grande conhecimento da neuroquímica, dos mecanismos fisiopatológicos e da etiopatogenia desta doença, ainda não foi descoberto um marcador biológico que pudesse ser utilizado em seu diagnóstico. De acordo com Emre (2003), há uma série de doenças que podem mimetizar a DP. Portanto, o estudo clínico dos pacientes de forma criteriosa ainda é o fator essencial para o diagnóstico correto (Caramelli; Carthery \& Charchat-Fichman, 2003).

A DP causada por questões estritamente genéticas é bastante rara. No entanto, há evidências do componente genético nesta patologia. Estudos com gêmeos revelaram que a herança genética desempenha papel relevante, principalmente nos casos onde a doença tem início antes dos 50 anos de idade (Tanner et al., 1999; Ferreira et al., 2010). Sendo assim, pode-se dizer que fatores genéticos apresentam maior influência na DP de início precoce. Apesar destas evidências, a DP herdada representa apenas 5\% dos casos. Alguns trabalhos relatam haver associação entre determinadas exposições ambientais, ocupacionais e estilos de vida para o desenvolvimento da DP. Estudos epidemiológicos sugerem que fatores ambientais como exposições a herbicidas, pesticidas e neurotoxinas contribuiriam para o aparecimento desta patologia, concluindo, portanto, que trabalhadores agrícolas, indivíduos expostos ao manganês e ainda aqueles que sofreram traumatismo crânio encefálico importante apresentam risco elevado para a DP (Tsai et al., 2002; Hindle, 2010).

Atualmente, a DP é caracterizada pela ocorrência de distúrbios de movimento, equilíbrio e alterações do controle motor fino, todos com características incapacitantes. Os sinais clínicos mais evidentes incluem tremor de repouso, bradicinesia (lentidão de movimentos), rigidez muscular, escassez de 
movimentos voluntários e alterações do equilíbrio. Estes sintomas são irreversíveis e causados pela perda de neurônios dopaminérgicos de uma região denominada substância negra pars compacta (Schapira, Bezard \& Brotchie, 2006). Presume-se a morte de ao menos $60 \%$ desses neurônios ao aparecerem os primeiros sintomas motores da doença (Lang \& Lozano, 1998; Hanna-Pladdy et al., 2013).

A redução na densidade neuronal dessa população celular gera uma diminuição na projeção de fibras dopaminérgicas, causando, por sua vez, uma consequente redução dos níveis de dopamina na estrutura dos núcleos da base. Esses núcleos, ou gânglios da base, compõem um grupo de núcleos subcorticais que possuem como função primordial o controle dos movimentos voluntários. São eles: estriado (caudado e putâmen), globo pálido (interno e externo), núcleo subtalâmico e substância negra (pars compacta e reticulata) (Burch \& Sheerin, 2005). Sabe-se, entretanto, que o processo fisiopatológico da DP ultrapassa o sistema dopaminérgico, estando também envolvidos os sistemas de neurotransmissores noradrenérgicos, serotonérgicos e colinérgicos (Leentjens, 2004; Filho et al., 2007).

Diferente dos sintomas motores, que se apresentam bem definidos, existem ainda manifestações não motoras. Psicose, declínio cognitivo, distúrbios do sono, depressão, dentre outros, são sintomas bastante comuns e não devem ser ignorados, uma vez que acarretam prejuízos na qualidade de vida dos indivíduos acometidos (Melo, Barbosa \& Caramelli, 2007). No entanto, estudos revelam que $62 \%$ dos sintomas não motores, como dores, apatia, distúrbios sexuais e constipação, deixam de ser declarados pelo paciente, já que estes não reconhecem tais sintomas como pertencentes à DP. O fato de haver um baixo relato e o não reconhecimento desses sintomas trazem implicações sociais e terapêuticas importantes. Quando não tratados, tais sintomas serão responsáveis por grande impacto na vida desses pacientes e constituem frequentemente a principal causa de hospitalização e institucionalização dos mesmos (Chaudhuri \& Schapira, 2009; Reid et al., 2011). 


\subsection{Depressão}

A depressão é considerada um dos agentes mais incapacitantes das funções sociais e atividades da vida diária, sendo responsável por aproximadamente 850 mil mortes por ano. No mundo, cerca de 340 milhões de pessoas são acometidas por esse transtorno anualmente (Giavoni et al., 2008). De acordo com projeção feita pela OMS, em 2020 a depressão será a segunda maior causa de prejuízo global para todas as idades e em ambos os sexos, o que faz da depressão uma questão de extrema importância para a saúde pública na atualidade (Wong, 2007).

O diagnóstico do transtorno depressivo é feito, principalmente, por meio de entrevistas clínicas, onde são coletadas informações a respeito da história do paciente, bem como a frequência e a duração dos principais sintomas. Caracterizase como um estado de alteração do humor, podendo apresentar irritabilidade, tristeza, apatia, disforia, incapacidade de sentir prazer e, ainda, alterações cognitivas, motoras e somáticas. A intensidade e a duração desses sintomas, além do impacto no funcionamento social, são aspectos importantes na diferenciação da depressão para uma tristeza normal (Paradela et al., 2005). Independente do tipo de patologia, um diagnóstico preciso é sempre pré-requisito para um planejamento terapêutico adequado. Diagnosticar um transtorno depressivo continua sendo um desafio para profissionais que procuram a forma mais adequada para sua classificação. A introdução de sistemas classificatórios, como CID-10 e DSM-IV, puramente descritivos e com categorias definidas operacionalmente, permitiu a uniformização da comunicação entre pesquisadores e profissionais de saúde, representando marco histórico no tratamento de transtornos psiquiátricos como um todo.

De acordo com o DSM-IV, o episódio depressivo maior tem como característica principal a presença de determinados sintomas em um período mínimo de 2 semanas. Durante esse tempo, o indivíduo deve apresentar humor deprimido ou perda de interesse nas atividades que lhe davam prazer anteriormente. Além disso, o sujeito deve exibir ao menos 5 dos seguintes sintomas: 
- Humor deprimido na maior parte do dia;

- diminuição do interesse ou do prazer por quase ou todas as atividades, na maior parte do dia;

- perda ou ganho significativo de peso sem estar em dieta, ou aumento ou diminuição de apetite;

- insônia ou hipersonia;

- $\quad$ agitação ou retardo psicomotor;

- fadiga ou diminuição da energia;

- $\quad$ sentimentos de desvalia ou culpa excessiva ou inadequada;

- dificuldades para pensar, concentrar-se ou tomar decisões;

- pensamentos recorrentes sobre morte ou ideação suicida, planos ou tentativas de suicídio.

O episódio deve permanecer durante a maior parte do dia por duas semanas consecutivas e deve ter adicionado prejuízo significativo nas atividades profissionais e funcionamento social.

\subsubsection{Depressão e envelhecimento}

Os sintomas depressivos estão entre as desordens psiquiátricas mais comuns na população idosa, juntamente com a depressão maior e a distimia. Alguns estudos feitos em comunidades mostraram a existência de uma correlação entre idade (principalmente acima de 65 anos) e presença de sintomas depressivos. Blazer (2003) encontrou sintomas depressivos em 14,7\% dos idosos vivendo em comunidade. No Brasil, a prevalência é semelhante: $15 \%$ dos idosos que vivem em comunidades brasileiras apresentam alguma forma de depressão (Nogueira et al., 2014; Oliveira et al., 2006). Estudos epidemiológicos verificaram que a depressão maior apresentava menor prevalência em idosos quando comparados com a população adulta, afetando somente $1 \%$ dos idosos residentes na comunidade (Fernades, Nascimento \& Costa, 2010). Grande parte desta 
população manifesta sintomatologia depressiva, não apresentando critérios para o diagnóstico de depressão maior.

Leite et al. (2006), a partir da constatação de que a depressão menor se apresenta de maneira mais prevalente em idosos, sugere uma abordagem mais funcional para o diagnóstico nesta população, visto que este tipo de depressão apresenta-se de forma menos evidente para observação clínica. Estudo recente afirma que os sintomas depressivos são responsáveis por $25 \%$ do comprometimento funcional no envelhecimento e são quatro vezes mais prevalentes nesta população do que a depressão diagnosticada por manuais estatísticos. Portanto, é possível concluir que sintomas depressivos e depressão são equivalentes na forma como impactam a funcionalidade do idoso (Silva et al., 2013).

Atualmente, envelhecer é sinônimo de falta de força, falta de prazer, solidão e amargura. Diferente de tempos atrás, quando em determinadas sociedades, conferiam ao idoso o poder e o respeito. Com o consumismo e a cultura imediatista, características dos dias atuais, cada vez mais a população idosa vem sendo considerada como um peso para a sociedade. Desprovidos de valor, já que não oferecem nada em troca, encontram dificuldades para inserção no mercado de trabalho. Desta forma, Oliveira et al. (2006) concluíram que a alta prevalência de depressão na população idosa é, em parte, resultante das limitações físicas, próprias do envelhecimento, associadas àquelas impostas pela sociedade (Paradela, 2011). Essa combinação de fatores acaba por conferir à depressão no idoso características bastante peculiares, como a presença simultânea de problemas clínicos e sociais, trazendo dificuldades para um diagnóstico preciso (Leite et al., 2006).

\subsubsection{Aspectos cognitivos da depressão}

Diversos estudos discutem a frequente associação entre sintomas depressivos e transtornos cognitivos (Baune et al., 2007; Jessen et al., 2007; Johnson et al., 2009; Mussele et al., 2014). Entretanto, algumas questões ainda encontram-se em debate, como, por exemplo: se a idade de início da depressão 
apresentaria relação com a gravidade do prognóstico, aumentando as chances para desenvolvimento de quadro demencial; se a ocorrência de déficits cognitivos em deprimidos seria fator preditivo de demência; se a remissão dos sintomas depressivos acarretaria também na remissão dos déficits cognitivos; se a depressão causa déficits cognitivos ou se os déficits cognitivos levam à depressão (Ávila \& Bottino, 2006).

$\mathrm{Na}$ maioria dos casos, essas questões apresentam-se de forma bastante controversa. Netto \& Landeira-Fernandez (2012), em estudo onde investigaram o perfil neuropsicológico de idosos com sintomas sugestivos de depressão e queixa de memória, afirmam que as alterações cognitivas presentes em quadro depressivo são reversíveis após tratamento medicamentoso. Outros estudos, no entanto, demonstraram haver reversão parcial desses comprometimentos ou mesmo casos onde não há reversibilidade, ainda que o sujeito tenha sido submetido a um tratamento efetivo, caracterizando quadro de DCL em comorbidade com a depressão e não de prejuízo cognitivo como consequência da depressão (SaézFonseca et al, 2007). Da mesma maneira, alguns autores consideram a depressão como fator de risco para demência, contrariando a opinião de outros que afirmam que aspectos neuropatológicos da demência ou do DCL causariam sintomas depressivos (Panza et al., 2010).

Há alguns anos, acreditava-se que mesmo os casos de depressão mais graves não eram capazes de causar alterações cognitivas significativas. Atualmente, no entanto, sabe-se que até mesmo sintomas depressivos mais leves associam-se a comprometimentos cognitivo e funcional (Blazer, 2003). Além disso, outros domínios cognitivos passaram a ser alvo de investigação no sujeito deprimido, não se limitando somente à memória, o que acabava por acarretar em supervalorização deste domínio em quadros depressivos. Ávila \& Bottino (2006), em revisão de literatura sobre as alterações cognitivas em idosos com depressão, concluíram que muitos estudos demonstram rebaixamento no desempenho de testes neuropsicológicos que avaliam a memória. Entretanto, as FE estão entre as funções que apresentam maior comprometimento, seguidas da atenção e velocidade de processamento. Portanto, de acordo com estes autores, os prejuízos 
na memória podem ser decorrentes, ou seja, secundários a uma síndrome disexecutiva, sendo o lobo frontal a região do cérebro mais afetada na depressão.

Thomas et al. (2010) propõem um subtipo de depressão que denominaram de Depressão da Síndrome Disexecutiva, a qual estaria associada à disfunção do circuito subcortical frontal. Tal afirmação tem como base achados clínicos, neuropatológicos e de neuroimagem, que confirmam a ideia de que alterações no circuito fronto-estriatal contribuem tanto para o desenvolvimento da depressão, quanto da síndrome disexecutiva. A perda do interesse ou prazer por atividades usuais e a lentificação motora são sintomas comuns, contribuindo bastante para a incapacidade funcional em sujeitos acometidos por este tipo de depressão.

Porto et al. (2002) investigaram as alterações neuropsicológicas na depressão e observaram que os domínios cognitivos mais afetados foram evocação após intervalo de tempo, aquisição da memória, atenção, flexibilidade cognitiva e abstração. Esclarecem, ainda, que déficits de memória associados à depressão são parecidos com aqueles presentes em sujeitos com disfunção subcortical. A associação entre a intensidade do déficit cognitivo e a severidade e quantidade de sintomas depressivos também tem sido amplamente discutida. Estudo longitudinal investigou a relação entre depressão e comprometimento cognitivo a partir da avaliação de 500 sujeitos, por um período de quatro anos. Observaram uma associação entre o aumento anual dos sintomas depressivos e alterações cognitivas nos domínios atenção, memória imediata e tardia, demonstrando que há piora cognitiva conforme agravamento dos sintomas de depressão (Vinkers et al., 2004).

Percebe-se, desta forma, que o perfil cognitivo do sujeito com depressão é bastante amplo e heterogêneo. No entanto, é importante ressaltar que diferentes resultados podem estar relacionados às questões metodológicas, como escolha dos instrumentos, faixa etária, objetivo do estudo e, ainda, intensidade e início dos sintomas depressivos. É de extrema importância o conhecimento dos aspectos neuropsicológicos da depressão, uma vez que consiste, muitas vezes, em peça chave para um diagnóstico diferencial. 


\subsubsection{Depressão e DP}

Diversos sintomas neuropsiquiátricos podem estar associados à DP. Em estudo sobre a prevalência e a variedade desses sintomas na DP, Aarsland et al. (1999) observaram que $61 \%$ dos parkinsonianos apresentavam pelo menos um sintoma neuropsiquiátrico, enquanto que $45 \%$ apresentavam dois ou mais sintomas. Destes, depressão e alucinação foram os sintomas mais frequentes. De acordo com a literatura, 17\% dos parkinsonianos apresentam depressão maior, $22 \%$ depressão menor e $13 \%$ distimia (Reijendrs et al., 2008).

Dentre os sintomas não motores, a depressão é a que mais se associa à DP, afetando 40\% dos pacientes (Silberman et al., 2004). Reijendrs et al. (2008) em recente revisão chamam atenção para grande variação observada na taxa de prevalência da depressão na DP (de 2,7\% a 90\%). De acordo com esses autores, tal fato pode ser explicado por diversos fatores, como o tipo de população estudada, instrumentos utilizados para o diagnóstico de depressão, tipo de depressão investigado e ainda, medidas estatísticas usadas nos estudos. Sendo assim, observou-se que trabalhos que adotam escalas de avaliação para quantificar sintomas depressivos tendem a apresentar taxas de prevalência mais elevadas se comparados àqueles que utilizam manuais para elaboração de diagnósticos (DSM, CID). Estudos que usam escalas de autoavaliação apresentam prevalências mais elevadas do que estudos com escalas preenchidas por familiares ou cuidadores. As menores taxas de prevalência são encontradas em estudos populacionais, diferente daqueles realizados com sujeitos institucionalizados ou usuários de serviços ambulatoriais.

Há uma similaridade entre os fatores de risco para depressão na população geral e naqueles acometidos pela DP. Sendo assim, pertencer ao sexo feminino, possuir idade avançada, apresentar histórico familiar para depressão e doenças crônicas aumentam a probabilidade de se desenvolver transtornos depressivos também nos parkinsonianos. Entretanto, a literatura sugere alguns fatores de risco próprios da depressão na $\mathrm{DP}$, como início precoce da doença, maior comprometimento funcional, acarretando em perda da autonomia, e histórico familiar da DP (Leentjens, 2004). 
Entre os fatores etiológicos da depressão na DP podemos citar o desequilíbrio de neurotransmissores e, ainda, a perda funcional decorrente da progressão desta patologia. Remy et al. (2005) acreditam que a dopamina também estaria associada à questão não motora da DP. Para estes autores, a disfunção no sistema límbico da combinação de dopamina, serotonina e norepinefrina estaria envolvida no desencadeamento da depressão. Tal fato é corroborado por Lieberman (2006), que em revisão sobre a depressão na DP concluiu que a morte de neurônios serotonérgicos pode, em parte, ser responsável pelos sintomas de depressão nesta patologia. Desta forma, tais sintomas não seriam apenas reação ao fato de ser portador de DP, mas, sobretudo, desencadeado devido à degeneração neuronal própria da doença (Blonder et al., 2013).

Uemura et al. (2013) afirmam que sujeitos com DP teriam duas vezes mais chances de adquirir depressão quando comparados àqueles que não possuem esta doença. Relacionaram, ainda, sintomas depressivos com comprometimento cognitivo e distúrbios motores, sugerindo que mudanças endógenas do sistema de neurotransmissores, somadas ao processo natural da doença, contribuiriam para o aparecimento dos sintomas de depressão. Chagas et al. (2014) investigaram de que maneira ocorre a associação entre depressão e DP. Para isso, avaliaram 1.451 sujeitos, sendo 1.409 sem o diagnóstico de DP e 42 com este diagnóstico. Todos os participantes apresentavam DCL. Quanto à depressão, 12 (28.5\%) parkinsonianos apresentaram depressão e 222 (15,8\%) não parkinsonianos, segundo critérios estabelecidos pelo CID-10. Após análise dos dados, observaram a existência de forte associação entre depressão e DP, a qual se mostrou ainda mais significativa após pareamento das variáveis idade, gênero e escolaridade. Quando dividiram a amostra de acordo com a intensidade do declínio cognitivo, observaram que a associação entre depressão e DP era mais forte naqueles com comprometimentos cognitivos mais severos. Assim, na DP a probabilidade de se desenvolver depressão aumenta conforme a severidade do comprometimento cognitivo. Os autores afirmam, ainda, que independente da patologia, prejuízos na cognição elevam as chances para depressão, sugerindo uma via de mão dupla onde depressão e cognição são mutuamente influenciadas. 
A comorbidade entre depressão e DP tem sido frequentemente alvo de discussão. Debate-se se os sintomas depressivos na DP devem ser considerados como parte intrínseca da doença ou como entidade clínica independente. Para Leentjens (2004), trata-se de uma discussão conceitual da psicopatologia. Segundo este autor, o DSM-IV usa o termo distúrbio (disorder) sem maiores explicações, podendo ser doença, com etiologia, curso e prognóstico, ou síndrome, com uma gama de sintomas, mas sem referência etiológica. Como uma síndrome, a depressão pode ser reconhecida como entidade clínica separada da DP, mas ao mesmo tempo é intrínseca a esta patologia, já que as duas condições compartilham determinados aspectos e sintomas.

Por ser demasiadamente incapacitante, a depressão não pode ser considerada como consequência natural do envelhecimento, mas como uma morbidade psíquica associada a um intenso sofrimento, podendo causar distúrbios cognitivos importantes (Diniz \& Forlenza, 2009). Sabe-se que a piora do estado clínico geral, o tempo de curso da doença e o aumento da idade associam-se com a piora da depressão e da cognição. Camargos et al. (2004) realizaram revisão sobre os sintomas que apresentam maior influência na qualidade de vida dos parkinsonianos. Segundo estes autores, os sintomas da DP podem afetar a qualidade de vida em diversos aspectos, como físico, emocional, social e econômico. Concluíram que a depressão é o sintoma emocional de maior impacto na vida de sujeitos com DP, já que é responsável por importante incapacidade e consequente dependência. Desta forma, quanto mais graves os sintomas de depressão, piores são os escores na Parkinson Disease Questionnaire-39 (PDQ39), quando comparados com pacientes sem depressão.

Poucos são os estudos na literatura que caracterizam os sintomas de depressão na DP. Sabe-se, no entanto, que sentimentos de culpa, autopunição e inutilidade não são característicos da depressão nesta patologia (Schrag et al., 2007). Seu reconhecimento na vigência de DP é bastante complexo, já que os sintomas do Parkinson acabam por se sobrepor àqueles pertencentes às síndromes depressivas. Apatia, lentidão de movimentos, distúrbios do sono, alterações da libido, dentre outros, também estão presentes nos parkinsonianos sem depressão 
(Veiga et al., 2009). Este fato acaba por contribuir para uma alta prevalência de subdiagnósticos, agravando e trazendo consequências problemáticas na evolução do processo da DP.

\subsubsection{Escalas de avaliação de depressão na DP}

Embora a comorbidade depressão e DP seja bastante comum, ainda é grande a dificuldade em estabelecer um diagnóstico preciso deste transtorno de humor em parkinsonianos. Sabendo-se da sobreposição de sintomas motores e não motores, bem como do impacto da depressão na qualidade de vida desses sujeitos, torna-se crucial o uso de instrumentos adequados para sua classificação. Diversas escalas vêm sendo utilizadas com o objetivo de se avaliar os sintomas depressivos na DP. Assim, a Movement Disorders organizou comissão técnica para avaliação psicométrica desses instrumentos e recomendação clínica para seu uso. As escalas escolhidas para revisão foram: Inventário de Depressão de Beck (BDI), Escala Hamilton de Depressão (HAM-D), Hospital Anxiety and Depression Scale (HADS), Zung Self-Rating Depression Scale (SDS), Geriatric Depression Scale (GDS), Montgomery - Asberg Depression Rating Scale (MADRS), Unified Parkinson's Disease Rating Scale (UPDRS) Part I, Cornell scale for de assessment of Depression in Dementia (CSDD) e, por último, a Center of Epidemiologic Studies Depression Scale (CES-D). Sete pesquisadores de países e profissões diferentes (psiquiatras, neurologistas e psicólogos), com experiência clínica em classificar depressão na DP, foram designados para avaliar as escalas selecionadas, sendo cada escala avaliada por dois membros. Ao final, todos os membros tinham acesso às revisões e modificações foram realizadas de acordo com as sugestões propostas, as quais foram ainda aprovadas pelo presidente e alteradas de acordo com recomendações do comitê científico da Movement Disorders.

De acordo com esta força tarefa da Movement Disorders, as escalas BDI, HAM-D e MADRS foram considerados bons instrumentos tanto para a triagem (rastreamento) quanto para a classificação da severidade da depressão em sujeitos acometidos pela DP. As escalas GDS e HADS são bons instrumentos quando o 
objetivo é o rastreio de sintomas de depressão; já as escalas CES-D e CSDD necessitam de validação para seu uso na DP (Schrag et al., 2007).

Estudo sobre a confiabilidade e validade do BDI em sujeitos com DP concluiu que esta escala possui elevada consistência interna para DP, bem como sensibilidade e especificidade suficientes tanto para rastrear como para diagnosticar a depressão em parkinsonianos. Devido ao seu potencial, o BDI é uma das escalas de depressão mais utilizadas, seja em contextos clínicos ou de pesquisa (Visser et al., 2006; Giavone et al., 2008).

\subsection{Declínio Cognitivo Leve}

Entende-se por cognição toda atividade mental envolvida na aquisição, processamento, armazenamento e recuperação de informação. O funcionamento cognitivo inclui uma variedade de habilidades, tais como aprendizagem, atenção, memória, linguagem, resolução de problemas, habilidades visuoespaciais, etc. Embora muitos idosos apresentem as habilidades cognitivas preservadas, pode-se perceber um declínio do funcionamento cognitivo com o envelhecimento. As informações não são mais armazenadas e recuperadas com a mesma facilidade de outrora. Existe, portanto, grande variabilidade no funcionamento das habilidades cognitivas nos idosos, sendo possível o declínio em áreas diferentes e até mesmo o aperfeiçoamento em outras (Papalia \& Olds, 2000). Embora seja considerado indicativo de desenvolvimento futuro de um quadro demencial, há casos onde, através de tratamento adequado, o comprometimento permanece estável ou até mesmo apresente remissão (Rabelo, 2009).

O DCL - ou comprometimento cognitivo leve (CCL) - pode ser caracterizado como um período de transição entre o envelhecimento saudável e o patológico. Foi considerado como entidade clínica há aproximadamente 20 anos e desde então indivíduos com este diagnóstico vêm sendo investigados sob variadas perspectivas: clínica, genética, epidemiológica, dentre outras (Reisberg et al., 1988). Inicialmente, de acordo com critério estabelecido pela Clínica Mayo, o DCL era reconhecido em indivíduos que apresentassem comprometimento na memória, mais especificamente na memória episódica. No entanto, não havia 
quadro demencial estabelecido e, portanto, com funcionamento cognitivo global e aspectos funcionais preservados (Petersen et al., 2014). Com o passar do tempo, foi verificado que a memória não era o único domínio comprometido no DCL. Então, critérios expandidos pela Clínica Mayo reconheceram o acometimento de outros domínios cognitivos (Petersen, 2004).

Desta forma, atualmente o DCL é descrito como uma condição clínica onde há declínio em um ou mais domínios cognitivos, incongruentes com a idade e escolaridade do sujeito, podendo afetar a capacidade em realizar atividades mais complexas, mas mantendo-se preservadas as atividades de vida diária. Apresenta etiologia diversificada, como doenças clínicas mal controladas, polimedicação, depressão, dentre outras, podendo evoluir para diversas patologias, não somente Doença de Alzheimer, como se pensava anteriormente (Radanovic et al.,2015). Dependendo da etiologia, o quadro poderá apresentar melhora, constância ou ainda progressão para demência. Estudos recentes demonstram que, por ano, 10\% dos sujeitos com DCL convertem para demência e que estes exibem 6,7 vezes mais chances de a desenvolverem (Bruscoli \& Lovestone, 2004; Boyle et al., 2006).

Estudos de revisão sobre o termo DCL levaram à diferenciação entre seus subtipos, sendo eles: amnésticos e não-amnésticos, de domínio único ou múltiplos domínios, conforme descrição a seguir (Petersen et al., 2009; Charchat-Fichman et al., 2013):

a. DCL amnéstico de domínio único: somente a função memória encontrase comprometida, devendo haver queixa subjetiva e déficit objetivo nesta função, comprovado por testes neuropsicológicos;

b. DCL amnéstico de múltiplos domínios: déficit objetivo da função memória e de, pelo menos, mais uma função cognitiva;

c. DCL não-amnéstico múltiplos domínios: comprometimento em mais de um domínio, com exceção da memória;

d. DCL não-amnéstico domínio único: caracterizado pelo comprometimento em um único domínio e função memória preservada; 
e. DCL não-amnéstico domínio único disexecutivo: caracterizado por comprometimento das funções executivas (organização e planejamento, resolução de problemas, julgamento, controle inibitório, flexibilidade cognitiva), mostra-se com pouca frequência na literatura, sendo citado somente em trabalhos onde o foco principal são outros domínios que não a memória (Balthazar \& Damasceno, 2008). Possui características próprias e um leve prejuízo nas atividades de vida diária pode ser observado neste subtipo de DCL (Charchat-Fichman et al., 2013). A figura 1 mostra os critérios diagnósticos para o DCL (Petersen et al., 1999). 
Figura 1: critérios para diagnóstico de DCL

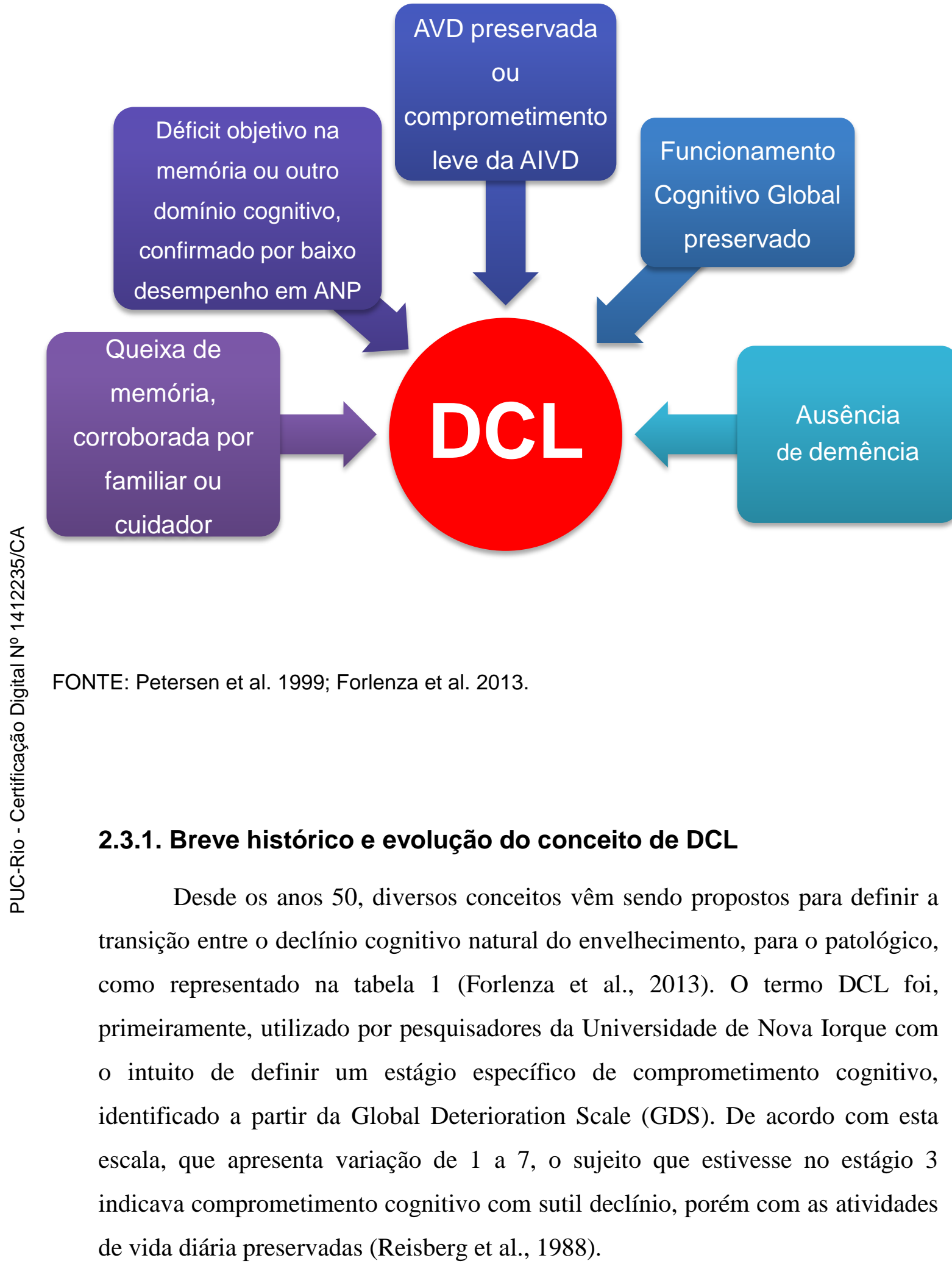

Na década de 80, pesquisadores da Universidade de Washington desenvolveram uma escala equivalente à GDS, denominada Escala de Avaliação 
Clínica de Demência (CDR). De acordo com este instrumento, o sujeito seria classificado de 0 a 3 , onde quanto maior a classificação mais grave seria o comprometimento cognitivo. Desta forma, CDR 0.5 e CDR 1 seriam indicativos de comprometimento cognitivo grave, enquanto CDR 2 e CDR 3 indicariam demência (Morris, 1993). No entanto, era possível observar estudos onde sujeitos classificados com CDR 0.5 eram considerados com quadro inicial de demência e outros com a mesma classificação sendo diagnosticados com DCL (Forlenza et al., 2013).

Foi então que, no final da década de 90, uma equipe da Clínica Mayo, chefiada por Ronald Petersen, propuseram 5 critérios operacionais para o diagnóstico de DCL (Petersen et al., 1999). Inicialmente, de acordo com estes autores, sujeitos classificados com DCL do tipo amnéstico demonstravam aumento significativo do risco para conversão para demência (mais especificamente DA). Nos anos seguintes, entretanto, investigações demonstraram que nem todos os sujeitos com DCL converteriam para demência e que existem outros padrões de comprometimento cognitivo, não se limitando somente ao comprometimento da memória, como já foi relatado neste estudo. A partir daí, passou-se a considerar prejuízos cognitivos em outros domínios, bem como conversão para tipos diversos de demência e não somente DA (Petersen et al., 2014; Forlenza \& Chiu, 2008).

Radanovic et al. (2015) esclarecem que a conversão de DCL para uma demência especifica está, na maioria das vezes, associada ao subtipo de DCL. Sendo assim, em casos onde há o comprometimento da memória episódica, com DCL estritamente amnéstico, existe elevado risco de conversão para DA. No entanto, DCL amnéstico múltiplos domínios já apresenta outras possibilidades de demência, como, por exemplo, demência vascular. Os autores alertam, ainda, para a possibilidade de possíveis sobreposições de domínios cognitivos, acarretando em conversão para um quadro demencial que não estava previsto, ou até mesmo a não progressão para demência. 
A tabela 1 mostra alguns conceitos de DCL utilizados ao longo da história.

Tabela 1:Conceitos e critérios de DCL

\begin{tabular}{|c|c|}
\hline CONCEITOS & CRITÉRIOS \\
\hline $\begin{array}{l}\text { Autorrelato de queixas de } \\
\text { memória }\end{array}$ & Queixas subjetivas de memória. \\
\hline Esquecimento senil benigno & $\begin{array}{c}\text { Dificuldade em evocar eventos remotos } \\
\text { não significativos. Utilização de } \\
\text { estratégias compensatórias. }\end{array}$ \\
\hline $\begin{array}{l}\text { Comprometimento da memória } \\
\text { associado à idade }\end{array}$ & $\begin{array}{l}\text { Declínio mnêmico gradual, com outras } \\
\text { funções cognitivas preservadas. } \\
\text { Funcionamento intelectual adequado. }\end{array}$ \\
\hline $\begin{array}{c}\text { Declínio cognitivo associado à } \\
\text { idade }\end{array}$ & $\begin{array}{l}\text { Comprometimento cognitivo abaixo das } \\
\text { normas estabelecidas para idade e } \\
\text { escolaridade em pelo menos uma } \\
\text { função cognitiva, há pelo menos } 6 \\
\text { meses, confirmado por familiar ou } \\
\text { cuidador. }\end{array}$ \\
\hline $\begin{array}{c}\text { Comprometimento cognitivo } \\
\text { não-demência }\end{array}$ & $\begin{array}{c}\text { Comprometimento de único ou múltiplos } \\
\text { domínios, de etiologias variadas, sem } \\
\text { evidencias de demência pelos critérios } \\
\text { do DSM-IV. }\end{array}$ \\
\hline $\begin{array}{c}\text { Declínio/Comprometimento } \\
\text { Cognitivo Leve }\end{array}$ & $\begin{array}{c}\text { Queixa subjetiva de comprometimento } \\
\text { cognitivo associado a resultados } \\
\text { objetivos. Funcionamento Cognitivo } \\
\text { Global e AIVD preservados. }\end{array}$ \\
\hline
\end{tabular}

Adaptado de Forlenza et al. 2013

\subsubsection{Taxas de prevalência e incidência de DCL}

Estudos recentes mostram que a prevalência de DCL, de forma geral, se apresenta em torno de 15 a $20 \%$, embora se admita grande variabilidade destas 
taxas, as quais estão diretamente associadas à metodologia, instrumentos selecionados, critérios diagnósticos utilizados e faixa etária da população investigada (Radanovic et al., 2015; Forlenza et al., 2013). Petersen et al. (2014) chamam atenção para a diferença nas taxas de prevalência quando o estudo é realizado em clínicas de referência ou na população em geral, afirmando que no primeiro caso as taxas são mais altas. Enquanto isso, Forlenza et al. (2013) demonstram a variabilidade da prevalência de DCL de acordo com a idade da população estudada. Afirmam que estudos com sujeitos de 60 anos ou mais apresentam $3 \%$ de prevalência, aumentando para $15 \%$ quando o estudo refere-se a sujeitos com 75 anos ou mais.

Em revisão sistemática recente, a incidência de DCL apresentou variação de 8.5 a 76.8 por 1000 pessoas/ano (Luck et al., 2010). No que diz respeito ao DCL amnéstico domínio único, as taxas de incidência variam de 8.5 a 14 por 1000 pessoas/ano. Quanto ao DCL amnéstico múltiplos domínios, DCL não amnéstico domínio único e DCL não amnéstico múltiplos domínios foi reportada incidência de 9, 23 e 5 por 1000 pessoas/ano (Manly et al., 2008). Radanovic et al. (2015) ressaltam que estudos a respeito da prevalência e incidência de DCL na população brasileira são demasiadamente limitados. De acordo com esses autores, um estudo desenvolvido no Brasil mostra que um terço dos idosos usuários de uma clínica de memória atendiam aos critérios clínicos para DCL, sendo 60\% DCL múltiplos domínios, 30\% DCL amnéstico e 10\% DCL não amnéstico (Diniz et al., 2008). Estudo realizado no sul do Brasil apresentou incidência anual de 13 sujeitos por 1000 idosos (Diniz et al., 2009). O mesmo estudo conclui que os fatores de risco para o desenvolvimento de DCL, de qualquer tipo, são: idade avançada, baixa escolaridade e hipertensão.

\subsubsection{DCL e DP}

Ao descrever pela primeira vez a doença, em 1817, James Parkinson postulou que o intelecto estaria inalterado, mesmo em estágios avançados. Assim, durante muitos anos a DP foi descrita como uma patologia com perturbações estritamente motoras, o que contribuía para negligenciar a disfunção mental e cognitiva associada à doença (Emre, 2003). Nas duas últimas décadas, no entanto, 
houve um crescente interesse nas alterações cognitivas presentes na DP, favorecendo a ideia de que o espectro clínico desta patologia é mais amplo do que foi considerado inicialmente (Chaudhuri et al., 2006).

Estudos têm demonstrado a ocorrência de declínio cognitivo em estágios ainda precoces da doença, $70 \%$ dos pacientes sem suspeita de distúrbios na cognição apresentam comprometimento quando avaliados (Pfeiffer et al., 2014; Prado, Ferreira \& Andrade, 2009; Nagano-Saito et al., 2014). Nestes casos, o declínio cognitivo se caracterizaria por uma disfunção executiva bastante evidente, frequentemente associada a um quadro de apatia e bradifrenia (lentidão psíquica), combinadas com uma relativa preservação da memória, da praxia e da linguagem (Goldmann-Gross et al, 2008).

Aarsland et al. (2010) investigaram, em estudo recente, a frequência e o perfil de DCL em indivíduos acometidos pela DP. Concluíram que 25,8\% dos pacientes avaliados apresentavam comprometimento cognitivo, sendo o DCL nãoamnéstico único domínio o mais encontrado, seguido pelo subgrupo amnéstico único domínio. Entretanto, os autores afirmam ter sido a memória o domínio cognitivo que apresentou maior número de comprometimentos. É importante destacar que os autores afirmam, no entanto, que na DP os comprometimentos na memória podem ser secundários a prejuízos nas funções executivas.

Polleti et al. (2011) relatam que a frequência de DCL na DP pode ser maior do que o encontrado na literatura, visto que a maior parte dos instrumentos utilizados não é sensível o suficiente para se detectar prejuízos cognitivos próprios da DP, acarretando em subdiagnósticos. Segundo esses autores, o DCL na DP é bastante heterogêneo, além de apresentar mudanças conforme a progressão da doença, visto que a redução de neurônios dopaminérgicos resulta não só em comprometimentos motores, mas também em déficits cognitivos e aspectos emocionais (Vasconcellos \& Pereira, 2015).

Parkinsonianos, portanto, irão apresentar prejuízos executivos, ainda que acompanhados por prejuízos em outros domínios, devido à disfunção frontoestriatal característico da DP. Estudo recente observou que sujeitos com disfunção 
executiva (fronto-estriatal) manifestavam outros déficits cognitivos em um período médio de 3,5 anos, podendo progredir para demência (Williams-Gray et al., 2009). Caviness et al. (2007) com o intuito de investigar de que maneira o DCL se apresenta na DP, concluíram que 67\% do grupo DP com DCL exibiam o subtipo único domínio, enquanto $33 \%$ o subtipo múltiplos domínios, sendo o comprometimento executivo o mais comum em ambos os casos, seguido de comprometimento amnéstico.

Apesar de haver poucos estudos relacionando sintomas motores $\mathrm{e}$ alterações cognitivas na DP, alguns autores mostram que pacientes com menos prejuízos cognitivos apresentam predomínio dos tremores (Tremblay et al., 2013). Em contrapartida, aqueles que apresentam maior instabilidade postural, dificuldades na marcha e rigidez muscular mostram-se mais comprometidos cognitivamente, sendo mais suscetíveis à conversão para demência (Galhardo et al., 2009 ; Jancovik et al., 1990). Com o objetivo de facilitar essa diferenciação e diagnosticar precocemente, Kehagia et al. (2013) classificaram duas síndromes cognitivas na DP. São elas:

I. Tremor dominante: avaliação neuropsicológica apresentando comprometimento em testes que avaliem FE (planejamento, memória de trabalho). Déficits estes associados à disfunção fronto-estriatal, a qual demonstra alguma resposta à reposição dopaminérgica (DCL);

II. Instabilidade postural e rigidez muscular: comprometimento nos testes que avaliem as funções visuoespacial e fluência verbal semântica. Tal comprometimento associa-se a prejuízos no córtex temporal e posterior, apresentando rápido declínio cognitivo, exibindo alguma resposta à terapêutica colinérgica (indicativo de demência).

Green et al. (2002) investigaram o comprometimento cognitivo em sujeitos que apresentavam DP em estágio avançado, encontrando associação entre pior desempenho nos testes neuropsicológicos e maior comprometimento motor, idade avançada, baixa escolaridade e maior tempo de doença. Desta forma, concluíram 
que o déficit cognitivo está presente na DP mesmo na ausência de demência ou de depressão.

\subsubsection{Diagnóstico de DCL na DP segundo critérios da Movement Disorder Society Task Force Guidelines}

O critério proposto pela Movement Disorder Society (MDS) para diagnosticar DCL na DP tem como base os critérios utilizados para se identificar DCL na população em geral. No entanto, algumas modificações foram realizadas já que foram abordadas questões bastante específicas da DP (Litvan et al., 2012).

De acordo com a MDS, o DCL na DP é uma síndrome definida a partir de critérios clínicos, cognitivos e funcionais. Estes critérios foram elaborados de forma que possibilitasse a aplicação em populações de características diversas, como diferentes níveis educacionais e etnias (Dubois et al., 2007). Além disso, são válidos e confiáveis para sua utilização em ensaios clínicos e estudos longitudinais onde o DCL é tema central ou faz parte dos critérios de inclusão e exclusão. A MDS esclarece, ainda, que a avaliação para identificação do DCL na DP pode ser realizada em duas etapas, denominadas de nível I e nível II. O primeiro nível consiste em uma avaliação breve das funções cognitivas, enquanto que o segundo nível corresponde a um protocolo de testes neuropsicológicos, capaz não só de diagnosticar o DCL como também classificá-lo.

Sendo assim, para que seja diagnosticado DCL no nível I, deve haver comprometimento em uma escala cognitiva global ou em pelo menos dois testes neuropsicológicos - uma vez que se trata de protocolo limitado, com menos de dois testes para cada domínio avaliado. Para o nível II há a exigência de um protocolo elaborado com, no mínimo, dois testes para cada domínio cognitivo, sendo o DCL diagnosticado quando houver 1 domínio comprometido (em ao menos 2 testes neuropsicológicos) ou 2 domínios comprometidos (em 1 teste neuropsicológico).

Desta forma, a MDS task force classifica o DCL na DP nos seguintes subtipos: 
a. DCL domínio único: comprometimento em um único domínio, representado por 2 testes neuropsicológicos;

b. DCL múltiplos domínios: comprometimento em 2 ou mais domínios, representado por pelo menos 1 teste neuropsicológico.

Tabela 2: Critérios Diagnósticos para DCL na DP

\begin{tabular}{|c|c|}
\hline \multirow{4}{*}{$\begin{array}{l}\text { Critérios de } \\
\text { Inclusão }\end{array}$} & Diagnóstico de DP de acordo com os critérios UKPDBB \\
\hline & $\begin{array}{l}\text { Declínio cognitivo gradual, no contexto estabelecido pela DP, } \\
\text { reportado pelo paciente, cuidador ou médico. }\end{array}$ \\
\hline & $\begin{array}{l}\text { Comprometimento cognitivo em testes neuropsicológicos ou } \\
\text { escalas de funcionamento cognitivo global. }\end{array}$ \\
\hline & $\begin{array}{l}\text { Comprometimento cognitivo sem prejuízo da autonomia, com } \\
\text { pequena dificuldade em tarefas complexas. }\end{array}$ \\
\hline \multirow{3}{*}{$\begin{array}{l}\text { Critérios de } \\
\text { Exclusão }\end{array}$} & Diagnóstico de demência na DP segundo critérios da MDS. \\
\hline & Déficits cognitivos explicados por outras causas primárias. \\
\hline & $\begin{array}{l}\text { Outras comorbidades associadas à DP que influenciam } \\
\text { significativamente no desempenho da avaliação cognitiva. }\end{array}$ \\
\hline \multirow[b]{2}{*}{ Níveis } & $\begin{array}{l}\text { Nível } 1 \text { (avaliação breve): } \\
\text { - Comprometimento em instrumento de avaliação cognitiva global } \\
\text { validade para DP; } \\
\text { - Comprometimento em pelo menos dois testes de uma avaliação } \\
\text { neuropsicológica breve. }\end{array}$ \\
\hline & $\begin{array}{l}\text { Nível 2: } \\
\text { - Cada domínio avaliado por pelo menos dois testes } \\
\text { neuropsicológicos; } \\
\text { - Comprometimento em pelo menos dois testes neuropsicológicos } \\
\text { (dois testes em um único domínio ou um teste em dois domínios } \\
\text { cognitivos diferentes); } \\
\text { - São considerados comprometidos os desempenhos em testes } \\
\text { neuropsicológicos onde: } \\
\text { Desempenho de aproximadamente } 1 \text { a } 2 \text { desvios } \\
\text { padrões abaixo das normas apropriadas; } \\
\text { Declínio significativo em vários testes cognitivos; } \\
\text { Declínio cognitivo significativo a partir de níveis pré- } \\
\text { mórbidos estimados. }\end{array}$ \\
\hline \multirow{2}{*}{ Subtipos } & $\begin{array}{l}\text { Domínio Único - Comprometimento cognitivo em um único } \\
\text { domínio, comprovado por alteração em dois testes. }\end{array}$ \\
\hline & $\begin{array}{l}\text { Múltiplos Domínios - Comprometimento em dois ou mais } \\
\text { domínios cognitivos em pelo menos um teste neuropsicológico. }\end{array}$ \\
\hline
\end{tabular}




\subsubsection{Conceito de reserva cognitiva na DP}

De acordo com a literatura, quanto maior a escolaridade menor será o risco em desenvolver um quadro demencial. Sendo assim, pode-se afirmar que uma escolaridade alta produz um efeito de proteção contra a progressão de doenças neurodegenerativas para os diferentes tipos de demência (Roe et al., 2007). Fatores genéticos, atividade física, tipos de ocupação profissional, bem como a estimulação mental ao longo da vida, são importantes para o estabelecimento de reserva cognitiva. Esta, por sua vez, permitirá o uso de redes cerebrais alternativas de forma mais eficaz, amenizando os déficits e proporcionando melhor adaptação à nova realidade do sujeito (Stern, 2006).

O modelo de reserva cognitiva preconiza que há uma tentativa ativa do cérebro em lidar com o dano cerebral existente. Para isso, ele se utiliza de processos cognitivos pré-existentes ou mobiliza estratégias compensatórias. Desta forma, quanto maior a reserva cognitiva do sujeito, melhor será sua resposta ao dano cerebral, ressaltando sempre que comprometimentos de mesma extensão em pessoas diferentes apresentam efeitos diferentes (Roe et al., 2007; Pires, Simões \& Firmino, 2010).

Embora grande parte dos trabalhos sobre reserva cognitiva utilizem amostras de sujeitos com DCL, os quais desenvolveram demências corticais (como DA), é possível dizer que este conceito também se aplica às patologias subcorticais, como a DP (Polletti et al, 2011). Cohen et al. (2007) demonstraram correlação inversa entre alta escolaridade e comprometimento cognitivo em uma amostra de 72 parkinsonianos. Da mesma forma, uma meta-análise com 25 estudos longitudinais concluiu que a escolaridade influencia sobremaneira no desempenho cognitivo de sujeitos com DP ao longo do tempo (Muslimovic et al., 2009). Segundo estes autores, quanto menor a escolaridade, maior o declínio cognitivo em todos os domínios, sendo mais acentuado na flexibilidade cognitiva, raciocínio, atenção e velocidade de processamento e memória, sugerindo um efeito protetor da escolaridade na cognição de parkinsonianos. 
Pode-se dizer, finalmente, que a reserva cognitiva atenua os efeitos clínicos de patologias neurodegenerativas, possibilitando melhor adaptação às consequências deixadas por elas e, muitas vezes, estagnando seus efeitos por um longo período de tempo.

\subsubsection{Sintomas de depressão, DCL e DP}

Os sintomas não motores na $\mathrm{DP}$, de forma geral, são responsáveis por consequências problemáticas, podendo afetar sobremaneira o curso da doença (Silberman et al., 2004). Piora da funcionalidade e da autonomia, impactando na qualidade de vida do paciente, aumento dos custos com tratamento, necessidade de hospitalizações, maior índice de mortalidade e sobrecarga do cuidador são algumas dessas consequências. Ainda assim, estudos relatam grande número de subdiagnósticos desses sintomas (Vasconcellos \& Pereira, 2015; Reid et al., 2011).

Sabe-se que na DP, DCL e depressão constituem fatores de risco para demência, sendo de extrema importância o reconhecimento e o tratamento precoce destas duas condições (Radanovic et al., 2015). Biundo et al. (2013) verificaram que, anualmente, entre 9 e 15\% de parkinsonianos evoluem para demência. Além disso, em muitos casos o quadro depressivo pode mimetizar DCL ou um processo pré-clínico de demência, dificultando a diferenciação diagnóstica e o tratamento dessas patologias. Trambley et al. (2013) chamam atenção para a heterogeneidade do comprometimento cognitivo na DP. Os autores relatam que muitos pesquisadores caracterizam os parkinsonianos em subtipos de acordo com diversos critérios, tais como: sintoma motor predominante, idade de início da doença e presença de depressão - sendo este um dos critérios mais utilizados para categorizá-los cognitivamente.

Em revisão sobre depressão como fator de risco na DP e seu impacto na cognição, Silberman et al. (2004) chamam atenção para o fato de que estudos que investigam cognição, depressão e DP apresentam muitas contradições e divergências, já que os limites entre os prejuízos cognitivos advindos da depressão e aqueles próprios da DP, são bastante tênues. Desta forma, recomenda-se 
periodicamente avaliação das funções cognitivas desses sujeitos, possibilitando um diagnóstico precoce e, consequentemente, plano de tratamento adequado e eficaz, visto que a comorbidade entre depressão e DCL exibe influência direta sobre a evolução da doença, aumentando as chances de conversão para um quadro demencial (Vasconcellos \& Pereira, 2015). 


\section{Metodologia}

\subsection{Sujeitos}

Grupo DP e grupo controle (GC) foram rigorosamente pareados quanto à idade e escolaridade, visto que estas variáveis podem influenciar o desempenho nos testes neuropsicológicos. Todos os participantes do grupo DP são atendidos em ambulatórios de neurologia da rede pública do estado do Rio de Janeiro. São estes: Ambulatório de Neurologia do Hospital Federal dos Servidores do Estado e Ambulatório de Neurologia do Hospital Universitário Pedro Ernesto.

O GC começou a ser formado por familiares de pacientes que mostrassem interesse em participar da pesquisa. No entanto, foi necessária uma mudança na estratégia de recrutamento desses sujeitos já que muitos apresentaram diagnóstico de depressão, talvez pelo fato de ter um parente próximo diagnosticado com DP. Foram, então, recrutados funcionários do próprio hospital que se encaixassem nos critérios de inclusão e exclusão deste estudo.

\subsubsection{Grupo DP}

Para o grupo DP foram utilizados os seguintes critérios de inclusão:

- $\quad$ idade entre 50 e 80 anos;

- escolaridade superior a 4 anos;

- diagnóstico de DP de acordo com a United Kingdom Parkinson's Disease Society Brain Bank (UKPDBB) (Hughes et al.,1992);

- tempo de DP superior a 3 e inferior a 10 anos;

- pontuação na Escala de Estágios de Incapacidade de Hoehn e Yahr entre 2 e 4 (Mello \& Botelho, 2010). Responsável por avaliar a incapacidade física de sujeitos com DP indicando seu estado geral de forma rápida. Neste estudo utilizou-se a forma modificada, a qual compreende sete estágios de classificação para avaliar a gravidade da DP, abrangendo, principalmente, medidas globais de sinais e sintomas que permitem classificar o indivíduo quanto ao nível de incapacidade. Os indivíduos classificados nos estágios de 1 a 3 apresentam 
incapacidade leve a moderada, enquanto os que estão nos estágios 4 e 5 apresentam incapacidade grave;

- DCL segundo critérios da Movement Disorder Society Task Force Guidelines (Litvan et al., 2012).

Critérios de exclusão utilizados na pesquisa para grupo DP:

- diagnóstico de depressão, segundo critérios do DSM-IV;

- pontuação no Mini Exame do Estado Mental (MEEM) abaixo do ponto de corte estabelecido, qual seja: 13 para analfabetos, 18 para até 8 anos de escolaridade e 26 para aqueles com escolaridade acima de 8 anos (Bertolucci et al., 1994);

- uso de anticolinérgicos e benzodiazepínicos, já que o uso contínuo desses medicamentos pode alterar as funções cognitivas (Tatsch et al.,2002; Caixeta \& Vieira, 2008);

- déficits visuais e/ou auditivos não corrigidos, os quais impossibilitem ao sujeito realizar os testes neuropsicológicos;

- distúrbios psiquiátricos;

- história atual ou prévia de abuso de álcool e/ou drogas ilícitas.

Sendo assim, dos 73 indivíduos do grupo DP, 9 foram excluídos por apresentarem pontuação no MEEM abaixo do ponto de corte utilizado neste estudo, 7 por não fecharem diagnóstico para DCL, 1 por ter sido diagnosticado com depressão segundo critérios do DSM-IV, 1 por apresentar tempo de doença superior a 10 anos, 1 por escolaridade inferior a 4 anos, 3 por estarem fora da faixa de idade estabelecida para o estudo e 3 por não estarem pareados quanto a idade e escolaridade. Portanto 48 indivíduos compuseram o grupo DP.

\subsubsection{Grupo dos controles:}

Para este grupo, foi utilizado como critério de inclusão:

- $\quad$ idade entre 50 e 80 anos; 
- escolaridade superior a 4 anos;

- diagnóstico de DCL (Petersen et al., 2004).

Critérios de exclusão:

- diagnóstico de depressão segundo critérios do DSM-IV;

- pontuação no MEEM abaixo do ponto de corte estabelecido para este estudo (Bertolucci et al., 1994), o que seria sugestivo de quadro demencial;

- distúrbios psiquiátricos;

- uso de benzodiazepínicos;

- déficit visual e/ou auditivo não corrigidos que impossibilitem ao sujeito a realização dos testes neuropsicológicos;

- história atual ou prévia de abuso de álcool e/ou drogas ilícitas.

Foram avaliados, no total, 149 indivíduos, sendo 76 do grupo controle e 73 do grupo DP. Sendo assim, dos 76 indivíduos que compunham o grupo controle, 2 foram excluídos por obter pontuação no MEEM abaixo do ponto de corte utilizado neste estudo (Bertolucci et al.,1994), 17 por não fechar diagnóstico para DCL, 1 por apresentar diagnóstico de depressão de acordo com DSM-IV, 1 por ter menos de 50 anos de idade, 9 por não estar pareado quanto a idade e escolaridade e 2 por outras questões clínicas (1 diagnosticado com tremor essencial; 1 uso de imunossupressor). Desta forma, 44 indivíduos compuseram o grupo controle.

\subsubsection{Frequência dos sintomas depressivos nos grupos DP e controle}

Com o objetivo de avaliar o impacto dos sintomas depressivos na cognição de pacientes e controles, a amostra foi dividida em 4 subgrupos:

- DP: DP sem sintomas depressivos;

- DDP: DP com sintomas depressivos;

- GC: controles sem sintomas depressivos;

- DGC: controles com sintomas depressivos; 
As figuras 2 e 3 a seguir mostram a porcentagem de sujeitos com e sem sintomas depressivos em ambos os grupos, formando os 4 subgrupos.

Figura 2: Frequência de sintomas depressivos grupo DP

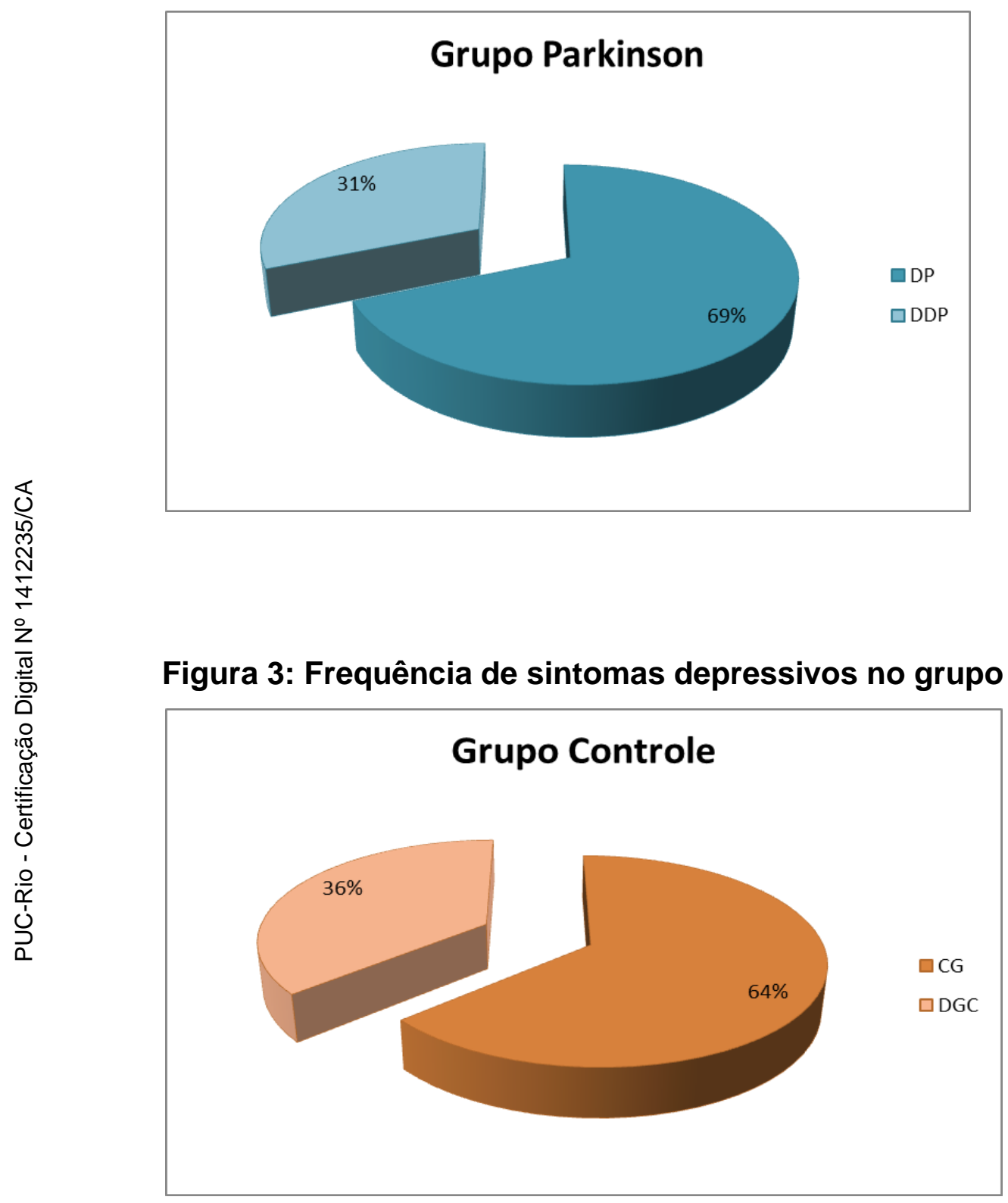

\subsection{Instrumentos}

A avaliação cognitiva foi realizada utilizando protocolo de testes neuropsicológicos previamente elaborado, seguindo as recomendações da Movement Disorder Society Task Force (Litvan et al., 2012). De acordo com este 
estudo, cada domínio deverá ser avaliado por pelo menos dois testes neuropsicológicos.

\subsubsection{Descrição dos testes neuropsicológicos:}

1. Mini Exame do Estado Mental (MEEM): Teste de rastreio que permite avaliar o funcionamento cognitivo global de forma rápida, orientação temporal e espacial (dia, mês, ano/nome do estado, cidade e local onde se encontra), atenção e cálculo (repetição de 3 palavras e subtrair 7 de 100 sucessivamente), memória recente (recordação das 3 palavras repetidas anteriormente), linguagem (nomeação de objetos, repetição de frase) e praxia (desenho dos pentágonos) (Folstein et al., 1975). Estudos prévios relatam a importância de se utilizar pontos de corte diferenciados para cada escolaridade (Bertolucci et al., 1994; Brucki et al., 2003).

2. Teste do Desenho do Relógio (TDR): Instrumento de rastreio cognitivo que verifica a praxia e habilidade visuoconstrutiva a partir de um comando verbal (Shulman, 2000). Pede-se ao sujeito para desenhar um relógio com todos os números e os ponteiros marcando $2 \mathrm{hs}$ e $45 \mathrm{~min}$. Caso o participante esqueça a hora que deverá ser marcada no relógio, o examinador não poderá repeti-la. Foram utilizados os critérios adaptados por Sunderland et al. (1989).

3. Teste de Fluência Verbal Semântica e Fonêmica: Avaliam a linguagem, atenção sustentada, organização, estratégia e perseveração (Nitrini et al., 2004) a partir da produção espontânea de palavras por categorias fonêmica e semântica. No Teste de Fluência Verbal semântica, o sujeito tem um minuto para falar o máximo de nomes de animais que puder se lembrar, não valendo nomes que comecem com o mesmo radical (ex: gato, gata; gatinho). No Teste de Fluência Verbal Fonêmica, o participante deve falar o maior número de palavras que comecem com a letra $\mathrm{F}$, logo após com a letra A e letra S, durante um minuto cada. Da mesma forma, não contam pontos nomes de mesmo radical e ainda nomes próprios. Estudos sugerem a interferência da idade e da escolaridade no desempenho destes testes (Silva et al., 2011; Caramelli et al., 2007). 
4. Teste de Memória de Figuras (TMF): Avalia memória episódica e é composto por diferentes tarefas, tais como: nomeação e percepção (o indivíduo deverá nomear corretamente 10 figuras apresentadas), MI (evocação livre das figuras nomeadas anteriormente), M1 (evocação das figuras logo após as mesmas terem sido expostas novamente durante 1 minuto), M2 (nova evocação após exposição das figuras no mesmo intervalo de tempo), M5 (após intervalo de 5 minutos, o participante deve evocar as figuras sem que elas sejam reapresentadas) e reconhecimento (dentre 20 figuras apresentadas, é pedido que o sujeito aponte quais faziam parte do conjunto apresentado anteriormente) (Nitrini et al., 1995; Vittielo et al.2007; Charchat-Fichman et al., 2013).

5. Teste Stroop de Cores e Palavras: Avalia atenção seletiva, flexibilidade cognitiva e controle inibitório através da resposta a estímulos específicos enquanto inibe processos mais automatizados (Spreen \& Strauss, 1998). Foi utilizada a versão Victória, como em estudos anteriores, onde se verificou a interferência da escolaridade no desempenho deste paradigma (Charchat-Fichman \& Oliveira, 2009; Klein et al., 2010) . Consiste em três cartelas, cada uma com seis linhas e quatro itens. Na primeira cartela, o sujeito deve nomear o mais rápido que puder as cores em que os quadrados estão pintados (azul, verde, vermelho e amarelo). Na segunda cartela há palavras aleatórias e o sujeito deve nomear o mais rápido possível as cores em que as palavras estão escritas, ignorando o significado das mesmas. A terceira cartela consiste em nomear as cores em que as palavras estão impressas e não ler o nome da cor. Por fim, é calculado o escore de interferência que consiste no quociente do tempo de execução da cartela 3 pelo da cartela $1(\mathrm{~T} 3 / \mathrm{T} 1)$.

6. Teste das Trilhas: Avalia a velocidade de processamento, atenção dividida e flexibilidade cognitiva (Spreen \& Strauss, 1998). Composto por duas tarefas, Tempo A e Tempo B. A primeira consiste em 25 números dispostos aleatoriamente em uma folha, que devem ser ligados em ordem crescente, o mais rápido possível. A segunda etapa consiste em números e letras, que deverão ser ligados intercalados, em ordem crescente e alfabética. Cada tarefa deve ser realizada em um período máximo de 5 minutos. Estudos sugerem que tanto a idade quanto a escolaridade 
interferem no tempo de execução deste paradigma (Hamdan \& Hamdan, 2009).

7. Span de Dígitos (WAIS-III): Avalia atenção verbal, memória de curtoprazo e memória de trabalho. Na primeira parte, o sujeito deve repetir cada sequencia de números, lidas em voz alta, na mesma ordem em que foram apresentadas. Na segunda tarefa, os números também devem ser repetidos, porém na ordem inversa. Critérios de avaliação e correção se basearam em estudos normatizados para a população brasileira (Figueiredo \& Nascimento, 2007).

8. Teste de Aprendizagem Auditivo Verbal de Rey (RAVLT): Avalia memória episódica, aprendizagem, suscetibilidade à interferência (através da apresentação de uma lista de palavras distratoras), retenção de informações após intervalo de tempo e capacidade de reconhecimento (Spreen \& Strauss, 1998). Uma lista (A) com quinze palavras é lida cinco vezes consecutivas (A1, A2, A3, A4, A5). Após cada leitura, o sujeito deve repetir o máximo de palavras que se lembrar. Depois da quinta tentativa, uma nova lista (de interferência) contendo quinze palavras diferentes é lida, e o sujeito deve repetir quantas puder se lembrar (B1). Logo após a evocação da lista $B$, pede-se que evoque as palavras da lista A, sem reapresentá-la (A6). Passados vinte minutos, pede-se que evoque a lista A, mais uma vez sem reapresentá-la (A7). Logo após, o examinador lê uma lista com 50 palavras, as quais correspondem à lista $\mathrm{A}$, lista B e novas palavras semelhantes semântica e fonéticamente (tarefa de reconhecimento). A cada palavra lida, o sujeito deverá dizer quais palavras pertencem à lista $\mathrm{A}$. Esta tarefa consiste na tarefa de reconhecimento. São calculadas ainda, a soma total de tentativas (A1 a A5), as taxas de Interferência Proativa (B1/A1), Interferência Retroativa (A6/A5) e Velocidade de Esquecimento (A7/A6). As variáveis nível de escolaridade e idade se correlacionam de forma positiva e negativa respectivamente com este teste (Malloy-Diniz et al. 2007; Salgado et al., 2011; Cotta et al., 2012).

9. Teste de Organização Visual de Hooper: Avalia as habilidades visuoespaciais (Spreen \& Strauss, 1998). Figuras de objetos fragmentados são apresentadas com dificuldades crescentes, sendo solicitado ao sujeito 
que organize mentalmente cada figura, através de discriminação visual, e as nomeie corretamente. As respostas são pontuadas em 0, 0,5 e 1,0. Estudos não apontam para diferenças no que se refere às variáveis sóciodemográficas (idade, escolaridade e sexo) no desempenho deste paradigma, mas fazem considerações importantes sobre as influências culturais para nomear os objetos (Torsello, 2005).

10. Inventário de Depressão de Beck (BDI): Avalia a presença de sintomas depressivos e sua intensidade (Spreen \& Strauss, 1998). Trata-se de 21 grupos de sentenças, cada qual com quatro afirmações. O sujeito deve marcar aquela que melhor descreve a maneira como vem se sentindo na última semana, incluindo o dia da avaliação. Cada afirmação equivale a um número $(0,1,2,3,4)$ e a pontuação será dada a partir da soma do total de números marcados. Os pontos de corte utilizados neste trabalho foram: 0 a 9 - sem depressão; 10 a 16 - leve a moderado; 17 a 29 - moderado a grave; 30 a 63 - severo (Cunha, 2011).

A tabela 3 a seguir apresenta os testes responsáveis por avaliar cada um dos cinco domínios (atenção, memória, funções executivas, percepção visual e linguagem) bem como a intensidade de depressão. 
Tabela 3: Testes utilizados na avaliação das funções cognitivas

\begin{tabular}{|c|c|}
\hline Domínios & Testes Neuropsicológicos \\
\hline Funções Executivas & $\begin{array}{l}\text { Teste Stroop de Cores e Palavras }{ }^{(1)} \text { (tempo) } \\
\text { Cartão } 1 \\
\text { Cartão } 2 \\
\text { Escore de interferência (T3/T1) } \\
\text { Erros cartão } 3 \\
\text { TMT }^{(2)} \\
\quad \text { Tempo de execução da parte B } \\
\text { Tempo de execução da parte A } \\
\text { FAS }^{(3)} \\
\text { Fluência Verbal Animais }^{(4)} \\
\text { TDR }^{(5)}\end{array}$ \\
\hline Atenção & $\begin{array}{l}\text { Teste Stroop de Cores e Palavras }{ }^{(1)} \text { (tempo e } \\
\text { erros) } \\
\quad \text { Cartão } 1 \\
\text { Cartão } 2 \\
\text { Cartão } 3 \\
\text { TMT }^{(2)} \\
\quad \text { Tempo de execução da parte A } \\
\text { Tempo de execução da parte B } \\
\text { RAVLT }^{(6)} \\
\text { A6 }\end{array}$ \\
\hline Memória de Trabalho & $\begin{array}{l}\text { RAVLT }^{(6)} \\
\mathrm{A} 1 \text { e B1 }^{\mathrm{B} 1} \\
\mathrm{TMF}^{(7)} \\
\text { Memória incidental } \\
\text { WAIS-III }^{(8)} \\
\text { Dígitos ordem direta } \\
\text { Dígitos ordem indireta }\end{array}$ \\
\hline Memória Episódica & $\begin{array}{l}\text { RAVLT }^{(6)} \\
\text { Somatório } \\
\text { A7 } \\
\text { Reconhecimento } \\
\text { TMF }^{(7)} \\
\text { M1 } \\
\text { Aprendizagem } \\
\text { M5 }\end{array}$ \\
\hline Memória Semântica & Fluência Verbal Animais $^{(4)}$ \\
\hline Percepção Visual & Hooper $^{(9)}$ \\
\hline Linguagem & $\begin{array}{l}\mathrm{FAS}^{(3)} \\
\mathrm{TMF}^{(7)} \\
\quad \text { Nomeação }\end{array}$ \\
\hline Escala de Depressão & $\mathrm{BDI}^{(10)}$ \\
\hline
\end{tabular}




\subsection{Procedimento}

Neste estudo, todos os sujeitos foram submetidos a duas etapas:

- Etapa 1: Avaliação clínica com neurologista, onde foram coletados dados demográficos, informações a respeito da existência de co-morbidades (como HAS, diabetes, hiperuricemia e alcoolismo), aplicação das escalas de Hohen-Yahr, Unified Parkinson's Disease Rating Scale (UPDRSavalia os sinais e sintomas do Parkinson bem como a funcionalidade do sujeito nas atividades de vida diária nos períodos on e off do medicamento, compreende 42 itens subdivididos em 4 subseções: IAtividade mental, comportamento e humor; II- Atividade de vida diária; III- Exame das funções motoras; IV- Complicações do tratamento. A pontuação de cada item é de 0 a 4 e quanto maior o a pontuação maior o comprometimento), PDQ-39 (escala específica de avaliação da qualidade de vida na DP e compreende 39 itens, cada item com cinco opções diferentes de resposta: "nunca"; "de vez em quando"; "às vezes"; "frequentemente"; "sempre" ou "é impossível para mim". Os escores em cada item variam de 0 a 4; a pontuação varia de 0 a 100 e quanto maior, pior é a percepção da qualidade de vida), e por fim classificação do subtipo de DP (tremulante, rígido-acinético ou misto).

- Etapa 2: avaliação neuropsicológica.

Para avaliação dos sujeitos foi respeitado um padrão estabelecido previamente pela equipe da pesquisa, tanto no que se refere à aplicação dos testes quanto à correção e interpretação dos mesmos. A avaliação neuropsicológica foi realizada por neuropsicólogas clínicas experientes e devidamente treinadas para aplicação, correção e interpretação dos resultados. A avaliação clínica foi realizada sempre pelo mesmo neurologista, que encaminhava o sujeito à equipe de neuropsicólogas após evidenciar a existência dos critérios de inclusão. As duas etapas eram cumpridas num mesmo dia, para que não houvesse risco de participação em somente uma delas o que impossibilitaria a inclusão do sujeito na pesquisa, além da necessidade de os sujeitos estarem nas mesmas condições física e mental em ambas as etapas. Para o grupo DP houve ainda a preocupação em avaliá-los no período on da medicação. 
As avaliações foram feitas em salas com condições adequadas para sua realização. Todos os participantes deste estudo foram avaliados por um mesmo protocolo de testes neuropsicológicos, que deveria ser aplicado na seguinte ordem: MEEM, Teste de Memória de Figuras (até a memória incidental 2), Teste do Desenho do Relógio, Teste de Fluência Verbal Semântica (animais), Evocação do Teste de Memória de Figuras (M5), Reconhecimento do Teste de Memória de Figuras, Teste de Aprendizagem Auditivo Verbal de Rey - RAVLT (A1, A2, A3, A4, A5, B1, A6), Dígitos (ordem direta e inversa), Teste Stroop de cores e palavras, Teste de Trilhas (tempos A e B), evocação (A7) e Reconhecimento do RAVLT, Teste de Fluência Verbal Fonêmica (FAS), Teste de Organização Visual de Hooper e por fim a Escala de Depressão de Beck (BDI), como mostra a figura 4 .

Figura 4: Ordem de aplicação dos testes neuropsicológicos

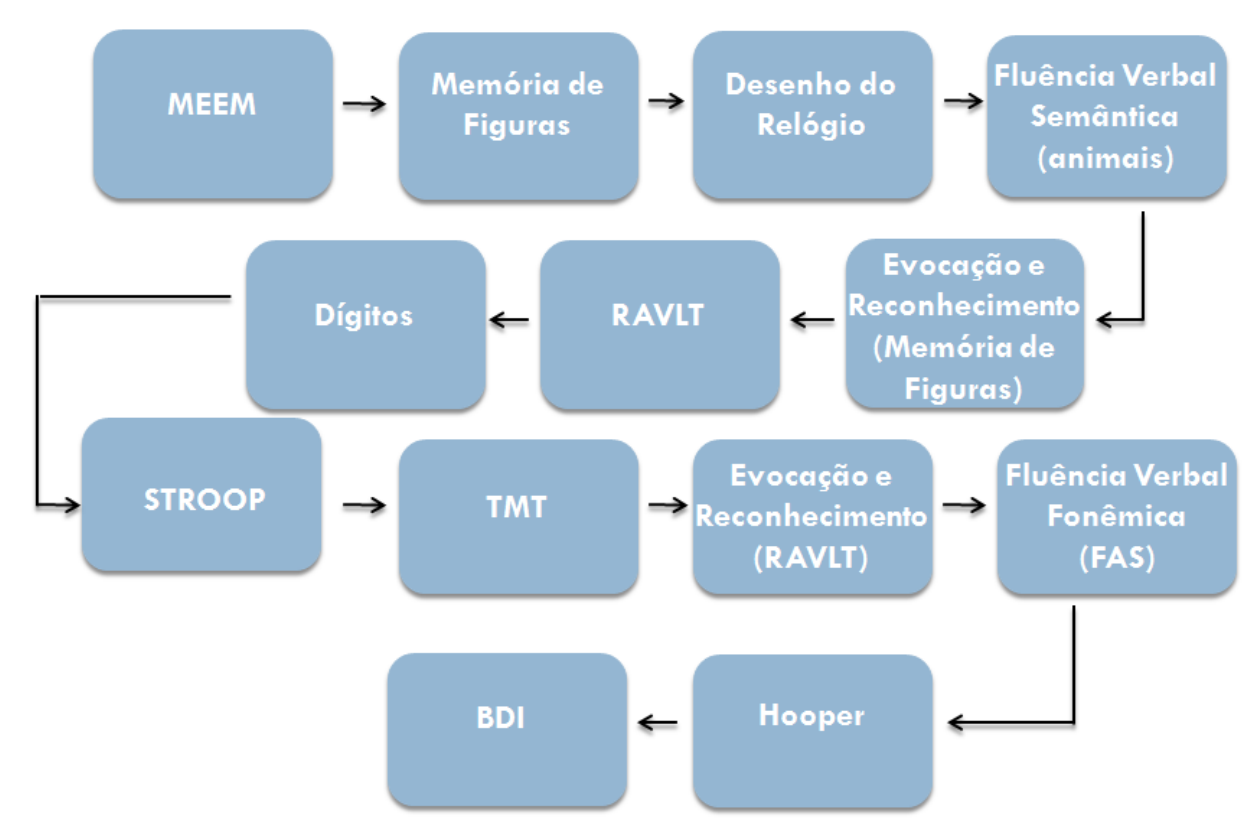




\subsection{Questões Éticas}

Este estudo foi realizado de janeiro de 2014 a setembro de 2015 e está inserido em um projeto mais amplo, que objetiva identificar fatores preditivos de demência na DP, desenvolvido pelo departamento de neurologia da Universidade Estadual do Rio de Janeiro em conjunto com o grupo de pesquisa em neuropsicologia clínica da PUC-Rio. Todos os pacientes frequentam regularmente ambulatórios de neurologia de hospitais da rede pública do Rio de Janeiro. Cada participante assinou o Termo de Consentimento Livre e Esclarecido (TCLE), aprovado pelo Comitê de Ética em Pesquisa do Hospital Universitário Pedro Ernesto, inserido na Plataforma Brasil - parecer $n^{0}$ 486.273. A participação no estudo foi feita de maneira voluntária, sem direito à remuneração, sem apresentar nenhum tipo de risco para a saúde e podendo ser interrompida a qualquer momento. 


\section{Análise dos dados}

As análises foram realizadas com auxílio do software estatístico Statistical Package for Social Sciences (SPSS), versão 22. Foram feitas análises quantitativas, delineadas da seguinte forma:

I. Análise descritiva das variáveis sociodemográficas (idade e escolaridade, gênero), cognitivas e dos sintomas depressivos (média e desvio padrão). Realização do teste $t$ de Student como meio de se comparar as médias entre grupos experimental e controle $(\mathrm{O}$ valor de $\mathrm{p}<0,05$ foi adotado para detectar diferenças significativas entre grupos).

II. Análise de chi-quadrado comparou as frequências dos sintomas depressivos entre os dois grupos, baseado na pontuação total na BDI.

III. Análise de correlação de Pearson entre a pontuação total do BDI e os testes cognitivos.

IV. A fim de comparar o desempenho nos testes neuropsicológicos de pacientes e controles com e sem sintomas depressivos, foi realizada análise de variância One-way (ANOVA), seguida de teste post-hoc Bonferroni. 


\section{Resultados}

\subsection{Análise descritiva dos grupos}

Grupos DP e controle não apresentaram diferença estatística nas médias de idade, escolaridade e pontuação do MEEM. A média de idade dos pacientes foi de 61,8 anos (dp 7,36) e dos controles 60,7 anos (dp 6,59). Quanto à escolaridade, os pacientes apresentaram em média 10,1 (dp 3,95) anos de estudo, enquanto os controles escolaridade média de 11,5 (dp 4,29) anos. O escore médio dos controles no MEEM foi de 27,4 (dp 1,98) para pacientes e 27,6 (dp 1,22) para controles. Quanto ao BDI, pacientes apresentaram pontuação média de 7,7 (dp 6,29) e controles 9,5 (dp 8,03). O teste $t$ de Student demonstrou não haver diferença significativa entre essas médias (idade: $p=0,233$; Escolaridade: $p=0,807$; MMSE: $p=0,900$; BDI: $p=0,219)$, conforme representado na tabela 4 .

\section{Tabela 4: Caracterização da Amostra}

\begin{tabular}{|c|c|c|c|}
\hline & $\begin{array}{c}\text { DP } \\
(n=48)\end{array}$ & $\begin{array}{l}\text { Controles } \\
(n=44)\end{array}$ & $p^{(4)}$ \\
\hline Idade $\bar{x}(d p)$ & $61,8(7,36)$ & $60,7(6,59)$ & 0,233 \\
\hline $\begin{array}{l}\text { Anos de Estudo } \bar{x} \\
\text { (dp) }\end{array}$ & $10,1(3,95)$ & $11,5(4,29)$ & 0,807 \\
\hline $\begin{array}{l}\text { Sexo } \\
\text { Feminino/Masculino }\end{array}$ & $31 / 69$ & $68 / 32$ & - \\
\hline $\begin{array}{l}\text { Tempo de Doença }{ }^{(1)} \\
\bar{x}(d p)\end{array}$ & $\begin{array}{c}73,7 \\
(41,78)\end{array}$ & - & - \\
\hline $\operatorname{MEEM}^{(2)} \bar{x}(d p)$ & $27,4(1,98)$ & $27,6(1,22)$ & 0,900 \\
\hline $\mathrm{BDI}^{(3)} \bar{x}(d p)$ & $7,7(6,29)$ & $9,5(8,03)$ & 0,219 \\
\hline
\end{tabular}




\subsection{Frequência dos sintomas depressivos}

A tabela 5 mostra a frequência dos sintomas depressivos nos grupos DP e controle.

Tabela 5: Frequência dos Sintomas Depressivos (\%)

\begin{tabular}{lccc}
\hline Sintomas Depressivos & Grupo DP & Grupo Controle & $\boldsymbol{p}^{(*)}$ \\
\hline Tristeza & 18,8 & 27,3 & $>0,05$ \\
Desânimo & 14,6 & 15,9 & $>0,05$ \\
Fracasso & 10,4 & 6,8 & $>0,05$ \\
Prazer & 33,3 & 45,5 & $>0,05$ \\
Culpa & 14,6 & 13,6 & $>0,05$ \\
Punição & 16,7 & 20,5 & $>0,05$ \\
Decepção & 6,3 & 18,2 & $>0,05$ \\
Erros & 25,0 & 43,2 & $>0,05$ \\
Suicídio & 4,2 & 9,1 & $>0,05$ \\
Choro & 27,1 & 27,3 & $>0,05$ \\
Irritabilidade & 33,3 & 52,3 & $>0,05$ \\
Interesse & 16,7 & 22,7 & $>0,05$ \\
Decisão & 37,5 & 38,6 & $>0,05$ \\
Aparência & 14,6 & 25,0 & $>0,05$ \\
Trabalho & 72,9 & 34,1 & $<0,05$ \\
Sono & 52,1 & 54,5 & $>0,05$ \\
Apetite & 25,0 & 18,2 & $>0,05$ \\
Fadiga & 60,4 & 45,5 & $>0,05$ \\
Peso & 20,8 & 15,9 & $>0,05$ \\
Saúde & 45,8 & 31,8 & $>0,05$ \\
Libido & 35,4 & 56,8 & $<0,05$ \\
\hline${ }^{*}$ )Chi-quadrado & & &
\end{tabular}

Para caracterização dos sintomas depressivos na DP, foram analisados os sintomas mais frequentes nos pacientes e nos controles, apresentados na figura 5. A partir da análise de chi quadrado observou-se diferença significativa entre as frequências dos sintomas, perda de interesse por sexo e dificuldades no trabalho. Não foi evidenciada diferença significativa entre os grupos nos sintomas irritabilidade, fadiga e distúrbios do sono. 


\section{Figura 5: Frequência dos sintomas de depressão}

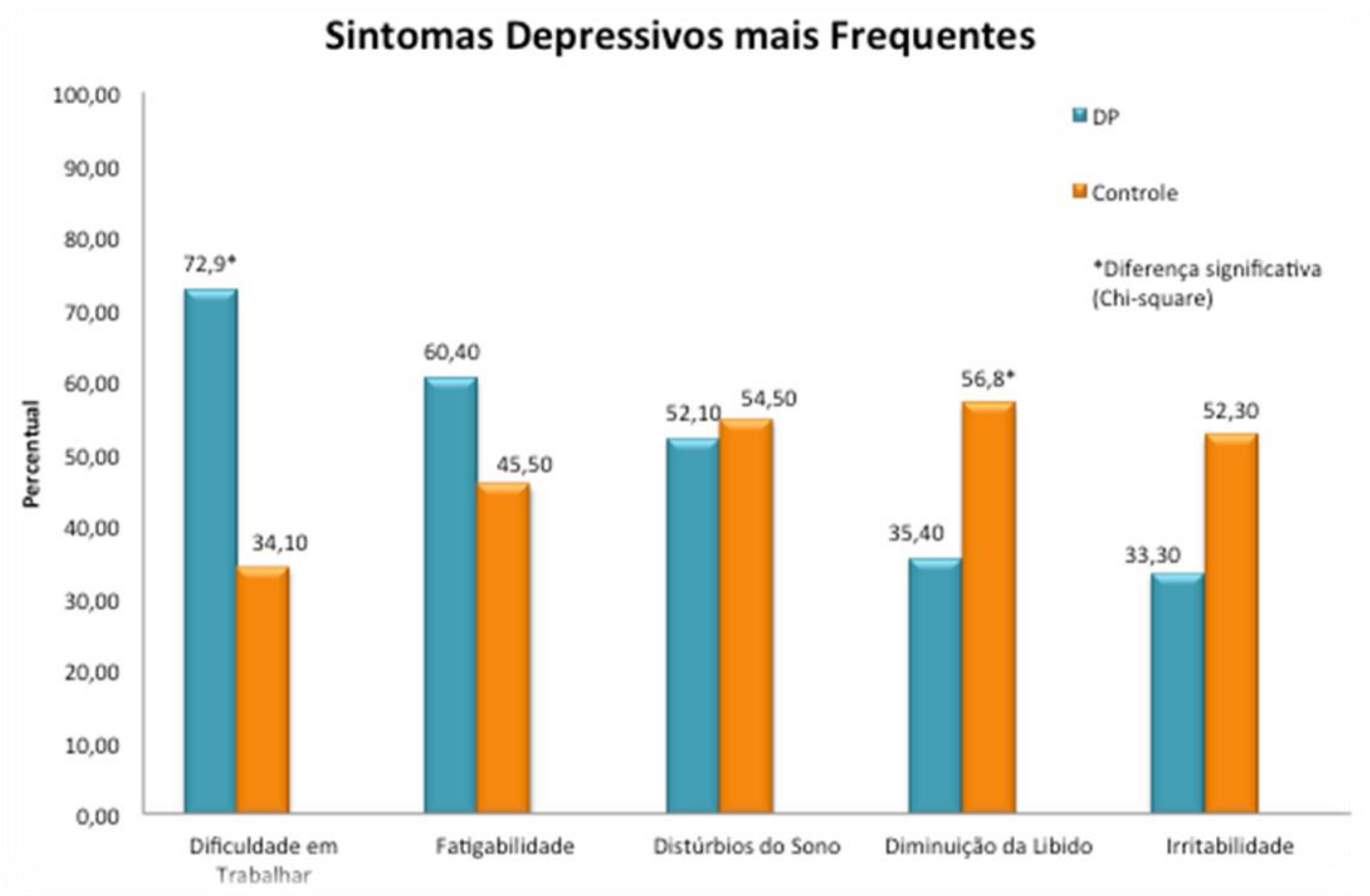

\subsection{Correlação entre BDI e os testes neuropsicológicos}

A análise de correlação de Pearson mostrou que no grupo DP a pontuação do BDI se correlacionou negativamente com M2 ( $\mathrm{r}=-0,292 ; p=0,044)$ bem como com a tarefa de reconhecimento (RAVLT) $(\mathrm{r}=-0,320 ; p=0,026)$. Quanto aos controles, a pontuação do BDI se correlacionou negativamente com M2 (r= $0,301 ; p=0,047)$, reconhecimento (RAVLT: $\mathrm{r}=-0,378 ; p=0,011)$ e M5 ( $\mathrm{r}=-0,520$; $p=<0,001 ; \mathrm{A} 7: \mathrm{r}=-0,330 ; p=0,029)$. Não houve correlação entre os demais testes e a escala BDI.

\subsection{Desempenho dos grupos DP e controle nos testes neuropsicológicos a partir da divisão em subgrupos com e sem sintomas de depressão}

A partir da comparação entre as médias do desempenho dos 4 grupos, foi possível observar em que medidas cognitivas os sintomas depressivos e a DP apresentavam maior impacto. Foram estas: M1, M5, reconhecimento (TMF e RAVLT), A6, A7 e Interferência retroativa (ITR), como representado na tabela 6. 
Tabela 6: Desempenho dos grupos nos Testes Neuropsicológicos (valores brutos)

\begin{tabular}{|c|c|c|c|c|c|}
\hline \multirow[b]{2}{*}{ Testes Neuropsicológicos } & \multicolumn{2}{|c|}{$\overline{\mathrm{DP}}$} & \multicolumn{2}{|c|}{ Controles } & \multirow[b]{2}{*}{$p^{(26)}$} \\
\hline & $\begin{array}{l}\mathrm{DP}^{(25)} \\
(\mathrm{n}=33)\end{array}$ & $\begin{array}{c}\text { DDP } \\
(n=15)\end{array}$ & $\begin{array}{l}\mathrm{GC}^{(25)} \\
(\mathrm{n}=28)\end{array}$ & $\begin{array}{c}\mathrm{DGC} \\
(\mathrm{n}=16)\end{array}$ & \\
\hline MEEM $\bar{x}(d p)$ & $27,4(1,68)$ & $27,4(2,59)$ & $27,8(1,23)$ & $27,3(1,20)$ & $>0,05$ \\
\hline $\mathrm{BDI} \bar{x}(d p)$ & $4,3(2,97)$ & $14,9(5,47)$ & $4,8(2,50)$ & $17,7(7,81)$ & $<0,05$ \\
\hline \multicolumn{6}{|l|}{ TMF } \\
\hline Nomeação & $10,0(0,00)$ & $10,0(0,00)$ & $9,6(1,89)$ & $10,0(0,00)$ & $>0,05$ \\
\hline $\mathrm{Ml}^{(1)} \overline{\mathrm{x}}(d p)$ & $5,3(1,43)$ & $5,1(1,51)$ & $5,6(1,13)$ & $5,5(0,89)$ & $>0,05$ \\
\hline $\mathrm{M} 1^{(2)} \bar{x}(d p)$ & $7,5(1,37)$ & $7,4(0,91)$ & $8,4(1,20)$ & $8,1(1,30)$ & $<0,05$ \\
\hline $\mathrm{M} 2^{(3)} \bar{x}(d p)$ & $8,7(0,98)$ & $8,5(1,12)$ & $9,0(1,39)$ & $8,6(0,96)$ & $>0,05$ \\
\hline$M 5^{(4)} \bar{x}(d p)$ & $7,4(1,97)$ & $7,00(1,51)$ & $8,7(1,08)$ & $7,9(1,46)$ & $<0,05$ \\
\hline Reconhecimento $\bar{x}(d p)$ & $10,0(0,17)$ & $9,7(0,46)$ & $10,0(0,00)$ & $10,0(0,25)$ & $<0,05$ \\
\hline $\operatorname{TDR} \bar{x}(d p)$ & $7,2(2,41)$ & $7,4(2,26)$ & $7,3(1,88)$ & $7,0(2,07)$ & $>0,05$ \\
\hline FVS $\bar{x}(d p)$ & $17,3(3,45)$ & $16,1(4,95)$ & $17,2(4,31)$ & $15,7(3,74)$ & $>0,05$ \\
\hline \multicolumn{6}{|l|}{ RAVLT } \\
\hline $\left.\mathrm{A} 1^{(5)}\right) \bar{x}(\mathrm{dp})$ & $4.5(1,28)$ & $4.1(0.83)$ & $5,2(1,71)$ & $4.9(1.46)$ & $>0.05$ \\
\hline $\mathrm{B} 1^{(6)} \overline{\mathrm{x}}(d p)$ & $4,8(1,55)$ & $3,7(1,40)$ & $4,8(2,11)$ & $4,5(2,37)$ & $>0,05$ \\
\hline$A 6^{(7)} \bar{x}(d p)$ & $5,8(3,25)$ & $5,0(3,03)$ & $7,8(2,9)$ & $6,8(2,77)$ & $<0,05$ \\
\hline$A 7^{(8)} \bar{x}(d p)$ & $6,3(3,43)$ & $5,0(2,93)$ & $8,5(3,18)$ & $6,4(3,05)$ & $<0,05$ \\
\hline $\operatorname{LOT}^{(9)} \bar{x}(d p)$ & $15,9(8,16)$ & $13,9(5,71)$ & $17,2(5,95)$ & $15,4(4,41)$ & $>0,05$ \\
\hline $\operatorname{ITP}^{(10)} \bar{x}(d p)$ & $1,3(0,95)$ & $0,9(0,46)$ & $1,0(0,47)$ & $1,0(0,52)$ & $>0,05$ \\
\hline$\varangle R^{(11)} \bar{x}(d p)$ & $0,6(0,26)$ & $0,6(0,29)$ & $0,8(0,22)$ & $0,7(0,25)$ & $<0,05$ \\
\hline$\Xi^{(12)} \bar{x}(d p)$ & $1,1(0,72)$ & $1,4(1,84)$ & $1,1(0,28)$ & $1,1(0,47)$ & $>0,05$ \\
\hline న్లి :conhecimento $\bar{x}(d p)$ & $7,9(3,97)$ & $4,5(5,43)$ & $8,4(4,32)$ & $4,1(5,44)$ & $<0,05$ \\
\hline$\stackrel{\square}{\square} J^{(13)} \bar{x}(d p)$ & $6,9(2,53)$ & $7,5(2,03)$ & $6,2(1,36)$ & $6,7(1,18)$ & $>0,05$ \\
\hline$\eta_{z}{ }^{(14)} \bar{x}(d p)$ & $4,7(1,94)$ & $4,9(1,41)$ & $4,1(1,57)$ & $3,8(1,57)$ & $>0,05$ \\
\hline$\underbrace{}_{\text {op }}{ }^{3}-\mathrm{Ol}^{(15)} \bar{x}(d p)$ & $2,2(1,72)$ & $2,6(1,88)$ & $2,0(1,44)$ & $2,3(1,82)$ & $>0,05$ \\
\hline :mpo $1^{(16)} \bar{x}(d p)$ & $19,9(7,24)$ & $21,2(14,41)$ & $17,1(3,59)$ & $20,2(6,32)$ & $>0,05$ \\
\hline $\mathbb{C}_{\mathscr{C}} \operatorname{ros} 1^{(17)} \bar{x}(d p)$ & $0,0(0,00)$ & $0,1(0,26)$ & $0,0(0,19)$ & $0,2(0,75)$ & $>0,05$ \\
\hline$\stackrel{\mathbb{J}}{=}: \mathrm{mpo} 2^{(18)} \bar{x}(d p)$ & $24,6(7,54)$ & $23,3(9,85)$ & $20,9(4,44)$ & $24,8(8,60)$ & $>0,05$ \\
\hline $\operatorname{ros} 2^{(19)} \bar{x}(d p)$ & $0,0(0,18)$ & $0,1(0,52)$ & $0,0(0,20)$ & $0,0(0,00)$ & $>0,05$ \\
\hline $\mathcal{J}: m p o 3^{(20)} \frac{1}{\times}(d p)$ & $42,5(17,82)$ & $41,3(24,77)$ & $35,2(11,27)$ & $42,1(15,05)$ & $>0,05$ \\
\hline$\dot{\operatorname{ros} 3^{(21)} \bar{x}(d p)}$ & $1,5(2,00)$ & $2,1(4,80)$ & $0,8(2,00)$ & $2,3(3,57)$ & $>0,05$ \\
\hline $\begin{array}{l}\bar{\gamma} \\
-\dot{c}^{\prime}\end{array}$ erferência $^{(22)} \bar{x}(d p)$ & $2,2(0,82)$ & $2,1(0,78)$ & $2,1(0,66)$ & $2,0(0,58)$ & $>0,05$ \\
\hline 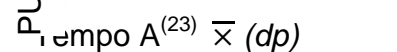 & $66,3(23,17)$ & $65,8(22,37)$ & $56,0(22,88)$ & $54,8(15,84)$ & $>0,05$ \\
\hline Tempo $\mathrm{B}^{(24)} \bar{x}(d p)$ & $197,3(122,43)$ & $191,8(72,03)$ & $156,4(84,51)$ & $168,2(91,63)$ & \\
\hline FAS $\bar{x}(d p)$ & $31,3(9,22)$ & 28,6 & $32,8(7,29)$ & $30,3($ & $>0,05$ \\
\hline Hooper $\bar{x}(d p)$ & $16,8(4,92)$ & $17,1(4,79)$ & $18,1(4,90)$ & $18,4(4,45)$ & $>0,05$ \\
\hline \multicolumn{6}{|c|}{ 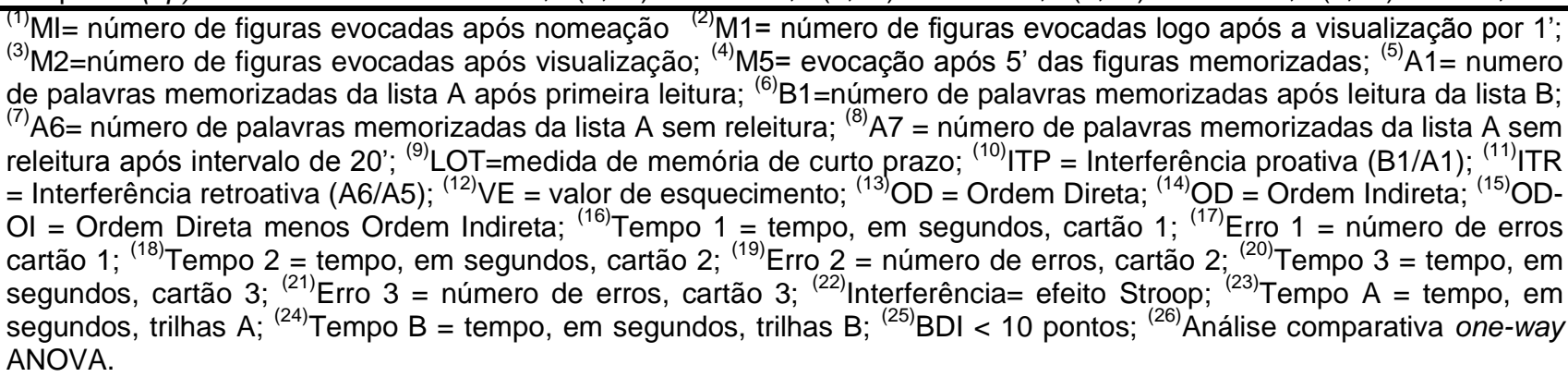 } \\
\hline
\end{tabular}


As figuras 6 e 7 apresentam o resultado do teste post-hoc de Bonferroni, o qual, a partir da comparação das médias dos 4 grupos, identificou diferença significativa entre o desempenho dos seguintes pares:

Figura 6: Resultado da análise post-hoc Bonferroni no TMF

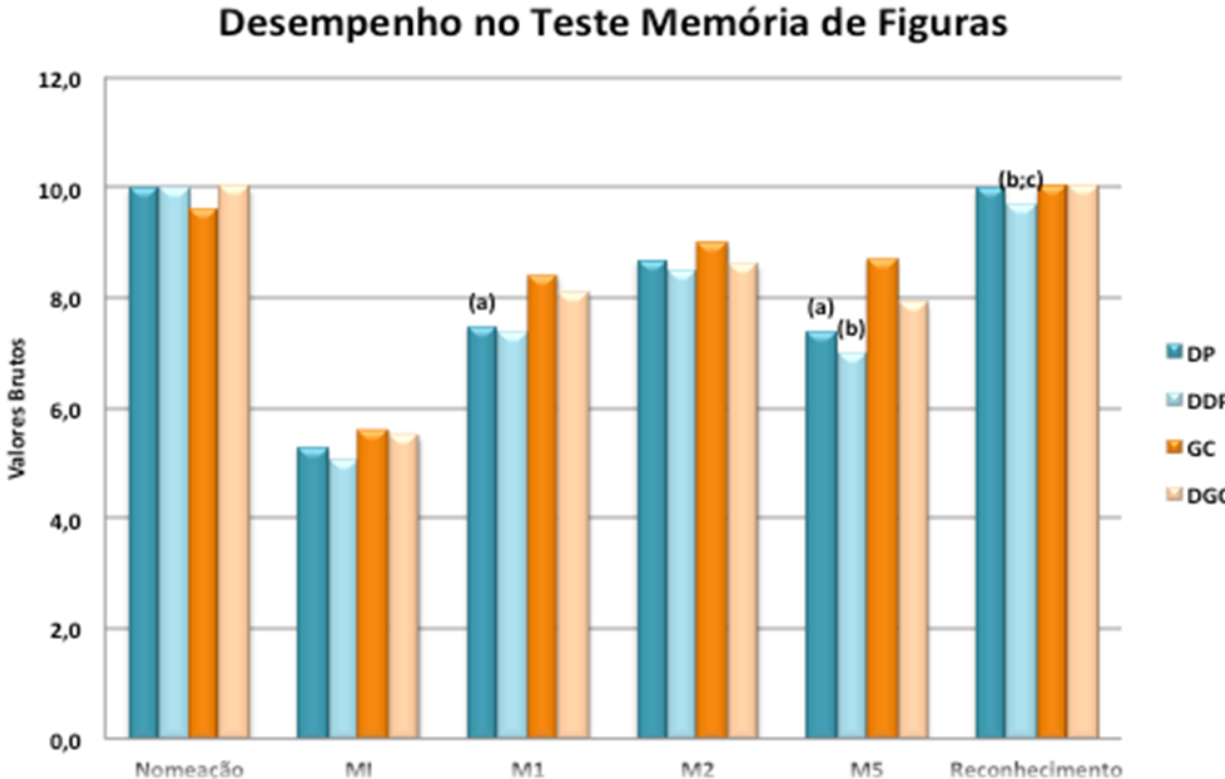

${ }^{(a)}$ Diferença significativa entre GC e DP; ${ }^{(b)}$ Diferença significativa entre GC e DPP; ${ }^{(c)}$ Diferença significativa entre DP e DDP. 
Figura 7: Resultado da análise post-hoc Bonferroni no RAVLT

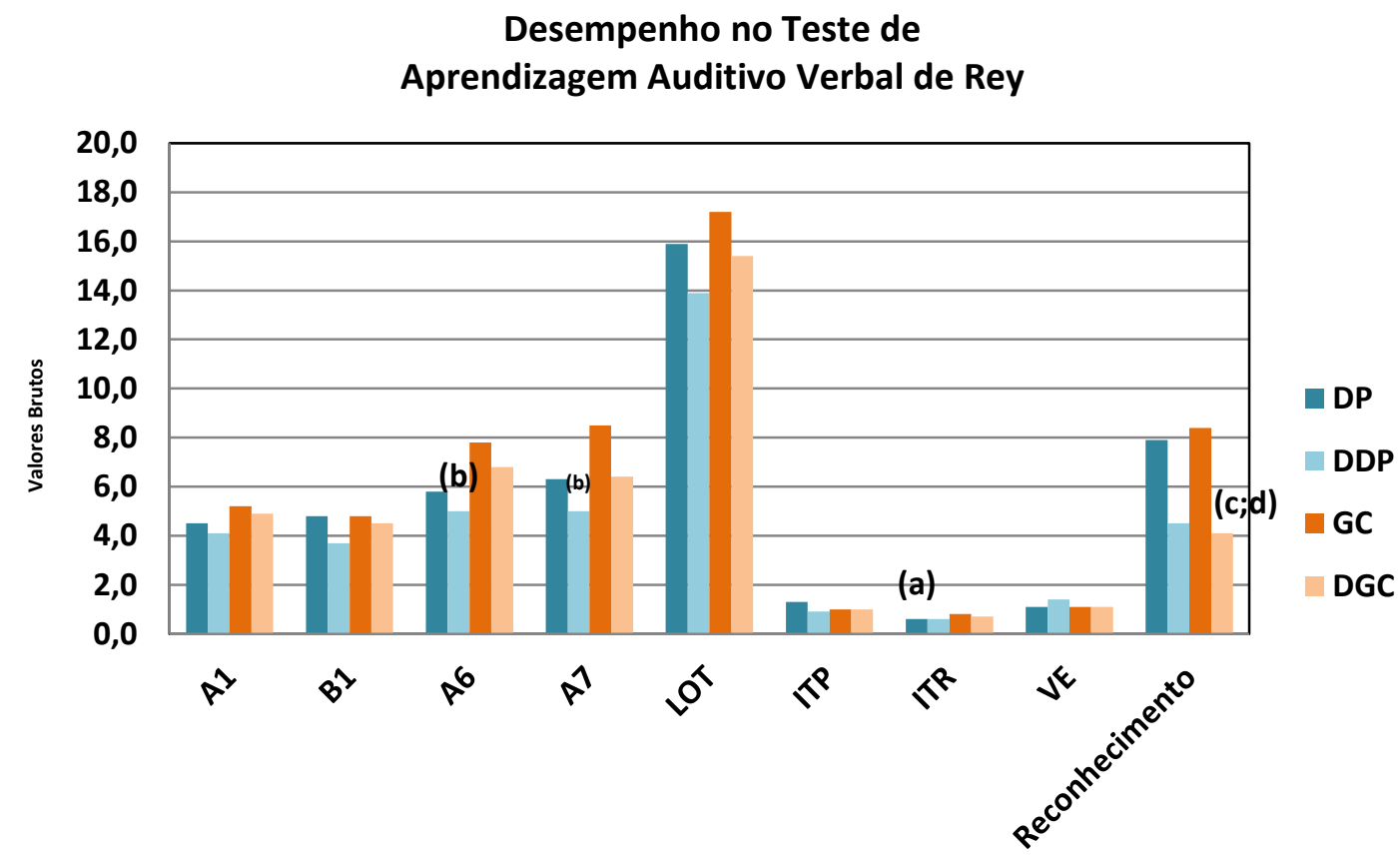

${ }^{(a)}$ Diferença significativa entre GC e DP; ${ }^{(b)}$ Diferença significativa entre GC e DPP; ${ }^{(c)}$ Diferença significativa entre o DP e o DGC; ${ }^{(d)}$ Diferença significativa entre GC e DGC. 


\section{Discussão}

No presente estudo verificou-se que os sintomas de depressão mais frequentes no grupo DP foram: dificuldades no trabalho, fadiga e distúrbios do sono. Estes sintomas podem ser considerados como secundários à DP e não à depressão. $\mathrm{O}$ grupo controle apresentou com maior frequência os sintomas de irritabilidade, diminuição da libido e também distúrbios do sono, os quais constituem sintomas característicos da síndrome depressiva. A memória de reconhecimento (TMF, RAVLT) mostrou-se alterada na presença da comorbidade entre sintomas depressivos e DCL, estando comprometida no grupo DDP quando comparado ao grupo DP e ainda no grupo DGC quando comparado ao GC. A memória de reconhecimento constitui uma medida importante no diagnóstico diferencial entre o envelhecimento normal e quadros de demência incipiente, confirmando a hipótese de que a combinação entre sintomas depressivos e DCL eleva os riscos de conversão para demência. A memória episódica foi a função cognitiva que demonstrou maior comprometimento nos testes neuropsicológicos, diferindo do perfil cognitivo padrão dos parkinsonianos, já que todos os sujeitos que compunham a amostra deste trabalho apresentavam o diagnóstico de DCL.

\subsection{Frequência dos sintomas de depressão}

No grupo DP, os sintomas depressivos mais frequentes foram: dificuldades no trabalho, fadiga e distúrbios do sono - sintomas estes que também podem ser atribuídos à DP. Tal fato é corroborado pela baixa frequência destes sintomas no GC, com exceção do sintoma distúrbios do sono, evidenciado em ambos os grupos.

Silva (2015) afirma que distúrbios do sono são próprios de doenças neurodegenerativas, bem como bastante prevalentes em sujeitos com DCL. Na DP, mais da metade dos pacientes apresentam alterações do sono (Arnulf et al., 2008; Friedman \& Millman, 2008). Esses sintomas, além de diminuir a qualidade de vida, causam déficits cognitivos na memória, aprendizagem e funções executivas. Além disso, o distúrbio do sono pode ser considerado um fator preditivo de demência (Santos et al., 2013), o que pode ser explicado pelo fato 
deste sintoma ter influência direta sobre medidas atencionais, prejudicando a aprendizagem e a consolidação da memória (Ribeiro, 2003).

O GC apresentou com maior frequência os sintomas irritabilidade e diminuição da libido, característicos da depressão. Esta diferença no perfil de sintomas depressivos nos grupos confirma a hipótese de que na DP os sintomas de depressão são secundários aos sintomas da doença e que, provavelmente, não são decorrentes da depressão. Aarsland et al. (2012), em revisão sobre depressão na DP afirmam que distúrbios do sono, alterações psicomotoras, apatia, perda de prazer (anedonia), dentre outros, são sintomas comuns às duas patologias. Com isso, confirma-se a complexidade em se diferenciar os sintomas de depressão daqueles próprios da DP, o que acaba por acarretar a alta prevalência de falhas no diagnóstico acurado da depressão nesta patologia. De acordo com critérios clínicos estabelecidos pelo DSM-IV para depressão em sujeitos com DP, para que não ocorram subdiagnósticos, não se deve tentar decidir se os sintomas são oriundos da depressão ou da DP, mas sim adotar uma abordagem mais inclusiva. Desta forma, sugere-se que alguns sintomas somáticos presentes na DP sejam avaliados e considerados como aspectos importantes na avaliação da depressão (Marsh et al., 2006; Schrag et al., 2007).

Cimino et al. (2011), em um estudo sobre a relação entre sintomas depressivos e DP, associam os sintomas de depressão à rápida progressão da DP, ao comprometimento nas atividades de vida diária e a prejuízos cognitivos mais severos, sendo proeminente a necessidade do diagnóstico com acurácia. Para estes autores, os sintomas depressivos causam maior impacto na funcionalidade dos parkinsonianos do que as dificuldades motoras oriundas da patologia.

A partir desta análise, torna-se evidente as diferenças na maneira como os sintomas depressivos se apresentam na DP e no DCL. No grupo DP, os sintomas depressivos estão associados aos sintomas motores da doença, permitindo pensar na hipótese de que a depressão é um transtorno intrínseco à DP, sendo decorrente, muitas vezes, da própria degeneração e alterações neuroquímicas que a doença traz. No grupo controle, a depressão se apresenta como uma comorbidade, sendo 
os sintomas depressivos um comportamento reativo às circunstâncias externas da vida desses sujeitos.

\subsection{Correlação entre a BDI e os testes neuropsicológicos}

Os resultados do presente estudo mostraram correlação negativa entre a pontuação total do BDI e aprendizagem (TMF) e, ainda, entre a pontuação total do BDI e memória de reconhecimento (RAVLT) para o grupo DP. Isto pode ser explicado pelo fato de os sintomas depressivos na DP estarem mais associados aos sintomas da doença do que à depressão em si. Na DP, devido às disfunções frontoestriatais próprias desta patologia, é possível perceber prejuízos nas estratégias de aprendizagem, prejuízos atencionais e ainda de acesso ao conteúdo demandado, observado na tarefa de reconhecimento.

No GC, onde há apenas a presença do DCL, o BDI também se correlacionou negativamente com a aprendizagem (TMF), com a memória de reconhecimento (RAVLT), adicionando-se, no entanto, a memória episódica tardia de evocação livre (TMF e RAVLT). Desta forma, quando se isola a presença de DCL, surge um grupo com maior risco de desenvolver demência, já que a comorbidade com sintomas depressivos trouxe um comprometimento adicional da memória de evocação tardia. Sabe-se que o comprometimento em tarefas de evocação livre após intervalo de tempo tem sido descrito na literatura como marcador precoce da DA e característico do DCL amnéstico.

Este resultado foi corroborado por diversos estudos que concluíram a existência de forte associação entre comprometimento na memória e depressão (Netto \& Landeira-Fernandez, 2012; Bartley et al., 2011; Sohabi et al., 2009). De acordo com Nebes et al. (2000), sujeitos com sintomas de depressão apresentam seus recursos cognitivos empobrecidos, acarretando em prejuízo de várias tarefas neuropsicológicas, principalmente na memória episódica. Isto sugere que a depressão pode estar associada ao declínio cognitivo em tarefas que requerem demandas substanciais dos recursos de processamento, já que tanto a aprendizagem como a memória tardia constituem medidas que requerem a busca ativa do conteúdo demandado (rememoração) (Cotta et al., 2012). Da mesma 
forma, o comprometimento da memória episódica pode ser um fator preditivo de conversão para demência causada pela Doença de Alzheimer, principalmente em tarefas de evocação livre após intervalo de tempo. Ávilla e Bottino (2006) relataram que testes de memória verbal e evocação tardia mostraram-se eficazes como instrumentos na diferenciação de pacientes com demência daqueles deprimidos, já que estes, embora apresentem prejuízo na capacidade de aprendizagem, conseguem armazenar informação e evocá-la após um intervalo de tempo. Percebe-se, desta forma, que alterações neste tipo de memória podem servir como indicativo de futuros quadros demenciais. Modrego \& Ferrández (2004) concluíram que a comorbidade depressão e DCL dobra o risco de conversão para DA quando comparados àqueles sem depressão.

\subsection{Desempenho nos testes neuropsicológicos}

Quanto ao desempenho na avaliação neuropsicológica, verificou-se que os grupos DP e GC apresentaram resultados semelhantes na maior parte dos testes que compunham o protocolo, tendo sido observada diferença estatística significativa no TMF e no RAVLT. O grupo DP apresentou desempenho inferior ao GC na memória episódica anterógrada (M1) e tardia (M5) e na interferência retroativa do RAVLT. Tais resultados sugerem, desta forma, que estes prejuízos cognitivos referem-se à DP com DCL, independente da presença de sintomas de depressão. Embora a literatura indique os déficits executivos frontais como prevalentes na DP, alguns autores concluíram que o DCL nesta patologia não pode ser caracterizado somente por este tipo de comprometimento. Em recente revisão sobre os déficits cognitivos na DP, Robbins \& Cools (2014) observaram que parkinsonianos possuem, como base, prejuízos executivos frontais, o que pode ser explicado pela associação anatômica entre o circuito córtico-estriatal e o córtex pré-frontal, sendo os déficits na memória restritos à memória de trabalho e de evocação livre, estando a memória de reconhecimento comprometida somente em estágios mais avançados ou em quadro demencial. Muslimovic et al. (2009), ao investigarem o perfil cognitivo de parkinsonianos, avaliaram 115 sujeitos (com DP) e 70 controles. Confirmaram a existência de prejuízos cognitivos ainda em fases iniciais da doença, não somente nos domínios das funções executivas, mas também da memória (principalmente memória incidental). 
Yarnall et al. (2014), em estudo sobre a caracterização do DCL na DP, avaliaram 219 parkinsonianos e 99 controles de acordo com recomendações da MDS Task Force. A partir de protocolo extenso (nível 2- MDS Task Force), observaram que a frequência de DCL na DP era de $42,5 \%$ e que dos cinco domínios avaliados, o comprometimento da memória foi o que se apresentou com maior frequência $(15,1 \%)$, seguido de comprometimentos visuoespacial $(13,2 \%)$, atencional / memória de trabalho (12,3\%) e funções executivas (11\%). Tais achados corroboram os resultados do presente estudo, demonstrando perfis cognitivos distintos na DP sem DCL e na DP com DCL, sendo o primeiro caracterizado por um padrão de comprometimento na atenção e funções executivas e o segundo por comprometimentos também na memória.

No entanto, estudos mostram que pacientes com DP não apresentam declínio na memória de reconhecimento. Robbins e Cools (2014), em uma revisão de literatura, observaram que os déficits cognitivos na DP são característicos de disfunções fronto-executivas, sendo mais comum prejuízos na memória de trabalho, aprendizagem e evocação livre, estando a memória de reconhecimento preservada. O baixo desempenho cognitivo no reconhecimento do grupo DDP, quando comparado ao grupo DP, sugere influência da associação entre os sintomas depressivos e o DCL, já que a mesma tarefa apresentou prejuízo quando comparado o desempenho entre os grupos DGC e DP e, ainda, entre os grupos DGC e GC. Portanto, DDP e DGC, quando comparados àqueles sem sintomas, apresentaram desempenho inferior no reconhecimento. Cotta et al. (2012), em revisão de literatura onde investigaram o potencial do RAVLT em discriminar o envelhecimento normal da DA, em termos cognitivos, afirmaram que a tarefa de reconhecimento deste teste é instrumento importante para a diferenciação de demências corticais das demências subcorticais. Além disso, comprometimento no componente reconhecimento denota que o sujeito não foi capaz de reconhecer aquele conteúdo como familiar, ou seja, como algo que já foi visto antes, comportamento este comum especificamente na DA (Cotta et al., 2012). Tais achados ratificam a hipótese de que a combinação depressão e DCL aumenta significativamente o risco de conversão para DA, sendo o comprometimento na 
memória de reconhecimento fator preditivo para o desenvolvimento deste tipo de demência.

Os resultados deste estudo mostraram ainda alterações na memória episódica (tardia), memória de reconhecimento e atenção (A6) no grupo DDP, quando comparados ao GC. Estes resultados sugerem, desta forma, que tais comprometimentos referem-se à combinação depressão, DCL e DP, corroborando a ideia de que na DP a comorbidade entre DCL e depressão aumenta os riscos para o desenvolvimento de quadro demencial já que, como citado anteriormente, prejuízos na memória de reconhecimento constituem um fator importante na sinalização da progressão do DCL para demência. Além disso, a memória episódica de evocação livre e a atenção seletiva requerem do sujeito recursos frontais, os quais encontram-se empobrecidos pela presença tanto da DP quanto da depressão. Evocar um conteúdo livremente requer uma busca ativa do sujeito ao conteúdo demandado, processo este que sofre influências de ambas DP e depressão. Da mesma forma, a atenção seletiva, a qual necessita que o sujeito iniba um conteúdo recentemente aprendido em favor de outro mais antigo, requerendo assim, recursos fronto-executivos que se apresentam prejudicados pela combinação DP e depressão.

O grupo DDP e o grupo DGC obtiveram desempenho semelhante nos testes neuropsicológicos. Ambos apresentaram piores resultados na memória de reconhecimento quando comparados aos grupos DP e GC, demonstrando mais uma vez o impacto da combinação DCL e depressão nesta medida cognitiva; estando, ainda, em consonância com a literatura que afirma que a depressão piora a cognição independentemente da existência de outra patologia. 


\section{Conclusão}

Os resultados aqui apresentados demonstraram que, de fato, os sintomas de depressão na DP se confundem com os sintomas motores desta mesma patologia. Fadiga e dificuldades no trabalho apresentaram-se como sintomas depressivos prevalentes somente no grupo DP, o que nos faz pensar que pertencem à doença $\mathrm{e}$ não exclusivamente à depressão. O sintoma distúrbio do sono se apresentou prevalente nos dois grupos, DP e controle. Na DP, a presença deste sintoma é comum e pode ser explicado pelas alterações neuroquímicas e fisiopatológicas próprias da doença. Além disso, estudos relataram que o sono sofre influência direta de determinados medicamentos antiparkinsonianos (Hwang et al., 1999; Chahine et al., 2013), confirmando, desta forma, a complexidade em se identificar os sintomas depressivos nos sujeitos acometidos pela DP .

Neste estudo, os domínios cognitivos que sofreram maior impacto da depressão foram memória episódica anterógrada (aprendizagem, tardia e de reconhecimento) e atenção seletiva. No entanto, a memória de reconhecimento foi a função cognitiva que chamou mais atenção. Após a divisão da amostra em quatro subgrupos, foi observado que somente os sujeitos que apresentavam sintomas de depressão mostravam baixo desempenho nesta medida cognitiva. Desta forma, pode-se concluir que, independente da patologia, neste estudo, o comprometimento da memória de reconhecimento refere-se à comorbidade entre sintoma de depressão e DCL. Tal achado se faz importante na medida em que possibilita pensar na utilização do comprometimento na memória de reconhecimento como um marcador da combinação depressão e DCL nos parkinsonianos, identificando, assim, os sujeitos que se mostram mais suscetíveis à conversão para um quadro demencial, já que a literatura afirma que prejuízo nesta medida cognitiva consiste em fator preditivo para o desenvolvimento de demência, mais especificamente do tipo Alzheimer.

Este estudo apresentou algumas limitações. O grupo controle foi composto por sujeitos com sintomas depressivos e DCL, justificando o desempenho semelhante ao grupo DP na maior parte dos testes neuropsicológicos que compunham o protocolo. Outra limitação corresponde ao fato de não haver um grupo DP com o diagnóstico de depressão segundo critérios do DSM-IV e sem 
DCL, possibilitando melhor caracterização da depressão nesta patologia tanto em termos cognitivos como comportamental. Por fim, a estratégia de realizar as avaliações clínica e neuropsicológica no mesmo dia possibilitou resultados mais fidedignos, uma vez que os sujeitos passaram por estas duas avaliações com as mesmas condições físicas e mentais. No entanto, houve a necessidade de se retirar paradigmas clássicos do protocolo neuropsicológico como meio de reduzir o tempo de aplicação, pois muitos sujeitos demonstravam cansaço, o que poderia influenciar no desempenho da avaliação.

Para estudos futuros, sugere-se acompanhar longitudinalmente parkinsonianos com depressão e após remissão deste transtorno, avaliando-os nestes dois momentos para melhor investigação do impacto da depressão na cognição dos mesmos, objetivando um marcador cognitivo da presença de depressão na DP. Além disso, a elaboração de escalas de depressão específicas para DP seria interessante, reduzindo de forma significativa os casos de subdiagnósticos. 


\section{Referências bibliográficas}

AARSLAND D.et al. Depression in Parkinson disease-epidemiology, mechanisms and management. Nat Rev Neurol, v 8, p. 35-47, 2012

AARSLAND, D. et al. Mild cognitive impairment in Parkinson's disease: a multicenter pooled analysis. Neurology, v.75, n12, p.1062-1069, 2010.

ARNULF, I.; Leu, S.; OUDIETTE, D. Abnormal sleep and sleepiness in Parkinson's disease. Curr Opin Neurol, v. 21, p. 472-477, 2008.

ÁVILA, R.; BOTTINO, C. Atualização sobre alterações cognitivas em idosos com síndrome depressiva. Rev Bras Psiquiatr, v. 28, n. 4, p. 316320, 2006.

BARBOSA, M.T. et al. Parkinsonism and Parkinson's disease in the elderly: a community-based survey in Brazil (the Bambui study). Mov Disord, v. 21, p. 800-808, 2006.

BAUNE B. T. et al. The relationship between psychological dimensions of depressive symptoms and cognitive functioning in the elderly. J Psychiatr Res, v. 41, n. 3-4, ..247-254, 2007.

BERTOLUCCI, P. H. F. et al. O Mini Exame do Estado Mental em uma população geral: impacto da escolaridade. Arq. Neuro-Psiquiatr, v.52, n. 1, p. 01-07, 1994.

BIUNDO, R. et al. Anatomical Correlates of Cognitive Functions in Early Parkinson's Disease Patients. PLoS ONE, v. 8, n. 5, e64222. doi:10.1371/journal.pone.0064222, 2013.

BLAZER, D. G. Depression in late life: review and commentary. J Gerontol A Biol Sci Med Sci, v. 58, n. 3, p. 249-65, 2003.

BLONDER, L. X. et al. Dopaminergic modulation of memory and affective processing in Parkinson depression. Psychiatr Res v. 210, n.1, p. 146149, 2013.

BOYLE, P.A. et al. Mild cognitive impairment: risk of Alzheimer disease and rate of cognitive decline. Neurology, v. 67, n. 3, p. 441-445, 2006.

BRUCKI, S. M. D. et al. Normas para o uso do Mini-Exame do Estado Mental (MEEM) em nosso meio. Arq Neuropsiquiatr. v. 60, p.46-47, 2003.

BRUSCOLI, M.; LOVESTONE, S. Is MCI really just early dementia? A systematic review of conversion studies. Int Psychogeriatr, v. 16, n. 2, p. 128-140, 2004.

BURCH D, SHEERIN F. Parkinson's Disease. Lancet v.365, p. 622-627. 2005. 
CAIXETA, L.; VIEIRA, R. T. Demência na doença de Parkinson. Rev. Bras. Psiquiatr, v. 30, n. 4, p. 375-383, 2008.

CAMARGOS, A. C. R. et al. O impacto da doença de Parkinson na qualidade de vida: uma revisão de literatura. Rev. bras. Fisioter, v.8, n.3, p. 267-272, 2004.

CARAMELLI, P.; CARTHERY, M. T.; CHARCHAT-FICHMAN, H. Teste de fluência verbal no diagnóstico de Doença de Alzheimer leve: notas de corte em função da escolaridade. Arq Neuropsiquiatr, v. 61, supl. 2, p. S32, 2003.

CARAMELLI, P. et al. Category fluence as a screening test for Alzheimer disease in illiterate and literate patients. Alzheimer Dis Assoc Disord, v. 21, n. 1, p. 65-67, 2007.

CARVALHO, J. A. M. de; GARCIA, R. A. O envelhecimento da população brasileira: um enfoque demográfico. Cad. Saúde Pública, Rio de Janeiro, v. 19, n. 3, p. 725-733, 2003.

CAVINESS, J. N. et al. Defining Mild Cognitive Impairment in Parkinson's Disease. Movement Disorders, v. 22, n. 9, p. 1272-1277, 2007.

CHAGAS, M. et al. Depression increases in patients with Parkinsons Disease according to the increasing severity of the cognitive impairment. Arq Neuropsiquiatr, v. 72, n. 6, p. 426-429, 2014.

CHARCHAT-FICHMAN, $\mathrm{H}$. et al. Predomínio de Comprometimento Cognitivo Leve Disexecutivo em idosos atendidos no ambulatório da geriatria de um hospital público terciário na cidade do Rio de Janeiro. Rev Neuropsi Latinoam, v. 5, n. 2, p. 31, 2013.

CHARCHAT-FICHMAN, H.; OLIVEIRA, R. M. Performance of 119 brazilian children on stroop paradigm - Victoria Version. Arq Neuropsiquiatr, v. 67, n. 2b, p. 445-449, 2009.

CHARCHAT-FICHMAN, $\mathrm{H}$. et al. Predomínio de Comprometimento Cognitivo Leve Disexecutivo em idosos atendidos no ambulatório da geriatria de um hospital público terciário na cidade do Rio de Janeiro. Rev Neuropsi Latinoam, v. 5, n. 1, p. 31-40, 2013.

CHAUDHURI, K. R.; SCHAPIRA, A. H. V. Non-motor symptoms of Parkinson's disease: dopaminergic pathophysiology and treatment. Lancet Neurol, v. 8, p. 464-474, 2009.

CHAUDHURI, K.R.; HEALY, D. G.; SCHAPIRA, A. H. National Institute for Clinical Excellence. Nonmotor symptoms of Parkinson's disease: diagnosis and management. Lancet Neurol, v. 5, n. 3, p. 235-245, 2006. 
CHEN, P. et al. Depression in Veterans with Parkinson's Disease: Frequency, Co-Morbidity, and Healthcare Utilization. Int J Geriatr Psychiatry, v. 22, p. 543-548, 2007.

CIMINO, C. R.; SIDERS, C. A.; ZESIEWICZ, T. A. Depressive Symptoms in Parkinson Disease: Degree of Association and Rate of Agreement of Clinician-Based and Self-Report Measures. J Geriatr Psychiatry Neurol, v. 24, n. 4, p. 199-205, 2011.

COHEN, O. S. et al. Educational level as a modulator of cognitive performance and neuropsychiatric features in Parkinson disease. Cogn Behav Neurol, v. 20, n. 1, 68-72, 2007.

COTTA M. F. et al. O teste de aprendizagem auditivo verbal de Rey (RAVLT) no diagnóstico diferencial do envelhecimento cognitivo normal e patológico. Contextos Clínicos, v. 5, n. 1, 2012.

CUMMINGS, J. L. Depression and Parkinson's Disease: A Review. Am J Psychiatry, v. 149, p. 43-454, 1992.

CUNHA, J. A. Escalas Beck. São Paulo: Casa do Psicólogo; 2011.

DINIZ, B. S. et al. Mild cognitive impairment: cognitive screening or neuropsychological assessment? Rev Bras Psiquiatr, v. 30, n. 4, p. 316321, 2008.

DUBOIS, B. et al. Diagnostic procedures for Parkinson"s disease dementia: recommendations from the movement disorder society task force. Mov Disord, v. 22, p. 2314-2324, 2007.

EMRE, M. What causes mental dysfunction in Parkinson's disease? Mov Disord. Suppl. 6, p. S63-71, 2003.

FERNANDES, M. G. M., NASCIMENTO N. F.S, COSTA, K. N. F. M. Prevalência e determinantes de sintomas depressivos em idosos atendidos na atençãoo primária de saúde. Rev. Rene. Fortaleza, v. 11, n. 1, p. 19-27, 2010.

FERREIRA, F. D. et al. Doença de Parkinson: aspectos fisiopatológicos e terapêuticos. Revista Saúde e Pesquisa, v. 3, n. 2, p. 221-228, maio/ago. 2010.

FIGUEIREDO, V. L. M.; NASCIMENTO, E. Desempenhos nas Duas Tarefas do Subteste Dígitos do WISC-III e do WAIS-III. Psicologia: Teoria e Pesquisa, v. 23, n. 3, p. 313-318, 2007.

FILHO, D. B. TEIVE, H. A.G.; WERNECK, L. C. Early-onset Parkinson's disease and depression. Arq Neuropsiquiatr, v. 65, n. 1, p. 5-10, 2007. 
FOLSTEIN, M. F.; FOLSTEIN, S. E.; MCHUGH, P. R. "Mini-mental state": A practical method for granding the cognitive state of patients for the clinician. J Psychiatr Res, v. 12, n. 3, p. 189-198, 1975.

FORLENZA O. V. et al. Mild cognitive impairment (part 1): clinical characteristics and predictors of dementia. Rev. Bras. Psiquiatr. v. 35, n.2, 2013

FORLENZA, O. V.; CHIU, E. Mild cognitive impairment : a concept ready to move on? Current Opinion in Psychiatry. v. 21, p. 529-532, 2008.

GALHARDO, M. M. A. M. C.; AMARAI, A. K. F. J.; VIEIRA, A. C. C. Caracterização dos distúrbios cognitivos na doença de Parkinson. Rev. CEFAC, v. 11, n. 2, p. 251-257, 2009.

GIAVONI, A. et al. Elaboração e Validação da Escala de Depressão para Idosos. Cad. Saúde Pública. Rio de Janeiro, v. 24, n. 5, p. 975-982, 2008.

GOLDMANN-GROSS R, SIDEROWF A, HURTIG HI. Cognitive Impairment in Parkinson's Disease and dementia with Lewy bodies: a spectrum of disease. Neurosignals, v. 16, n. 1, p. 24-34, 2008.

GREEN, J. et al. Cognitive impairments in advanced PD without dementia. Neurology, v. 59, n. 9, p. 1320-1324, 2002.

HAMDAN, A. C.; HAMDAN, E. M. L. R. Effects of age and education level on the trail making test in a healthy Brazilian sample. Psychol Neurosci., v. 2, n. 2, p. 199-203, 2009.

HANNA-PLADDY, B. et al. Predictors of Mild Cognitive Impairment in Early-Stage Parkinson's Disease. Dement Geriatr Cogn Disord Extra, v. 3, p. 168-178, 2013.

HINDLE, J. V. Ageing, neurodegeneration and Parkinson's disease. Age Ageing, v 39; n. 2; p 156-161, 2010.

HUGHES, A. J. et al. Accuracy of clinical diagnosis of idiopathic Parkinson's disease: a clinico-pathological study of 100 cases. J Neurol Neurosurg Psychiatry, p. 181-184, 1992.

IKUTA, Y. M. et al. Avaliação da Função Cognitiva em pacientes com Doença de Parkinson. Rev Para Med 26, 2012.

JANKOVIC, J. et al. Variable expression of Parkinson's disease: a baseline analysis of the DATATOP cohort. Neurology, v. 40, n. 10 p. 1529, 1990.

JESSEN, F. et al. Patterns of subjective memory impairment in the elderly: association with memory performance. Psychol Med, v. 37, n. 12, p. 17531762, 2007. 
JOHNSON, D. K. et al. Longitudinal study of the transition from healthy aging to Alzheimer disease. Arch. Neurol, v. 66, p. 1254- 1259, 2009.

KEHAGIA, A. A., BARKER, R. A., ROBBINS, T. W. Cognitive impairment in Parkinson's disease: The dual syndrome hypothesis. Neurodegener Dis, v.11, p. 79-92, 2013.

KLEIN, M. et al. O paradigma stroop em uma amostra de idosos brasileiros. Psicol Hosp, v. 8, n. 1, p. 93-112, 2010.

LANG, A. E.; LOZANO, A. M. Parkinson's disease. First of two parts. N Engl J Med, v. 339, n. 15, p. 1044-1053,1998.

LEENTJENS, A, F. Depression in Parkinson's Disease: Conceptual Issues and Clinical Challenges. J Geriatr Psychiatry Neurol, v. 17, p. 120-126, 2004

LEITE, V. M. M. et al. Depressão e envelhecimento: estudo nos participantes do Programa Universidade Aberta à Terceira Idade. Rev. Bras. Saúde Matern. Infant, v. 6, n. 1, p. 31-38, 2006.

LIEBERMAN, A. Depression in Parkinson's disease: a review. Acta Neurol Scand, v. 113, p. 1-6, 2006.

LITVAN, I. et al. Diagnostic criteria for mild cognitive impairment in Parkinson's disease: Movement Disorder Society Task Force guidelines. Mov Disord. v. 27, p. 349-356, 2012.

LUCK, T. et al. Incidence of Mild Cognitive Impairment: A Systematic Review. Dement Geriatr Cogn Disord, v. 29, p. 164-175, 2010.

MALLOY-DINIZ, L. F. et al. Teste de aprendizagem auditivo-verbal de Rey: aplicabilidade na população idosa brasileira. Rev Bras Psiquiatr, v. 29, n. 4, 324-329, 2007.

MANLY, J. J. et al. Frequency and course of mild cognitive impairment in a multiethnic community. Ann Neurol, v. 63, p. 494-506, 2008.

MARSH, L. et al. Provisional diagnostic criteria for depression in Parkinson's disease: report of an NINDS/NIMH Work Group. Mov. Disord, v. 21, p. 148-158, 2006.

MCPHERSON, S.; CUMMINGS, J. Neuropsychological aspects of Parkinson's disease and parkinsonism. In: GRANT, I.; ADAMS, K. Neuropsychological assessment of neuropsychiatric and neuromedical disorders. Nova York: Oxford University Press, p .199-222, 2009. 
MELLO, M. P. B. de; BOTELHO, A. C. G. Correlação das escalas de avaliação utilizadas na doença de Parkinson com aplicabilidade na fisioterapia. Fisioter Mov, v. 23, n. 1, p. 121-127, 2010.

MELO, L. M., BARBOSA, E. R., CARAMELLi, P. Declínio cognitivo e demência associados à doença de Parkinson: características clínicas e tratamento. Rev. Psiq. Clín, v.34, n.4, p.176-183, 2007.

MODREGO, P. J.; FERRÁNDEZ, J. Depression in patients with mild cognitive impairment increases the risk of developing dementia of Alzheimer type: a prospective cohort study. Arch Neurol, v. 61, n. 8, p. 1290-1293, 2004.

MUSLIMOVIC, D. et al. Cognitive decline in Parkinson's disease: a prospective longitudinal study. J Int Neuropsychol Soc, v. 15, p. 426-437, 2009.

NAGANO-SAITO, A. et al. Effect of mild cognitive impairment on the patterns of neural activity in early Parkinson's disease. Neurobiol Aging, v. 35, p. 223-231, 2014.

NASRI, F. O envelhecimento populacional no Brasil. Einstein, v. 6, Supl 1, p. S4-S6, 2008.

NEBES, R. D. et al. Decreased working memory and processing speed mediate cognitive impairment in geriatric depression. Psychol Med, v. 30, n. 3, p. 679-691, 2000.

NETTO T. M.; LANDEIRA-FERNANDES J. Perfil neuropsicológico preliminar de idosos com queixas mnemônicas e sintomas sugestivos de depressão. Rev Neuropsi Latinoam, v. 4, n. 4, p. 19-27, 2012.

NITRINI, R. et al. Testes neuropsicológicos de aplicação simples para o diagnóstico de demência. Arq Neuro psiquiatr, v. 52, p. 457-465,1995.

NOGUEIRA, E. L. Rastreamento de sintomas depressivos em idosos na Estratégia Saúde da Família, Porto Alegre. Rev Saude Publica, v. 48, n. 3, p. 368-377, 2014.

OLIVEIRA, D. A. A. P.; GOMES, L.; OLIVEIRA, Rodrigo F. Prevalência de depressão em idosos que frequentam centros de convivência. Rev Saúde Pública, v. 40, n. 4, p. 734-736, 2006.

OLIVEIRA, D. L. C.; GORETTI, L. C.; PEREIRA, L. S. M. O desempenho de idosos institucionalizados com alteração cognitiva em atividades de vida diária e mobilidade: estudo piloto. Rev Bras Fisioter,v. 10, n. 1, p. 9196, 2006.

ORGANIZAÇÃO MUNDIAL DE SAÚDE. World Population Ageing 19502050. Population Division, DESA. New York: United Nations, 2002. 
PANZA, F. et al. Latelife depression, mild cognitive impairment, and dementia: possible continuum? Am J Geriatr Psychiatry, v. 18, n. 2, p. 98116, 2010.

PAPALIA, D. E.; OLDS, S. W. Desenvolvimento Humano, 7. Porto Alegre: Artes Médicas Sul, 2000.

PARADELA, E. M. P. Depressão em Idosos. Rev Hospital Universitário Pedro Ernesto, v. 10, p. 3-11, 2011.

PARK A. STACY M. Dopamine-Induced Nonmotor Symptoms of Parkinson's Disease. Parkinson's Disease. v. 2011, p. 1-6, 2011.

PETERSEN, R. C. et al. Mild Cognitive Impairment: a concept in evolution. J of Intern Med, v. 275, p. 214-228, 2014.

PETERSEN, R. C. et al. Mild cognitive impairment: ten years later. Arch Neurol, v. 66, p. 1447-1455, 2009.

PETERSEN, R. C. et al. Mild Cognitive Impairment: clinical characterization and outcome. Arch Neurol, v. 56, n. 3, p. 303-308, 1999.

PFEIFFER, H. C. et al. Cognitive impairment in early-stage non-demented Parkinson's disease patients. Acta Neurol Scand, v. 129, n. 5, p. 307-318, 2014.

PIRES, L. M. S.; SIMÕES, M. R.; FIRMINO, H. A. Envelhecimento e Doença de Alzheimer: implicações para a hipótese da reserva cognitiva. Psicol Educ Cult, v. 14, n. 1, p. 5-22, 2010.

POLETTI, M. et al. Mild Cognitive Impairment and cognitive reserve in Parkinson`s Disease. Parkinsonism Relat Disord. v. 17, p. 579-586, 2011.

PORTO, P., HERMOLIN, M.; VENTURA, P. Alterações neuropsicológicas associadas à depressão. Rev Bras Ter Comport Cogn, v. 4, n. 1, 2002.

PRADO, R. C. P.; FERREIRA, L. C.; ANDRADE, V. M. Perfil cognitivo de pacientes portadores de doença de Parkinson. Scientia Plena, v. 5, n. 11. 2009.

RABELO, D. F. Comprometimento Cognitivo Leve em Idosos: avaliação, fatores associados e possibilidades de intervenção. Rev Kairós Gerontol, v.12, n. 2, p. 65-79, 2009.

RADANOVIC, M.; STELLA, F.; FORLENZA, O. V. Comprometimento cognitivo leve. Rev Med (São Paulo), v. 94, n. 3, p. 162-168, 2015.

RAVINA, M. S. C. E. B. et al. The impact of depressive symptoms in early Parkinson disease. Neurology, v. 69, n. 4, 342-347, 2007. 
REID, W. G. J. et al. Dementia in Parkinson's Disease: A 20-year neuropsychological study (Sydney Multicentre Study). J Neurol Neurosurg Psychiatry,, v. 82, p. 1033-1136, 2011.

REIJENDRS, J. S. et al. A systematic review of prevalence studies of depression in Parkinson's disease. Mov Disord, v. 23, n. 2, p. 183-189, 2008.

REISBERG, B. et al. Stage-specific behavioral, cognitive, and in vivo changes in community residing subjects with age-associated memory impairment and primary degenerative dementia of the Alzheimer type. Drug Dev Res, v. 15, p. 101-114, 1988

REMY, P. et al. Depression in Parkinson's disease: loss of dopamine and noradrenaline innervations in the limbic system. Brain, v. 128, p. 13141322, 2005.

RIBEIRO, S. Sonho, memória e o reencontro de Freud com o cérebro. Rev Bras Psiquiatr, v. 25, Supl II, p. 59-63, 2003.

ROBBINS, T. W.; COOLS, R. Cognitive Deficits in Parkinson's Disease: A Cognitive Neuroscience Perspective. Mov Disord, v. 29, n. 5. p. 597-607, 2014.

ROE, M. C. et al. Education and Alzheimer disease without dementia. Support for the cognitive reserve hypothesis. Neurology, v. 68, p. 223e8, 2007.

SÁEZ-FONSECA, J. A.; LEE, L.; WALKER, Z. Long-term outcome of depressive pseudodementia in the elderly. J Affect Disord, v. 101, p. 123129, 2007.

SALGADO, J. V. et al. O Teste de Aprendizagem Auditivo-Verbal de Rey: aplicabilidade para uma amostra de adultos brasileiros. Rev Bras Psiq, v. 33, n. $3,2011$.

SANTOS, A. et al. Relação entre qualidade de sono e funções cognitivas em pacientes com doença de Parkinson. Univ Sci, v. 18, n. 3, p. 269-281, 2013.

SCHARG et al. Depression Rating Scales in Parkinson's Disease: Critique and Recommendations. Mov Disord, v. 22, n. 8, p. 1077-1092, 2007.

SHULMAN, L. M. Apathy in patients with Parkinson's disease. Int Rev Psychiatry, v. 12, p. 2298-306, 2000.

SILBERMAN, C. D. et al. Uma revisão sobre depressão como fator de risco na doença de Parkinson e seu impacto na cognição. Rev psiquiatr Rio Grande do Sul, v. 26, n. 1, p. 52-60, 2004. 
SILVA, R. A. P. C. Sleep disturbances and mild cognitive impairment: a review. Sleep Science, v. 8, p. 36-41, 2015.

SILVA, T. B. L. et al. Fluência verbal e variáveis sóciodemográficas no processo de envelhecimento: um estudo epidemiológico. Psicol Reflex Crit, v. 24, n. 4, p. 739-746, 2011.

SPREEN, O.; STRAUSS, E. A Compendium of Neuropsychological Tests. 2nd ed. New York: Oxford University Press; 1998.

STERN, Y. Cognitive reserve and Alzheimer disease. Alzheimer Dis Assoc Disord, v. 20, p. 112e7, 2006.

SUNDERLAND, T. et al. Clock drawing in Alzheimer's disease: A novel measure of dementia severity. J Am Geriatr Soc, v. 37, n. 8, p. 725-729, 1989.

TANNER, C. M. et al. Parkinson disease in twins: an etiologic study. JAMA, v. 281, n. 4, p. 341-346, 1999.

TATSCH, M. F.; NITRINI. R.; LOUZÃ NETO, M. R. Demência com corpúsculos de Lewy: uma entidade distinta com tratamento específico? Rev Bras Psiq, São Paulo, v. 24, n. 3, p. 152-156, 2002.

TEIVE H. A. G. O papel de charcot na doença de parkinson. Arq Neuropsiquiatr, v. 56, n. 1, p. 141-145, 1998.

TOSELLO, D. J. T. Contribuição para o estudo normativo do Hooper Visual Organization Test (VOT). Psicol Hosp, v. 3, n. 1, p. 59-63, 2005.

TRAMBLEY, $C$ et al. The heterogeneity of cognitive symptoms in Parkinson's disease: a meta-analysis. J Neurol Neurosurg Psychiatry, v. 84, n. 11, p. 1265-1272, 2013.

TSAI, C. H. et al. Environmental risk factors of young onset Parkinson's disease: a case-control study. Clin Neurol Neurosurg, v. 104, n. 4, p. 328333, 2002.

UEMURA, Y. et al. Depression and cognitive impairment in patients with mild parkinsonian signs. Acta Neurol Scand, v. 128, n. 3, p. 153-159, 2013.

VASCONCELLOS L. F. R., PEREIRA J. S. Parkinson's disease dementia: Diagnostic criteria and risk factor review. J Clin Exp Neuropsychol, v. 37, n. 9, p 988-993, 2015.

VEAZEY, C. et al. Prevalence and Treatment of Depression in Parkinson's Disease. J Neuropsychi Clin Neurosci, v. 17, p. 310-323, 2005. 
VEIGA, B. A. A. G. et al. Depressão na doença de Parkinson: análise clínico-epidemiológica e comparação com um grupo de pacientes geriátricos não parkinsonianos. Rev Bras Psiquiatr, v.31, n.1, p. 39-42. 2009.

VINKERS, D. J. et al. Temporal relation between depression and cognitive impairment in old age: prospective population based study. BMJ, v. 329, n. 7471, p. 881, 2004.

VITIELLO A.P.P. et al. Avaliação cognitiva breve de pacientes atendidos em ambulatório de neurologia geral. Arq Neuropsiquiatr, v. 67, n. 2a, p. 299-303, 2007.

WILLIAMS-GRAY, C. H. et al. The distinct cognitive syndromes of Parkinson's disease: 5-year follow-up of the CamPalGN cohort. Brain, v. 132, p. 2958-2969, 2009.

WOOTEN, G. F. et al. Are men at greater risk for Parkinson's disease than women? J Neurol Neurosurg Psychiatr., v. 75, p. 637-639, 2004 


\section{ANEXO I}

\section{TERMO DE CONSENTIMENTO LIVRE E ESCLARECIDO}

Você está sendo convidado(a) para participar voluntariamente do estudo intitulado "AVALIAÇÃO DE PREDITORES CLÍNICOS E DE NEUROIMAGEM NA DEMÊNCIA DA DOENÇA DE PARKINSON", a ser realizado no Setor de Distúrbios do Movimento do Serviço de Neurologia do Hospital Universitário Pedro Ernesto/UERJ, sob responsabilidade do Dr Luiz Felipe Rocha Vasconcellos, sob orientação do Prof. Dr. João Santos Pereira, com objetivo de analisar a variáveis clínicas e de ressonância magnética de crânio relacionadas a comprometimento cognitivo/demência em indivíduos com Doença de Parkinson (DP).

Apesar de ser classificada como uma desordem primária do movimento, com manifestações de rigidez, bradicinesia (lentidão dos movimentos), tremor e instabilidade postural, os sintomas não motores são parte integrante da DP.

Comprometimento cognitivo (memória, atenção, comportamento) é relativamente comum na DP, estando relacionada a tempo de doença, idade, dentre outros. A gravidade dos sintomas é variável, podendo ser leve ("Comprometimento Cognitivo Leve" da DP) ou não ( demência da DP).

O diagnóstico precoce do comprometimento cognitivo é importante, pois existem medicações utilizadas na DP que podem agravar sintomas nãomotores/cognitivos além de existir medicamentos aprovados para uso na demência da DP.

A pesquisa terá como avaliações preliminares a história clínica e o exame neurológico, além da aplicação do Mini-Exame do Estado Mental, desenho do relógio, teste de MOCA, fluência verbal, teste de reconhecimento de figuras, Escala Depressão de Beck, Escala Unificada de Avaliação da Doença de Parkinson (UPDRS). Posteriormente, os participantes serão submetidos a exame de ressonância magnética de crânio sem contraste e avaliação neuropsicológica. Para os pacientes que não tiverem exames de sangue recentes serão solicitados os seguintes itens: hemograma, uréia, creatinina, glicemia, TSH, T4L, B 12, folato e VDRL.

$\mathrm{O}$ exame de ressonância magnética $(\mathrm{RM})$ de crânio será previamente agendado, não será administrado contraste e a duração média do exame é de 30 minutos. Você irá receber uma cópia em $\mathrm{CD}$ do seu exame com laudo.

A avaliação neuropsicológica será constituída de testes que avaliam de forma mais detalhada a cognição e para conclusão pode ser necessária mais de 1 consulta.

Ao final de 18 meses todos os procedimentos serão novamente realizados á exceção da RM de crânio e exames de sangue.

Seu compromisso será comparecer regularmente às consultas e exames agendados, na hora e data marcados, o que, infelizmente, se não ocorrer implicará em desligamento do estudo.

Como os procedimentos empregados são não invasivos, os riscos serão inexistentes ou mínimos. Caberá aos pesquisadores responsáveis, o acompanhamento neurológico durante todas as etapas do estudo, assim como contato com os familiares e reuniões para orientação e qualquer esclarecimento sobre este assunto durante e ao término da pesquisa. Qualquer dano pessoal que porventura possa vir a ocorrer, comprovadamente pelo procedimento proposto, nos responsabilizaremos pelo acompanhamento médico na instituição. Caso tenha alguma consideração ou dúvida poderá entrar em contato com Comitê de Ética em Pesquisa (CEP) da instituição. 
O sigilo e a confidencialidade das informações obtidas pelo estudo serão preservados, assim como, não será revelada a identidade dos participantes ou de seus responsáveis. Os resultados serão fornecidos a cada participante e os registros e imagens disponíveis serão disponibilizados para o uso da pesquisa, podendo ser utilizados apenas para fins científicos, apresentados e publicados em congressos e/ou revistas científicas.

Sua participação ou da pessoa sob sua responsabilidade neste estudo é voluntária, sem qualquer ônus ou benefício financeiro, podendo se recusar a participar ou se afastar do mesmo a qualquer momento durante sua realização, sem qualquer penalidade, prejuízo ou perda no atendimento e acompanhamento no Serviço de Neurologia.

Após ter lido o termo de consentimento e ter sido esclarecido(a) verbalmente sobre os detalhes da pesquisa, declaro que entendi e concordo voluntariamente, sem qualquer tipo de coação, em participar deste estudo, autorizando a divulgação dos resultados.

Rio de Janeiro, de de 20_.

PESQUISADORES:

Luiz Felipe Rocha Vasconcellos

João Santos Pereira

PARTICIPANTE/RESPONSÁVEL:

Assinatura do participante/ responsável

NOME:

IDENTIDADE:

CONTATO COM OS PESQUISADORES

Hospital Universitário Pedro Ernesto

Av. 28 de Setembro, 77- $2^{\circ}$ andar -Serviço de Neurologia - Vila Isabel-RJ.

TEL: 2868-8130 / 2868-8080 


\section{ANEXO II}

PROTOCOLO DE PESQUISA - PARKINSON PUC / HFSE / HUPE

\section{IDENTIFICAÇÃO}

Nome:

Número do prontuário:

Data: ___ _ _ _ _ Data de nascimento:

Idade completa: Sexo: M ( ) F ( ) Cor: Branca ( ) Preta ( ) Parda ( ) Amarela ( )

Escolaridade: anos Estado civil: Cas. ( ) Solt. ( ) Viúv. ( ) Desq. ( ) Div. ( ) Nacionalidade: Bras. ( ) Outra: Natural de (cidade, estado):

Profissão: Aposentado?

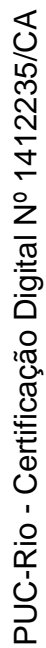

Você tem algum problema de saúde? Não ( ) Sim ( )

Se sim, quais?

Quais remédios você tomou nas duas últimas semanas?

Endereço:

Telefone:

Nome do pesquisador: 
MINI EXAME DO ESTADO MENTAL - MEEM

\section{ORIENTAÇÃO}

- Dia da seman

- Dia do mês

- Mês

- Ano

- Hora aproximada

- Local específico (aposento ou setor)

- Instituição (hospital, residência, clínica)

- Bairro ou rua próxima

- Cidade

- Estado

MEMÓRIA IMEDIATA

- Vaso / Carro / Tijolo

\section{ATENÇÃO E CÁLCULO}

$-100-7$ sucessivos

EVOCAÇÃO

- Recordar as 3 palavras

LINGUAGEM

- Nomear um relógio e uma caneta

- Repetir: "nem aqui, nem ali, nem lá

- Comando: "Pegue este papel com sua mão direita, dobre ao meio e coloque no chão"

- Ler e obedecer: "Feche os olhos

- Escrever uma frase

- Copiar um desenho

ESCORE 30

SOLETRAR

- Soletre a palavra "mundo"de trás para frente

ESCORE 35
PONTOS

\begin{tabular}{|l|l|}
\hline 1 & \\
\hline 1 & \\
\hline 1 & \\
\hline 1 & \\
\hline 1 & \\
\hline 1 & \\
\hline 1 & \\
\hline 1 & \\
\hline 1 & \\
\hline 1 & \\
\hline
\end{tabular}

3
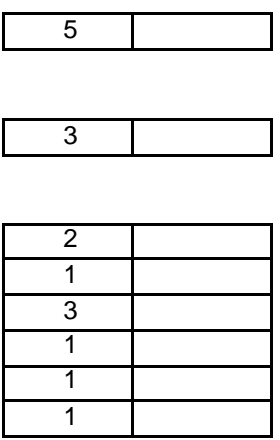

30

\begin{tabular}{|l|l|}
\hline 5 & \\
\hline
\end{tabular}

\begin{tabular}{|l|l|}
\hline 35 & \\
\hline
\end{tabular} 
TESTE DE MEMORIA DE FIGURAS

\begin{tabular}{|c|c|c|c|c|c|}
\hline & NOMEAÇÃO & $\begin{array}{l}\text { MEMORIA } \\
\text { INCIDENTAL }\end{array}$ & M.I. 1 & M.I. 2 & M.I. 5 \\
\hline \multicolumn{6}{|l|}{ Sapato } \\
\hline \multicolumn{6}{|l|}{ Casa } \\
\hline \multirow{2}{*}{\multicolumn{6}{|c|}{$\begin{array}{l}\text { Pente } \\
\text { Chave }\end{array}$}} \\
\hline \multicolumn{5}{|l|}{ Chave } & \\
\hline \multicolumn{6}{|l|}{ Avião } \\
\hline \multicolumn{6}{|l|}{ Balde } \\
\hline \multicolumn{6}{|l|}{ Tartaruga } \\
\hline \multicolumn{6}{|l|}{ Livro } \\
\hline Colher & & & & & \\
\hline \multicolumn{6}{|l|}{ Árvore } \\
\hline \multicolumn{6}{|l|}{ Corretas } \\
\hline Intrusões & & & & & \\
\hline
\end{tabular}

\section{RECONHECIMENTO}

\begin{tabular}{|l|l|l|l|l|l|l|l|}
\hline Caminhão & & Tartaruga & & Árvore & & Balde & \\
\hline Ferro & & Avião & & Banana & & Livro & \\
\hline Pente & & Casa & & Navio & & Sapato & \\
\hline Fruta & & Bule & & Porco & & Palito & \\
\hline Folha & & Bicicleta & & Colher & & Chave & \\
\hline
\end{tabular}

DESENHO DO RELÓGIO

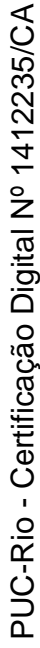

\section{TESTE DE FLUÊNCIA VERBAL - ANIMAIS}

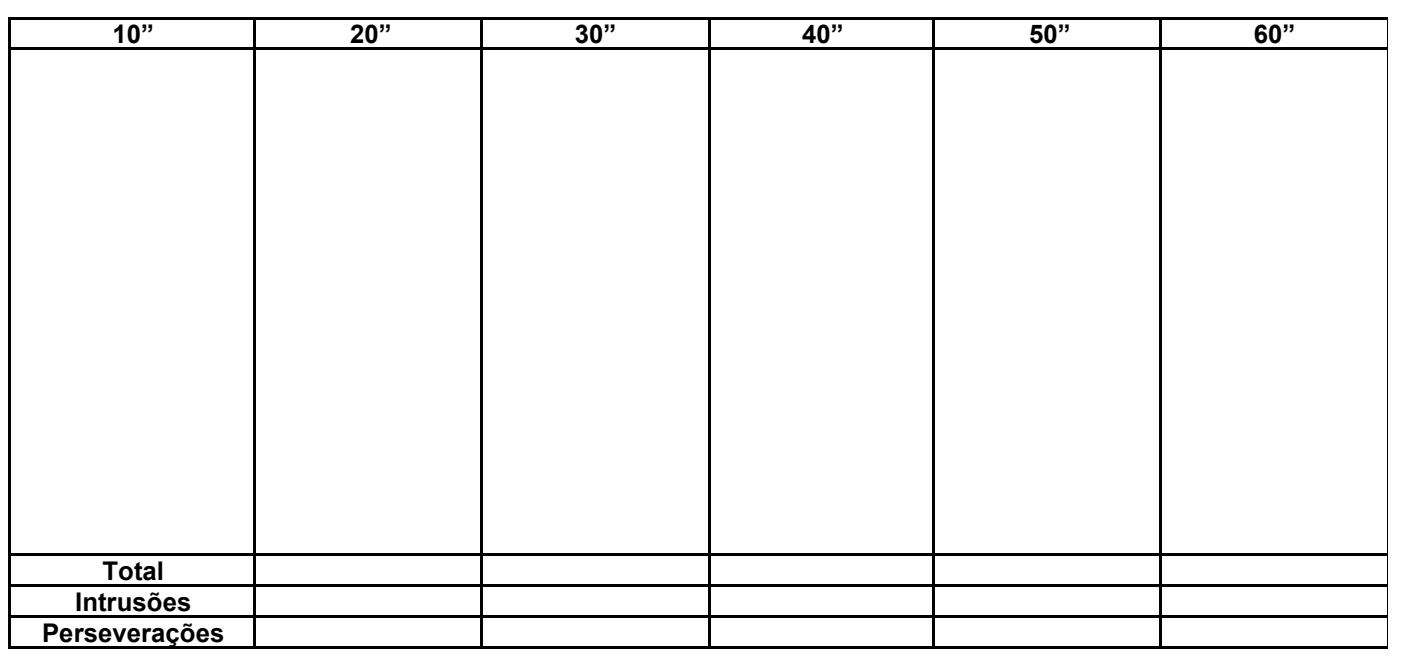


TESTE DE MEMORIA DE FIGURAS

Evocação (M.I. 5) e Reconhecimento

REY AUDITORY VERBAL LEARNING TEST (RAVLT)

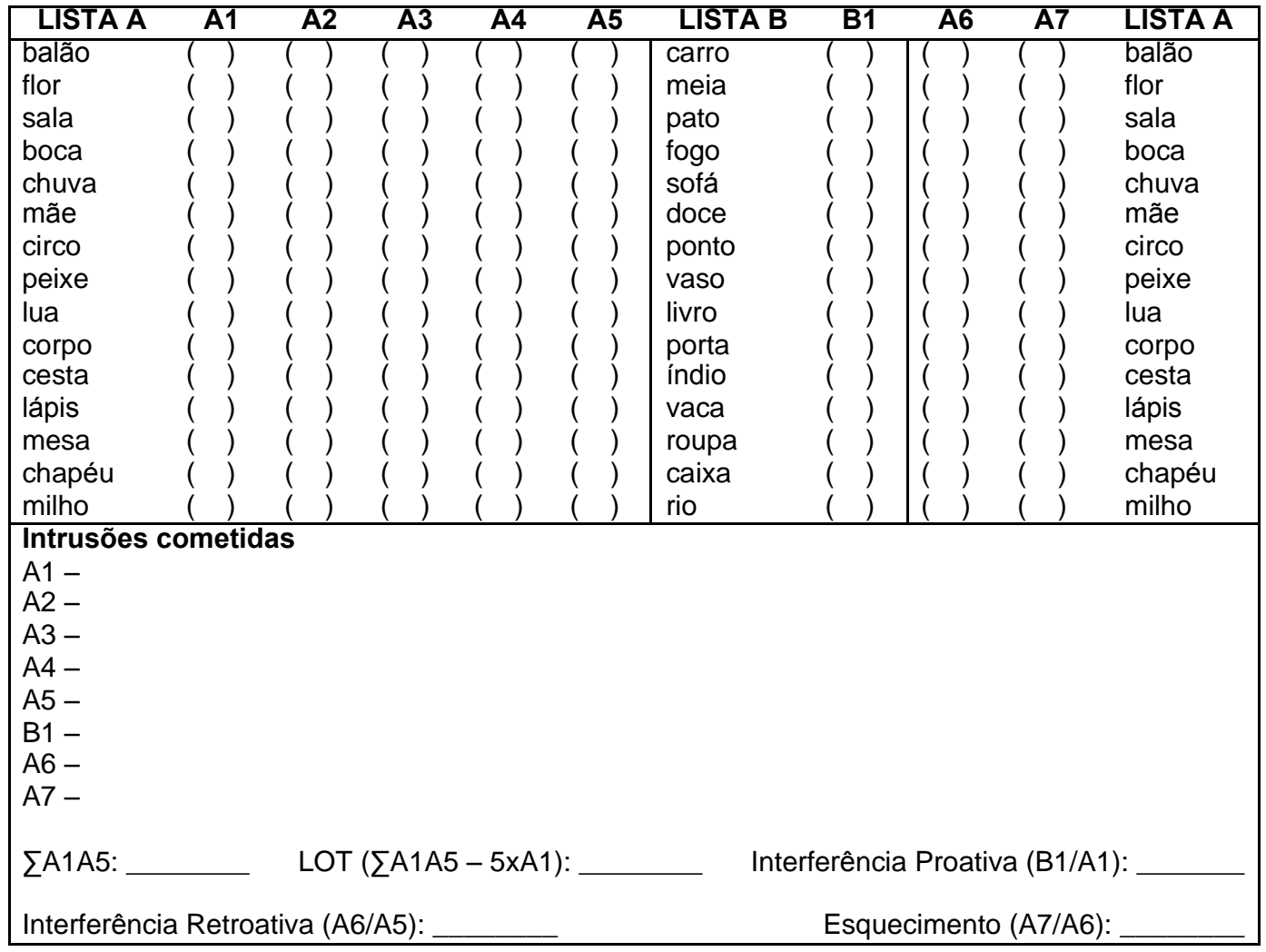

\section{RECONHECIMENTO}

\begin{tabular}{|c|c|c|c|c|}
\hline $\begin{array}{ll} & \text { lua }(A) \\
& \text { galo }(S B) \\
\text { fogo }(B) \\
\text { chapéu }(A) \\
\text { vaso }(B) \\
\text { mesa (A) } \\
\text { lago (SB) } \\
\text { porta (B) } \\
\text { dente (SA) } \\
\text { rio (B) }\end{array}$ & $\begin{array}{ll} & \text { cor (FA) } \\
\text { indio }(B) \\
\text { balão }(A) \\
\text { rua (FA) } \\
\text { planta (SA/SB) } \\
\text { roupa (B) } \\
\text { corpo }(A) \\
\text { pato (B) } \\
\text { cesta (A) } \\
\text { livro (B) }\end{array}$ & $\begin{array}{ll} & \text { ponto }(B) \\
\text { flor }(A) \\
\text { isca }(S A) \\
\text { boca }(A) \\
\text { chuva }(A) \\
\text { caixa }(B) \\
\text { rosa }(S A) \\
\text { circo }(A) \\
\text { carro }(B) \\
\text { lápis }(A)\end{array}$ & $\begin{array}{l}\text { vaca (B) } \\
\text { sala (A) } \\
\text { filho (SA /FA) } \\
\text { bola (SA) } \\
\text { aula (SA) } \\
\text { milho (A) } \\
\text { bolo (SB) } \\
\text { beixe (A) } \\
\text { peix } \\
\text { botão (FA) } \\
\text { leite (SA) }\end{array}$ & $\begin{array}{ll} & \text { meia (B) } \\
& \text { jardim (SA) } \\
\text { sofá (B) } \\
\text { festa (FA) } \\
\text { doce (B) } \\
\text { sol (SA) } \\
\text { mãe (A) } \\
\text { papel (FA) } \\
\text { par (SB) } \\
\text { mento (FB) }\end{array}$ \\
\hline \multicolumn{5}{|c|}{$\begin{array}{l}\text { Total de acertos (pertence ou não a lista A): } \\
\text { Reconhecimento (acertos }-35) \text { : }\end{array}$} \\
\hline
\end{tabular}


DIGITOS - WAIS-III

\begin{tabular}{|c|c|c|c|}
\hline \multicolumn{2}{|l|}{ ORDEM DIRETA } & \multicolumn{2}{|c|}{ ORDEM INDIRETA } \\
\hline $1-7$ & $(1)(0)$ & $2-4$ & $(1)(0)$ \\
\hline $6-3$ & $(1)(0)$ & $5-7$ & $(1)(0)$ \\
\hline $5-8-2$ & $(1)(0)$ & $4-1-5$ & $(1)(0)$ \\
\hline $6-9-4$ & $(1)(0)$ & $6-2-9$ & $(1)(0)$ \\
\hline $6-4-3-9$ & $(1)(0)$ & $3-2-7-9$ & $(1)(0)$ \\
\hline $7-2-8-6$ & $(1)(0)$ & $4-9-6-8$ & $(1)(0)$ \\
\hline $4-2-7-3-1$ & $(1)(0)$ & $1-5-2-8-6$ & $(1)(0)$ \\
\hline $7-5-8-3-6$ & $(1)(0)$ & $6-1-8-4-3$ & $(1)(0)$ \\
\hline $6-1-9-4-7-3$ & $(1)(0)$ & $5-3-9-4-1-8$ & $(1)(0)$ \\
\hline 3-9-2-4-8-7 & $(1)(0)$ & $7-2-4-8-5-6$ & $(1)(0)$ \\
\hline $5-9-1-7-4-2-8$ & $(1)(0)$ & $8-1-2-9-3-6-5$ & $(1)(0)$ \\
\hline $4-1-7-9-3-8-6$ & $(1)(0)$ & 4-7-3-9-1-2-8 & $(1)(0)$ \\
\hline 3-8-2-9-5-1-7-4 & $(1)(0)$ & $7-2-8-1-9-6-5-3$ & $(1)(0)$ \\
\hline $5-8-1-9-2-6-4-7$ & $(1)(0)$ & $9-4-3-7-6-2-5-8$ & $(1)(0)$ \\
\hline $2-7-5-8-6-2-5-8-4$ & $(1)(0)$ & & \\
\hline $7-1-3-9-4-2-5-6-8$ & $(1)(0)$ & & \\
\hline Acertos OD: $\_/ 16$ Mx OD: $\quad / 9$ & certos $\mathrm{O}$ & /14 Mx OI: & \\
\hline
\end{tabular}

\section{STROOP}

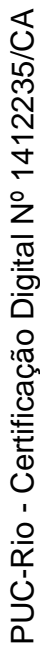

$\operatorname{COR}(1) \rightarrow$

\begin{tabular}{|c|c|c|c|}
\hline VERDE & VERMELHO & AZUL & AMARELO \\
\hline VERMELHO & AMARELO & VERDE & AZUL \\
\hline AZUL & VERDE & VERMELHO & AMARELO \\
\hline AMARELO & VERMELHO & AZUL & VERDE \\
\hline VERMELHO & AZUL & VERDE & AMARELO \\
\hline AMARELO & VERDE & AZUL & VERMELHO \\
\hline
\end{tabular}

TEMPO

PALAVRA (2) $\rightarrow$

\begin{tabular}{|c|c|c|c|}
\hline VERDE & VERMELHO & AZUL & AMARELO \\
\hline VERMELHO & AMARELO & VERDE & AZUL \\
\hline AZUL & VERDE & VERMELHO & AMARELO \\
\hline AMARELO & VERMELHO & AZUL & VERDE \\
\hline VERMELHO & AZUL & VERDE & AMARELO \\
\hline AMARELO & VERDE & AZUL & VERMELHO \\
\hline
\end{tabular}

TEMPO:

PALAVRA-COR (3) $\rightarrow$

\begin{tabular}{|c|c|c|c|}
\hline VERDE & VERMELHO & AZUL & AMARELO \\
\hline VERMELHO & AMARELO & VERDE & AZUL \\
\hline AZUL & VERDE & VERMELHO & AMARELO \\
\hline AMARELO & VERMELHO & AZUL & VERDE \\
\hline VERMELHO & AZUL & VERDE & AMARELO \\
\hline AMARELO & VERDE & AZUL & VERMELHO \\
\hline
\end{tabular}

INTERFERÊNCIA: Tempo 3 / Tempo 1: 


\section{PARTE A}

\section{TRAIL MAKING TEST}

Tempo (limite 5min):

$\begin{array}{llllllllllll}\text { ( ) } 1-2 & \text { ( ) 2-3 } & \text { ( ) 3-4 } & \text { ( ) 4-5 } & \text { ( ) 5-6 } & \text { ( ) 6-7 } & \text { ( ) 7-8 } & \text { ( ) 8-9 } & \text { ( ) 9-10 ( ) 10-11 }\end{array}$

$\begin{array}{lllllllll}\text { ( ) } 11-12 & \text { ( ) } 12-13 & \text { ( ) } 13-14 & \text { ( ) 14-15 } & \text { ( ) 15-16 } & \text { ( ) 16-17 } & \text { ( ) 17-18 } & \text { ( ) 18-19 }\end{array}$

$\begin{array}{llllll}\text { ( ) } 19-20 & \text { ( ) 20-21 } & \text { ( ) 21-22 } & \text { ( )22-23 ( ) 23-24 } & \text { ( ) 24-25 }\end{array}$

COMENTÁRIOS:

\section{PARTE B}

Tempo (limite 5min):

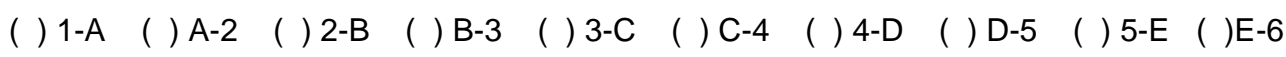

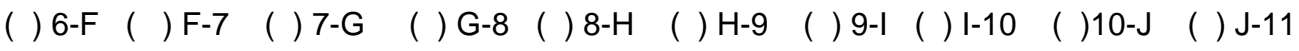

( ) $11-\mathrm{L} \quad($ )L-12 ( ) 12-M ( ) M-13

COMENTÁRIOS:

REY AUDITORY VERBAL LEARNING TEST (RAVLT)

Evocação (A7) e Reconhecimento 
FLUENCIA VERBAL ORTOGRAFICA - FAS

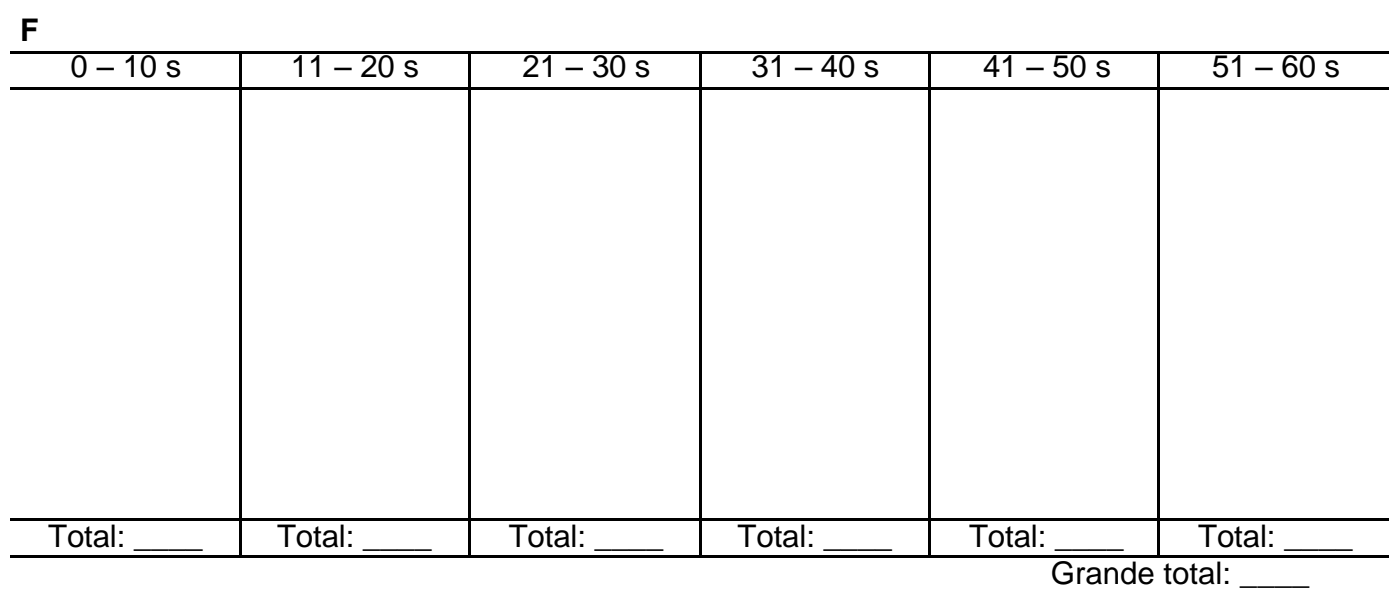

A

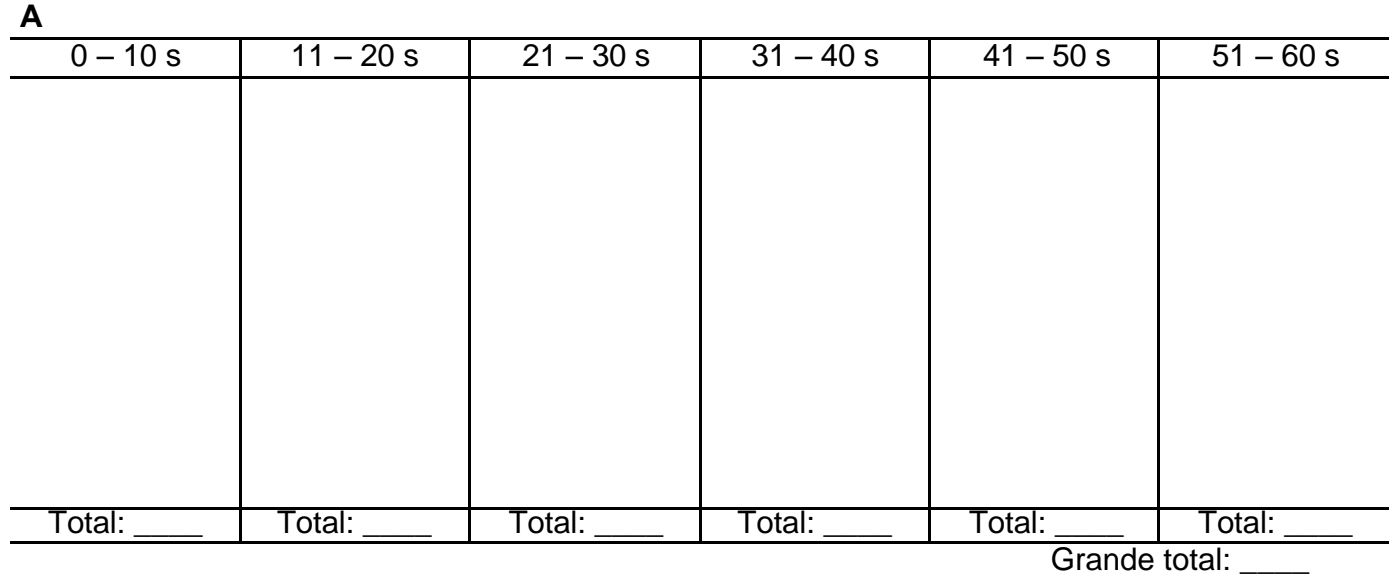

s

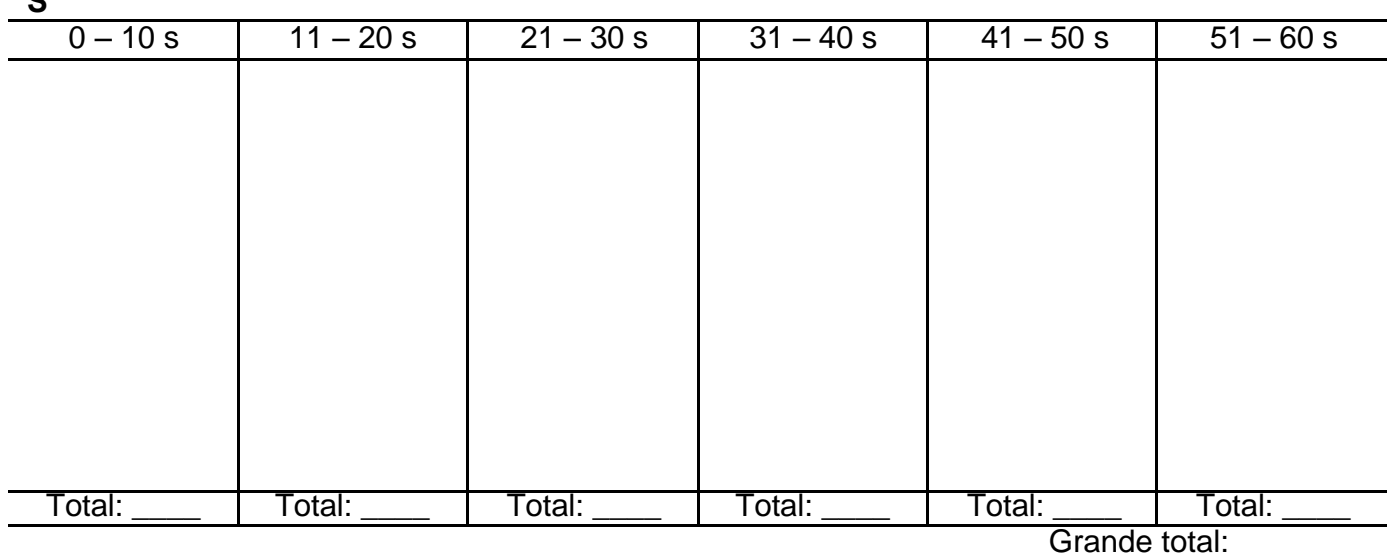




\section{HOOPER}

\begin{tabular}{|l|l|l|l|}
\hline 1 - PEIXE & $16-$ CHALEIRA & \\
\hline 2 - SERROTE & & $17-$ SOFÁ & \\
\hline $3-$ MESA & $18-$ CASTIÇAL COM VELA & \\
\hline $4-$ AVIAO & $19-$ BULE & \\
\hline $5-$ BOLA & $20-$ GATO & \\
\hline $6-$ MARTELO & & $21-$ FLOR & \\
\hline $7-$ CACHORRO & & $22-$ RATO & \\
\hline $8-$ CAMINHAO & & $23-$ LIVRO & \\
\hline $9-$ XICARA & & $24-$ COELHO & \\
\hline $10-$ MAO & & $25-$ CUBO & \\
\hline $11-$ MAÇA & & $26-$ FAROL & \\
\hline $12-$ CESTA & & $27-$ SAPATO & \\
\hline $13-$ TESOURA & & $28-$ CHAVE & \\
\hline $14-$ BENGALA & & $29-$ ANEL & \\
\hline $15-$ BARCO & & $30-$ VASSOURA & \\
\hline
\end{tabular}

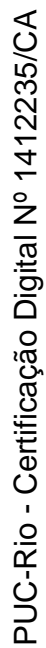


$\underline{B D I}$

Este questionário consiste em 21 grupos de afirmações. Depois de ler cuidadosamente cada grupo, faça um círculo em torno do número $(0,1,2$ ou 3$)$ próximo à afirmação, em cada grupo, que descreve melhor a maneira que você tem se sentido na última semana, incluindo hoje. Se várias afirmações num grupo parecerem se aplicar igualmente bem, faça um círculo em cada uma. Tome o cuidado de ler todas as afirmações, em cada grupo, antes de fazer a sua escolha.

\begin{tabular}{|c|c|c|c|}
\hline 1 & $\begin{array}{ll}0 & \text { Não me sinto triste. } \\
1 & \text { Eu me sinto triste. } \\
2 & \text { Estou sempre triste e não consigo sair } \\
& \text { disto. } \\
3 & \text { Estou tão triste ou infeliz que não consigo } \\
\text { suportar. }\end{array}$ & 7 & $\begin{array}{lll}0 & \text { Não me sinto decepcionado comigo } \\
& \text { mesmo. } \\
1 & \text { Estou decepcionado comigo mesmo. } \\
2 & \text { Estou enojado de mim. } \\
3 & \text { Eu me odeio. }\end{array}$ \\
\hline 2 & $\begin{array}{ll}0 & \text { Não estou especialmente desanimado } \\
& \text { quanto ao futuro. } \\
1 & \text { Eu me sinto desanimado quanto ao futuro. } \\
2 & \text { Acho que nada tenho a esperar. } \\
3 & \text { Acho que o futuro sem esperança e tenho } \\
\text { a impressão de que as coisas não podem } \\
\text { melhorar. }\end{array}$ & 8 & $\begin{array}{ll}0 & \text { Não me sinto de qualquer modo pior que os } \\
& \text { outros. } \\
1 & \text { Sou crítico em relação a mim por minhas } \\
\text { fraquezas ou erros. } \\
2 & \text { Eu me culpo sempre por minhas falhas. } \\
3 & \text { Eu me culpo por tudo de mal que acontece. }\end{array}$ \\
\hline 3 & $\begin{array}{l}0 \text { Não me sinto um fracasso. } \\
1 \text { Acho que fracassei mais que uma pessoa } \\
\text { comum. } \\
2 \text { Quando olho para trás, na minha vida, } \\
\text { tudo o que posso ver é um monte de } \\
\text { fracassos. } \\
3 \text { Acho que, como pessoa, sou um fracasso } \\
\text { completo. }\end{array}$ & 9 & $\begin{array}{ll}0 & \text { Não tenho quaisquer idéias de me matar. } \\
1 & \text { Tenho idéias de me matar, mas não as } \\
& \text { executaria. } \\
2 & \text { Gostaria de me matar. } \\
3 & \text { Eu me mataria se tivesse oportunidade. }\end{array}$ \\
\hline 4 & $\begin{array}{ll}0 & \text { Tenho tanto prazer em tudo quanto antes. } \\
1 & \text { Não sinto mais prazer nas coisas como } \\
\text { antes. } \\
2 \text { Não encontro um prazer real em mais } \\
\text { nada. } \\
3 \text { Estou insatisfeito ou aborrecido com tudo. }\end{array}$ & 10 & $\begin{array}{ll}0 & \text { Não choro mais que o habitual. } \\
1 & \text { Choro mais agora do que costumava. } \\
2 & \text { Agora, choro o tempo todo. } \\
3 & \text { Costumava ser capaz de chorar, mas agora } \\
& \text { não consigo mesmo que o queira. }\end{array}$ \\
\hline 5 & $\begin{array}{l}0 \text { Não me sinto especialmente culpado. } \\
1 \text { Eu me sinto culpado grande parte do } \\
\text { tempo. } \\
2 \text { Eu me sinto culpado na maior parte do } \\
\text { tempo. } \\
3 \text { Eu me sinto sempre culpado. }\end{array}$ & 11 & $\begin{array}{ll}0 & \text { Não sou mais irritado agora do que já fui. } \\
1 & \text { Fico aborrecido ou irritado mais facilmente } \\
\text { do que costumava. } \\
2 \text { Agora, eu me sinto irritado o tempo todo. } \\
3 \text { Não me irrito mais com coisas que } \\
\text { costumavam me irritar. }\end{array}$ \\
\hline 6 & $\begin{array}{ll}0 & \text { Não acho que esteja sendo punido. } \\
1 & \text { Acho que posso ser punido. } \\
2 & \text { Creio que vou ser punido. } \\
3 & \text { Acho que estou sendo punido. }\end{array}$ & 12 & $\begin{array}{ll}0 & \text { Não perdi o interesse pelas outras pessoas. } \\
1 & \text { Estou menos interessado pelas outras } \\
\text { pessoas do que costumava estar. } \\
2 & \begin{array}{l}\text { Perdi a maior parte do meu interesse pelas } \\
\text { outras pessoas. }\end{array} \\
3 & \text { Perdi todo o interesse pelas outras pessoas. }\end{array}$ \\
\hline
\end{tabular}




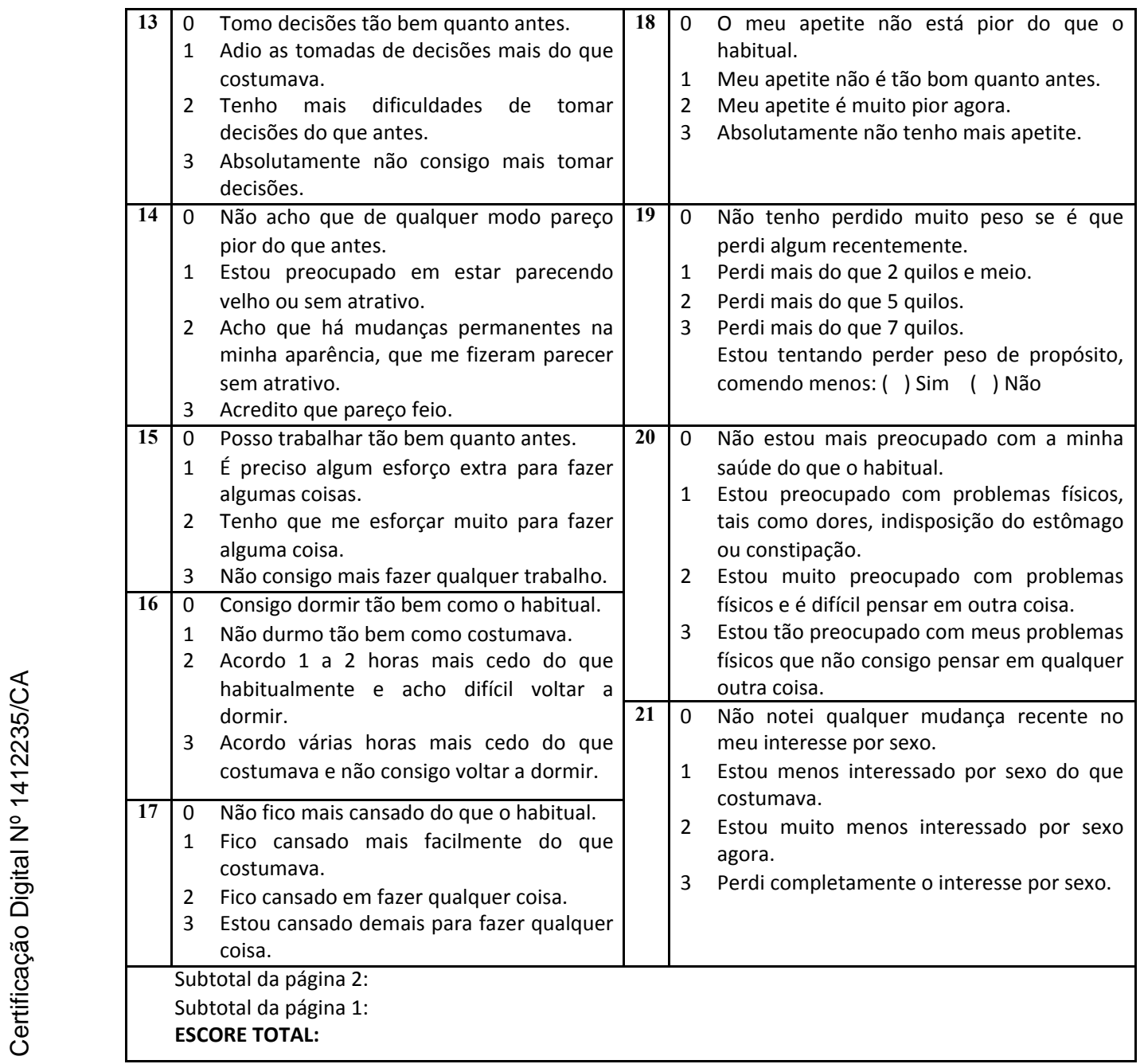




\section{ANEXO III - ARTIGO EMPÍRICO}

\section{SYMPTOMS OF DEPRESSION IN PATIENTS WITH MILD COGNITIVE IMPAIMENT IN PARKINSON'S DISEASE}

Malak ALSB ${ }^{(1)}, G_{\text {reca DV }}^{(1)}$, Cruz $^{(1)}$, Alves HVD ${ }^{(1)}$, Vasconcellos LFR ${ }^{(2)}$, Pereira JS ${ }^{(2)}$, Charchat-Fichman $\mathrm{H}^{(1)}$

${ }^{(1)}$ Departamento de Psicologia; Pontifícia Universidade Católica do Rio de Janeiro; Rio de Janeiro; Brasil

${ }^{(2)}$ Departamento de Neurologia; Hospital Universitário Pedro Ernesto; Universidade Estadual do Rio de Janeiro; Rio de Janeiro; Brasil

\section{ABSTRACT}

Objective: To investigate the most frequent depressive symptoms and their impact on cognition in Parkinson's Disease (PD) patients with mild cognitive impairment (MCI). Method: 48 patients with PD and 44 controls (CG), aged between 50 and 80 years and having at least 4 years of formal education, all with MCI and none diagnosed with depression were assessed. They were matched for age, education, and MMSE score. Participants underwent clinical evaluation with neurologist followed by neuropsychological assessment employing with the following instruments: MMSE, Clock Drawing Test, Verbal Fluency Test (semantic and phonemic), Figures Memory Test, Stroop Test, Trail Making Test, Digit Span (WAIS III), RAVLT, Hooper Visual Organization Test, and the Beck Depression Inventory (BDI). Results: The most frequent depressive symptoms in the PD group were: difficulty to work, fatigue and sleep disorders (this one also being common in the CG). The BDI score correlated negatively with learning and recognition memory in both groups. In this study, episodic memory was the cognitive function showing greater impairment. Conclusion: The prevalent depressive symptoms in PD patients with $\mathrm{MCI}$ can be attributed exclusively to PD, complicating differential 
diagnoses. Studies aiming the characterization of depression in PD patients with MCI are important once these conditions constitute risk factors for dementia

Keywords: Parkinson's disease, Depression, Cognition, Mild Cognitive Impairment.

\section{INTRODUCTION}

Parkinson's disease (PD) is one of the most common neurological disorders in the elderly population, accounting for up to two-thirds of patients who seek major movement disorder centers worldwide. In every 100,000 individuals, 350 develop this disease and nine million new cases are estimated by $2030^{(1)}$. PD has a higher incidence in men than in women, but no differences are evident among races and ethnic groups(2). The greatest risk factor for PD is age, with the appearance of the first symptoms between the fourth and seventh decade of life.

Traditionally, PD is characterized by the occurrence of movement disorders and changes in fine motor control. The most prominent clinical signs include resting tremor, bradykinesia (slowness of movement), muscular rigidity, lack of voluntary movements, and changes in balance, which are irreversible motor abnormalities ${ }^{(3)}$. These signs result from the loss of dopaminergic neurons in a particular region called substantia nigra pars compacta.

Unlike the motor symptoms, which are well-defined, there are also non-motor manifestations. Psychosis, cognitive impairment, sleep disorders, depression, among others, are common symptoms and should not be ignored, since they entail substantial losses in patients' quality of life(4). However, studies show that $62 \%$ of non-motor symptoms such as pain, apathy, sexual disorders, and 
constipation are not reported, as patients do not recognize such symptoms as belonging to $\mathrm{PD}(5)$. The few reports and the failure to recognize these symptoms have important social and therapeutic implications. When untreated, these symptoms will be responsible for a major impact on the lives of these patients and are often the leading cause of hospitalization and institutionalization(6).

Describing the disease for the first time in 1817, James Parkinson postulated that the intellect would be preserved even in advanced stages. Thus, for many years, PD has been described as a pathology with strictly motor disturbances, which contributed to the neglect of the cognitive and psychiatric dysfunctions associated with the illness(7). In the last two decades, however, there has been a growing interest in the cognitive changes in $\mathrm{PD}$, favoring the idea that the clinical spectrum of this disease is wider than it was initially considered(6). Studies have shown the presence of cognitive decline even in early stages of the disease, with $70 \%$ of patients without apparent cognitive decline showing impairments when assessed(8,9). In these cases, cognitive decline is characterized by a very evident executive dysfunction, commonly associated with apathy and bradyphrenia (slowness in mental processing), combined with relative preservation of memory, language, and praxis(9).

Among the non-motor symptoms, depression is the one most commonly associated with PD, affecting $40 \%$ of patients ${ }^{(10)}$. Among the etiological factors of depression in PD, we can point out the imbalance of neurotransmitters and also the functional loss due to the progression of this disease. Remy et al.(11) believe that dopamine would also be linked to non-motor aspects of PD. For these authors, a dysfunction in the limbic system combining dopamine, serotonin, and norepinephrine is involved in triggering depression. Uemura et al.(12) state that subjects with PD are twice as likely to get depression when 
compared to those who do not have this disease. They correlated depressive symptoms with cognitive impairment and motor disorders, suggesting that endogenous changes in the neurotransmitter system, besides the natural progression of the disease, would contribute to the onset of depressive symptoms. Similarly, Chagas et al.(13) investigated the association between depression and PD, and concluded that this association is stronger for those with cognitive deficits. The comorbidity between PD and depression becomes larger with increasing cognitive impairment, suggesting a two-way mechanism, where depression and cognition are mutually influenced.

The prevalence of depressive symptoms in PD is highly variable, which can be explained by various factors, such as the type of population studied, instruments used for the diagnosis of depression, type of depression investigated, and the statistical methods used in the studies. Thus, works adopting rating scales to quantify depressive symptoms tend to have higher prevalence rates compared to those using manuals to elaborate diagnoses (DSM, ICD, APA). Studies using self-assessment scales have higher prevalence rates than studies with scales filled by family members or caregivers. The lowest prevalence rates are found in population studies, unlike those conducted with institutionalized subjects or users of outpatient services(14). Many studies have investigated the association between depression and PD or between cognitive decline and DP, but few have explored the effects of depressive symptoms on cognition in PD patients. The overlap of these symptoms with the ones that are characteristic of DP makes it difficult to differentiate between what is proper to one or the other. Today, the idea that non-motor aspects of DP engines, such as cognitive and psychiatric disorders, contribute to the progression of the disease is consensual. Therefore, they are linked to other issues such as loss of autonomy and functionality, decreased 
quality of life for both of the patients and their caregivers and, finally, high institutionalization and mortality rates. In this context, the present study aimed to investigate the impact of depressive symptoms on the cognition of PD patients, comparing the profile of these symptoms in PD patients and controls, as well as determining which cognitive measures are affected by the presence of depression symptoms. This research is justified by the need to increase our current understanding regarding the influence of depressive symptoms in PD with MCI, describing what is typical for each pathology in order to enable better clinical and treatment planning strategies.

\section{METHOD}

The study was conducted between January 2014 and September 2015. It is part of a larger project that aims to identify predictors of dementia in PD, conducted by the neurology department of the State University of Rio de Janeiro in collaboration with the clinical neuropsychology research group of PUC-Rio. All patients regularly attended neurology outpatient services of public hospitals in Rio de Janeiro. Each participant signed an Informed Consent Form approved by the Ethics Committee of Pedro Ernesto University Hospital, inserted into Plataforma Brasil (no 486.273).

\section{$\underline{\text { Participants }}$}

A total of 105 subjects, with ages ranging between 50 and 80 years, with at least 4 years of formal education, all diagnosed with Mild Cognitive Impairment (MCI) but not diagnosed with depression, were evaluated. Of these, 11 (9=DP group; 2=control group) were excluded due to Mini-Mental State Examination (MMSE) scores below the established cutoff point(15); and 2 controls due to other clinical issues. Thus, 48 PD patients and 44 healthy controls, matched for age, education, and MMSE score, participated in the study. 
In the experimental group were included individuals who fulfilled the criteria for DP in accordance with the United Kingdom Parkinson's Disease Society Brain Bank (UKPDSBB), with time of disease greater than three but less than ten years, and scores between 2 and 4 in the Hoehn-Yahr scale. In the control group we excluded individuals with psychiatric or neurological disorders, and current or previous history of alcohol abuse and/or illegal drugs.

\section{Instruments}

Cognitive assessment was performed using a previously assembled neuropsychological testing protocol, comprised of the following instruments:

1. MMSE - screening test designed to quickly measure global cognitive functioning, temporal and spatial orientation, attention, immediate and shortterm memory, language, praxis, and calculation(15).

2. Clock Drawing Test (CDT) - cognitive screening tool that checks praxis and visuoconstructive ability from a verbal command(17).

3. Semantic and Phonemic Verbal Fluency Test - assess language, sustained attention, organization, strategy, and perseveration(18).

4. Figures Memory Test (FMT) - evaluates episodic memory and consists of different tasks: naming and perception, incidental memory (IM), immediate memory (M1), learning (M2), delayed recall (M5), and recognition(19,20).

5. Stroop Color and Word Test - Victoria version (Stroop) - evaluates selective attention, cognitive flexibility, and inhibitory control through the response to specific stimuli while inhibiting more automated processes(21).

6. Trail Making Test (TMT) - evaluates processing speed, divided attention, and cognitive flexibility(22).

7. Span Digits WAIS III (Digits) - measures verbal attention, short-term memory, and working memory(23). 
8. Rey Auditory Verbal Learning Test (RAVLT) - Evaluates episodic memory, learning, susceptibility to interference (by presenting a list of distracting words), information retention, and recognition(24).

9. Hooper Visual Organization Test (Hooper) - assesses visuospatial abilities(25).

10. Beck Depression Inventory (BDI) - evaluates the presence of depressive symptoms and their intensity(26).

\section{Procedure}

Initially, patients and controls were submitted to a clinical evaluation with a neurologist, where demographic data and information regarding the existence of comorbidities (such as hypertension, diabetes, hyperuricemia, and alcoholism) were collected, the Hohen-Yahr, UPDRS and PDQ-39 scales were applied, and PD subtype was classified (trembling, rigid-akinetic or mixed). Next, the neuropsychological assessment was conducted by trained psychologists, in a single session that lasted for one hour. The assessments were conducted in rooms with adequate testing conditions. All participants were evaluated through the same neuropsychological protocol in the following fixed order: MMSE, FMT, CDT, Semantic Verbal Fluency Test (animals), FMT (delayed recall and recognition), RAVLT, Digit Span (forward and backward), Stroop, TMT (A and B forms), RAVLT (delayed recall and recognition), Phonemic Verbal Fluency Test (FAS), Hooper, and BDI.

\section{$\underline{\text { Statistical analyses }}$}

The analyses were performed using the Statistical Package for Social Sciences (SPSS) software, version 22. Descriptive analysis was conducted for the frequencies of the following variables: gender, age, education, cognition, and depressive symptoms. Student's t-test was used to compare groups (PD and control) in terms of age, education, MMSE and BDI scores. A chi-square 
analysis compared the frequency of depressive symptoms in the two groups. Pearson correlation was conducted between BDI total score and the scores of the cognitive tests. In order to compare the neuropsychological performance of patients and controls with and without depressive symptoms, one-way ANOVA was performed, followed by a Bonferroni post hoc test. Statistical significance was set at $p<0.05$ for all analyses.

\section{RESULTS}

The mean age of the PD group was 61.8 years $(\mathrm{SD}=7.36)$ and mean education was 10.1 years $(\mathrm{SD}=3.95)$. The control group had a mean age of 60.7 years $(\mathrm{SD}=6.59)$ and mean education of 11.5 years $(\mathrm{SD}=4.29)$. The mean MMSE score of the PD group was 27.4 $(\mathrm{SD}=1.98)$ and of the control group was 27.6 $(\mathrm{SD}=1.22)$. As for the BDI, the PD group had a mean score of $7.7(\mathrm{SD}=6.29)$ and the control group $9.5(\mathrm{SD}=8.03)$. The t-test revealed no significant difference between groups in any of the variables (Age: $p=0.233$; Education: $p=0.807$; MMSE: $p=0.900 ; \mathrm{BDI}: p=0.219)$.

For the characterization of depressive symptoms in PD, the most common symptoms in patients and controls were analyzed, as shown in Figure 1. The chi-square analysis indicated a significant difference in the frequencies of the symptoms "decreased libido" and "difficulty to work". There was no significant difference for "irritability", "fatigue" and "sleep disorders". Pearson correlation analysis showed that in the PD group BDI scores correlated negatively with learning (M2: $p=0.044 ; \mathrm{r}=-0.292$ ) and with recognition in the RAVLT $(p=0.026 ; \mathrm{r}=-0.320)$. As for the control group, the BDI score also correlated negatively with learning (M2: $p=0.047 ; \mathrm{r}=-0.301$ ), recognition in the RAVLT ( $p=0.011 ; \mathrm{r}=-0.378)$, and delayed recall (M5: $p=<0.001 ; \mathrm{r}=-0.520$ and A7: $p=0.029 ; \mathrm{r}=-0.330)$. 
In order to assess the impact of depressive symptoms on cognitive measures of patients and controls, the sample was divided into 4 groups: patients without depressive symptoms (PD), patients with depressive symptoms (PDD), controls without depressive symptoms (CG) and controls with depressive symptoms (CGD). Analysis of variance (ANOVA) was performed, followed by a Bonferroni post hoc test. Table 1 presents groups' performance on the neuropsychological tests. The other tests that made up the neuropsychological battery did not show statistically significant differences.

\section{DISCUSSION}

The present study aimed to investigate the impact of depressive symptoms on the cognition of PD patients with MCI, correlating the severity of these symptoms with different cognitive measures, and comparing them to a control group.

Traditionally, DP was considered a purely motor pathology. Neuropsychiatric symptoms such as depression and cognitive decline were neglected for a long time(6). It is acknowledged, however, that these are very incapacitating symptoms, contributing to loss of functionality and autonomy, therefore worsening the quality of life of both caregivers and patients( ${ }^{(4)}$

The literature points to a difficulty in diagnosing depression in PD because symptoms overlap(27,28). In this study, the most frequent depressive symptoms in the PD group were difficulty to work, fatigue, and sleep disorders, which can be related exclusively to PD. This result is supported by the low frequency of these symptoms in the control group, except for sleep disorders, which was present in both groups. The control group presented, more often, irritability symptoms and decreased libido, which is characteristic of depression. This difference in the profile of depressive symptoms between groups confirms the hypothesis that, in PD, they may be secondary to disease symptoms and are 
probably not due to depression. Cimino, Siders \& Zesiewicz ${ }^{(29)}$ associate the symptoms of depression to PD's rapid progression, the impairment in activities of daily living, and the most severe cognitive impairments. Thus, an accurate diagnosis is extremely important. For these authors, the depressive symptoms cause greater impact on the functionality of a PD patient than the motor difficulties arising from the pathology.

The results of the present study showed a negative correlation between BDI and learning (FMT), and also between BDI and recognition memory (RAVLT), both in the PD group and in the control group. Thus, more depressive symptoms, regardless of PD, caused worse the performance in these tests. The sleep disorder symptom was present in both groups, suggesting an association between this symptom and worse performance. Studies shown that sleep is involved in learning and memory processes consolidation and concluded that sleep disorders in PD, besides reducing quality of life, cause cognitive deficits in memory, learning, and executive functions ${ }^{(30)}$. Other studies also shown that sleep disorders are more prevalent in subjects with MCI than in those without cognitive impairment, according to a review by Silva(31).

In the control group, BDI scores correlated negatively with delayed episodic memory (FMT and RAVLT), showing an association between the presence of depressive symptoms and poor performance in these tasks. Studies suggest that impaired episodic memory is a predictive factor of conversion to dementia, particularly in free recall tasks after a time interval(32). Similarly, Avilla \& Bottino(33) report that verbal and delayed recall memory tests are effective tools for differentiating patients with dementia from those with depression, as they, despite having an impaired learning capacity, can store information and evoke it after a time interval. It is clear, therefore, that changes in this specific form of memory may serve as an indication of future 
dementia cases. Modrego \& Ferrández ${ }^{(34)}$ concluded that a combination between depression and MCI doubles the risk of conversion to Alzheimer's Disease (AD) compared to individuals without depression.

As for the performance in the neuropsychological assessment, the PD and control groups showed similar results in most tests that made up the battery. Statistically significant differences were observed only in the FMT and RAVLT. The DP group had an inferior performance in late anterograde episodic memory (FMT) and retroactive interference (RAVLT). These results suggest, therefore, that these cognitive impairments are related to PD with $\mathrm{MCI}$, regardless of the presence of depressive symptoms. Although the literature indicates frontal executive deficits as prevalent in $\mathrm{PD}$, some authors have concluded that the MCI in this pathology cannot be characterized only by this type of impairment. Muslimovic et al.(35) confirmed this hypothesis by demonstrating the existence of cognitive impairments in early stages of the disease, not only in executive functions, but also in memory. The study by Janvin et al.(36) demonstrated that more than $50 \%$ of PD patients have some type of cognitive impairment, $20 \%$ being predominantly related to memory deficits, $30 \%$ to executive dysfunctions, and $50 \%$ to decline in global cognitive function.

However, studies show that PD patients show no decline in recognition memory $(7,37)$. The impaired recognition performance in the PDD group, when compared to the PD group, suggests an influence of the association between depressive symptoms and MCI, once the same task showed a decline when the performance between the CGD and PD groups, and the CGD and CG groups was compared. Therefore, PDD and CGD, compared to those without symptoms, had impaired recognition performance. These findings are in line with the study of Nebes et al.(38), which concluded that access to cognitive 
resources becomes deficient in depressed subjects, leading to cognitive decline in several neuropsychological tasks, especially episodic memory. The authors also ratify the hypothesis that the combination between depression and $\mathrm{MCI}$ significantly increases the risk of conversion to $\mathrm{AD}^{(34)}$, since impairment in recognition memory is a predictive factor for the development of this type of dementia.

The results of the present study indicated changes in episodic memory and attention in the PDD group when compared to the control group, corroborating the idea that depressive symptoms influence the extent of cognitive deficits in PD patients but not the severity(10). The PDD group and the CGD group demonstrated a similar pattern of performance in the neuropsychological tests. Both had worse results when compared to the PD and CG groups, in accordance with the literature, which states that depression worsens cognition regardless of the existence of another pathology.

This study has the limitation of not having a PD group with MCI diagnosed with depression according to DSM-IV criteria. Probably, the fact that these patients only show symptoms and not a diagnosis of depression, contributed to the fact that both groups had similar performance in most of neuropsychological tests employed.

It is known that in PD, MCI and depression are risk factors for dementia, making early detection and treatment of these two conditions extremely important( ${ }^{(34)}$. Biundo et al. ${ }^{(39)}$ reported that each year, between 9 and $15 \%$ of PD patients evolve to dementia. In addition, depression and MCI directly affect autonomy and independence, resulting in poor quality of life and high rates of institutionalization and mortality. In many cases, depressive symptoms can mimic MCI or preclinical dementia, making the differential diagnosis and treatment of these pathologies crucial(33). Trambley et al.(40) emphasize the 
heterogeneity of cognitive impairment in PD. They report that many researchers characterize PD patients into subtypes according to different criteria, such as predominant motor symptom, age of onset of the disease, and the presence of depression, which is one of the most commonly used criterion to categorize them cognitively. Thus, the importance of an early detection of these symptoms is clear, characterizing $\mathrm{MCI}$ in $\mathrm{PD}$, as this condition increases the likelihood of a conversion to dementia.

In this context, we suggest that future studies include patients with PD and MCI, and depression, enabling the characterization of their neuropsychological profile in order to differentiate deficits resulting from PD caused by the presence of depression.

\section{REFERENCES}

1 - McPherson S, Cummings J. Neuropsychological aspects of Parkinson's disease and parkinsonism. In Grant I, Adams K. Neuropsychological assessment of neuropsychiatric and neuromedical disorders. Nova York: Oxford University Press; 2009. p.199-222.

2 - Wooten GF, Currie LJ, Boybjerg VE, Lee JK, Patrie, J. Are men at greater risk for Parkinson's disease than women? J Neurol Neurosurg Psychiatr. 2004;75:637-639.

3 - Schapira AHV, Bezard E, Brotchie J, Calon F, Collingridge GL, Ferger B, et al. What contributes to quality of life in patients with Parkinson's disease. Neurol Neurosurg Psychiatry. 2000;69:308-312.

4 - Melo LM, Barbosa ER, Caramelli P. Declínio cognitivo e demência associados à doença de Parkinson: características clínicas e tratamento. Rev Psiq Clín. 2007; 34(4):176-183. 
5 - Nicaretta DH, Pereira JS, Pimentel MLV. Distúrbios autonômicos na doença de Parkinson. Rev Assoc Med Bras. 1998 Jun;44(2):120-122.

6 - Chaudhuri KR, Schapira AHV. Non-motor symptoms of Parkinson's disease: dopaminergic pathophysiology and treatment. Lancet Neurol.2009;8:464474.

7 - Emre M. What causes mental dysfunction in Parkinson's disease? Mov Disord. 2003;18(6):63-71.

8- Pfeiffer HC, Lokegaard A, Zoetmulder M, Friberg L, Werdelin L. Cognitive impairment in early-stage non-demented Parkinson's disease patients. Acta Neurol Scand. 2014;129(5):307-318.

9 - Nagano-Saito A, Habak C, Mejía-Constaín B, Degroot C, Monetta L, Jubault T et al. Effect of mild cognitive impairment on the patterns of neural activity in early Parkinson's disease. Neurobiol Aging. 2014; 35:223-231

10 - Silberman CD, Laks J, Rodrigues CS, Engelhardt E. Uma revisão sobre depressão como fator de risco na doença de Parkinson e seu impacto na cognição. Rev psiquiatr Rio Gd Sul.2004:26(1):52-60

11 - Remy P, Doder M, Lees A, Turjanski N, Brooks D. Depression in Parkinson's disease: loss of dopamine and noradrenaline innervations in the limbic system. Brain. 2005;128:1314-22.

12 - Uemura Y, Wada-Isoe K, Nakashita S , Nakashima K. Depression and cognitive impairment in patients with mild parkinsonian signs. Acta Neurol Scand. 2013 Sep;128(3):153-159.

13 - Chagas M, Mariyama T, Felicio A, Sosa AL, Bressan R, Ferri C. Depression increases in patients with Parkinsons Disease according to the increasing severity of the cognitive impairment. Arq Neuropsiquiatr. 2014;72(6): 426429. 
14 - Reijnders JS, Ehrt U, Weber WE, Aarsland D, Leentjens AF. A Systematic Review of Prevalence Studies of Depression in Parkinson's Disease. Mov Disord. 2008 Jan 30; 23(2):183-189.

15 - Bertolucci PHF, Brucki SMD, Campacci SR, Juliano Y. O Mini-Exame do Estado Mental em uma população geral: impacto da escolaridade. Arq. NeuroPsiquiatr. 1994; 52(1):01-07.

16 - Litvan I, Goldman JG, Troster AI, et al. Diagnostic criteria for mild cognitive impairment in Parkinson's disease: Movement Disorder Society Task Force guidelines. Mov Disord. 2012;27:349-356.

17 - Sunderland T, Hill JL, Mellow A M, Lawlor BA, Gundersheimer J, Newhouse PA, et al. Clock drawing in Alzheimer's disease: A novel measure of dementia severity. J Am Geriatr Soc. 1989;37(8):725-729.

18 - Silva TBL, Yassuda MS, Guimarães VV, Florindo AA. Fluência verbal e variáveis sóciodemográficas no processo de envelhecimento: um estudo epidemiológico. Psicol Reflex Crit. 2011;24(4):739-746.

19 - Nitrini R, Lefèvre BH, Mathias SC, Caramelli P, Carrilho PEM, Sauaia N, et al. Testes neuropsicológicos de aplicação simples para o diagnóstico de demência. Arq Neuro psiquiatr.1995;52:457-465.

20 - Charchat-Fichman H, Fernandes CS, Oliveira RS, Caramelli P, Aguiar D, Novaes R. Predomínio de Comprometimento Cognitivo Leve Disexecutivo em idosos atendidos no ambulatório da geriatria de um hospital público terciário na cidade do Rio de Janeiro. Revista Neuropsicologia Latinoamericana. 2013;5(2):31-40.

21 - Klein M, Adda CC, Miotto EC, Lucia MCS, Scaff M. O paradigma stroop em uma amostra de idosos brasileiros. Psicol Hosp. (São Paulo). 2010;8(1):93112.

22 - Hamdan AC, Hamdan EMLR. Effects of age and education level on the trail 
making test in a healthy Brazilian sample. Psychol Neurosci. 2009;2(2):199203.

23 - Figueiredo VLM e Nascimento E. Desempenhos nas Duas Tarefas do Subteste Dígitos do WISC-III e do WAIS-III Psicologia: Teoria e Pesquisa Jul-Set 2007, 23(3): 313-318.

24 - Malloy-Diniz LF, Lasmar VAP, Gazinelli LSR, Fuentes D, Salgado JV. Teste de aprendizagem auditivo-verbal de Rey: aplicabilidade na população idosa brasileira. Rev Bras Psiquiatr. 2007; 29 (4):324-9.

25 - Tosello, DJT. Contribuição para o estudo normativo do Hooper Visual Organization Test (VOT). Psicol hosp 2005; 3(1):59-63.

26 - Cunha JA. Escalas Beck. São Paulo: Casa do Psicólogo; 2011.

27 - Rickards H. Depression in neurological disorders: Parkinson's disease, multiple sclerosis and stroke. J Neurol Neurosurg Psychiatry. 2005;76(1):4852.

28 - Nakabayashi TIK, Chagas MHN, Corrêa ACL, Tumas V, Loureiro SR, Crippa JAS. Prevalência de depressão na doença de Parkinson. Rev. psiquiatr. clin. 2008;35(6):219-27.

29 - Cimino CR, Siders CA, Zesiewicz TA. Depressive Symptoms in Parkinson Disease: Degree of Association and Rate of Agreement of Clinician-Based and Self-Report Measures. J Geriatr Psychiatry Neurol. 2011;24(4):199-205.

30 - Santos A, Campos S, Ribeiro S, Morales L, Gonzales J, Trindade J, Barreto G. Relação entre qualidade de sono e funções cognitivas em pacientes com doença de Parkinson. Univ Sci. 2013;18(3):269-281.

31 - Silva RAPC. Sleep disturbances and mild cognitive impairment: a review. Sleep Science 2015;8:36-41. 
32 - Charchat-Fichman H, Caramelli P, Sameshima K, Nitrini R. Declínio da Capacidade Cognitiva durante o envelhecimento. Rev Bras Psiquiatr. 2005;27(12):79-82.

33 - Ávila R, Bottino C. Atualização sobre alterações cognitivas em idosos com syndrome depressive. Rev Bras Psiquiatr. 2006;28(4):316-320.

34 - Modrego PJ, Ferrández J. Depression in patients with mild cognitive impairment increases the risk of developing dementia of Alzheimer type: a prospective cohort study. Arch Neurol. 2004 Aug;61(8):1290-3.

35 - Muslimovic D, Post B, Speelman JD, Schmand B. et al. Cognitive profile of patients with newly diagnosed Parkinson disease. Neurology 2005; 65:12391245.

36 - Janvin C, Aarsland D, Larsen JP, Hugdahl K. Neuropsychological profile of patients with Parkinson's disease without dementia. Dement Geriatr Cogn Disord. 2003;15:126-131.

37 - Galhardo MMAMC, Amaral AKFJ, Vieira, ACC. Caracterização dos distúrbios cognitivos na doença de Parkinson. Rev. CEFAC. 2009;11(2):251257.

38 - Nebes RD, Butters MA, Mulsant BH, Pollock BG, Zmuda MD, Houck PR, et al. Decreased working memory and processing speed mediate cognitive impairment in geriatric depression. Psychol Med. 2000; 30(3):679-691. 39 - Biundo R, Calabrese M, Weis L, Facchini S, Ricchieri G, Gallo P, et al. Anatomical Correlates of Cognitive Functions in Early Parkinson's Disease Patients. PLoS ONE 2013; 8(5): e64222. doi:10.1371/journal.pone.0064222. 40 - Trambley C, Achim AM, Macoir J, Monetta L. The heterogeneity of cognitive symptoms in Parkinson's disease: a meta-analysis. J Neurol Neurosurg Psychiatry. 2013 Nov;84(11):1265-72. 
Figure 1: Frequency of Depressive Symptoms

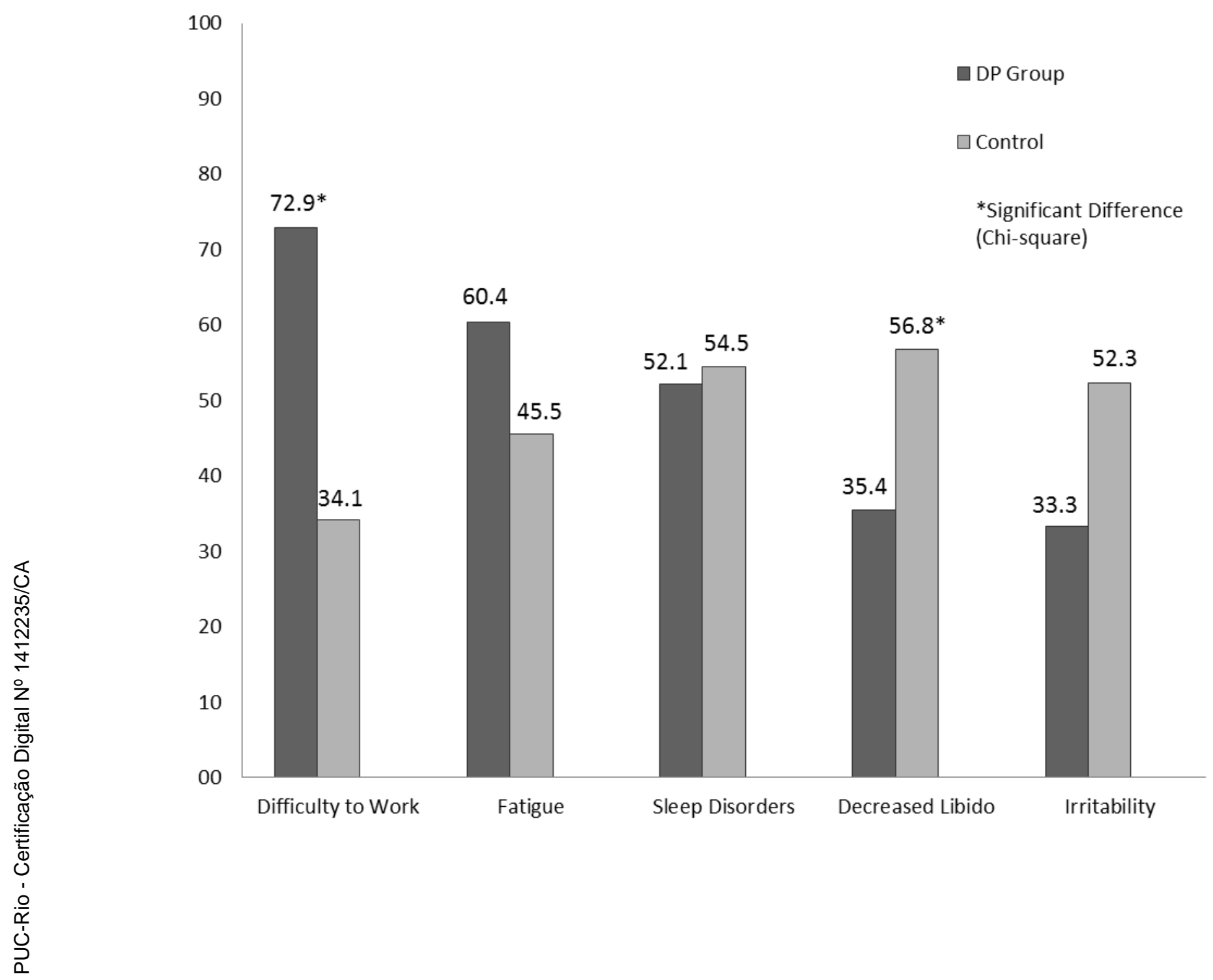


Table 1: Performance of Patients and Controls in the Neuropsychological Tests (raw scores)

\begin{tabular}{|c|c|c|c|c|c|}
\hline \multirow{2}{*}{$\begin{array}{c}\text { Neuropsychol } \\
\text { ogical } \\
\text { Tests }\end{array}$} & \multicolumn{2}{|c|}{ Patients } & \multicolumn{2}{|c|}{ Controls } & \multirow{2}{*}{$p_{1)}^{(1}$} \\
\hline & $\begin{array}{l}\mathrm{PD}^{(10)} \\
(\mathrm{n}=33)\end{array}$ & $\begin{array}{l}\text { PDD } \\
(n=15)\end{array}$ & $\begin{array}{c}\mathrm{CG}^{(10)} \\
(\mathrm{n}=28)\end{array}$ & $\begin{array}{c}\text { CGD } \\
(n=16)\end{array}$ & \\
\hline $\operatorname{MEEM}^{(1)} \bar{x}(s d)$ & $\begin{array}{c}27.4 \\
(1.68)\end{array}$ & $\begin{array}{c}27.4 \\
(2.59)\end{array}$ & $\begin{array}{c}27.8 \\
(1.23)\end{array}$ & $\begin{array}{c}27.3 \\
(1.20)\end{array}$ & $\begin{array}{l}0 . \\
7 \\
6\end{array}$ \\
\hline $\mathrm{BDI}^{(2)} \bar{x}(s d)$ & $\begin{array}{c}4.3 \\
(2.97)\end{array}$ & $\begin{array}{c}14.9 \\
(5.47)\end{array}$ & $\begin{array}{c}4.8 \\
(2.50)\end{array}$ & $\begin{array}{c}17.7 \\
(7.81)\end{array}$ & 0 \\
\hline \multicolumn{6}{|l|}{$\mathrm{FMT}^{(3)}$} \\
\hline$M 1^{(4)} \bar{x}(s d)$ & $\begin{array}{c}7.5 \\
(1.37)^{(\mathrm{a}}\end{array}$ & $\begin{array}{c}7.4 \\
(0.91)\end{array}$ & $\begin{array}{c}8.4 \\
(1.20)\end{array}$ & $\begin{array}{c}8.1 \\
(1.30)\end{array}$ & $\begin{array}{l}0 . \\
0 \\
2\end{array}$ \\
\hline$M 5^{(5)} \bar{x}(s d)$ & $\begin{array}{c}7.4 \\
(1.97)^{(\mathrm{a}}\end{array}$ & $\begin{array}{c}7.00 \\
(1.51)^{(b)}\end{array}$ & $\begin{array}{c}8.7 \\
(1.08)\end{array}$ & $\begin{array}{c}7.9 \\
(1.46)\end{array}$ & $\begin{array}{l}0 . \\
0 \\
0\end{array}$ \\
\hline $\begin{array}{l}\text { Recognition } \\
\overline{\bar{x}}(s d)\end{array}$ & $\begin{array}{c}10.0 \\
(0.17)\end{array}$ & $\begin{array}{c}9.7 \\
(0.46) \\
\mathrm{c})\end{array}$ & $\begin{array}{c}10.0 \\
(<0.01)\end{array}$ & $\begin{array}{c}10.0 \\
(0.25)\end{array}$ & 0 \\
\hline
\end{tabular}

$\operatorname{RAVLT} T^{(6)}$

\begin{tabular}{|c|c|c|c|c|}
\hline $\mathrm{A} 6^{(7)} \bar{x}(s d)$ & $\begin{array}{c}5.8 \\
(3.25)\end{array}$ & $\begin{array}{c}5.0 \\
(3.03)^{(b)}\end{array}$ & $\begin{array}{c}7.8 \\
(2.9)\end{array}$ & $\begin{array}{c}6.8 \\
(2.77)\end{array}$ \\
\hline $\mathrm{A} 7^{(8)} \overline{\times}(s d)$ & $\begin{array}{c}6.3 \\
(3.43)\end{array}$ & $\begin{array}{c}5.0 \\
(2.93)^{(b)}\end{array}$ & $\begin{array}{c}8.5 \\
(3.18)\end{array}$ & $\begin{array}{c}6.4 \\
(3.05)\end{array}$ \\
\hline $\mathrm{RI}^{(9)} \overline{\mathrm{x}}(\mathrm{sd})$ & $\begin{array}{c}0.6 \\
(0.26)^{(a)}\end{array}$ & $\begin{array}{c}0.6 \\
(0.29)\end{array}$ & $\begin{array}{c}0.8 \\
(0.22)\end{array}$ & $\begin{array}{c}0.7 \\
(0.25)\end{array}$ \\
\hline $\begin{array}{l}\text { Recognition } \\
\bar{x}(s d)\end{array}$ & $\begin{array}{c}7.9 \\
(3.97)\end{array}$ & $\begin{array}{c}4.5 \\
(5.43)\end{array}$ & $\begin{array}{c}8.4 \\
(4.32)\end{array}$ & 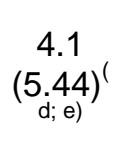 \\
\hline
\end{tabular}

(1)Mini Mental State Examination - Bertolucci (1994); (2)Beck Depression Inventory - Cunha (2001); ${ }^{(3)}$ Figures Memory Test - Nitrini (1994); ${ }^{(4)} \mathrm{M} 1=$ number of figures recalled after 1 -minute visualization; ${ }^{(5)} \mathrm{M} 5=$ recall of memorized figures after 5 minutes; ${ }^{(6)}$ Rey Auditory Verbal Learning Test - Malloy-Diniz $(2007) ;{ }^{(7)} A 6=$ number of words memorized from list $A$ without reread; ${ }^{(8)} A 7=$ number of words memorized from list $A$, without reread, after 20 minute interval; ${ }^{(9)} \mathrm{RI}=$ Retroactive Interference (A6/A5); ${ }^{(10)} \mathrm{BDI}<10$ points; ${ }^{(11)}$ One-way ANOVA. ${ }^{(a)}$ Significant difference between CG and PD; ${ }^{(b)}$ Significant difference between $C G$ and PDD; ${ }^{(c)}$ Significant difference between PD and PDD; ${ }^{(d)}$ Significant difference between PD and CGD; ${ }^{(e)}$ Significant difference between CG and CGD. 